The Pains of Jail Imprisonment:

Experiences at The Ottawa-Carleton Detention Centre

by

\title{
Laura McKendy
}

A thesis submitted to the Faculty of Graduate and Postdoctoral Affairs in partial fulfillment of the requirements for the degree of

Doctor of Philosophy

in

Sociology

Carleton University

Ottawa, Ontario

(C) 2018, Laura McKendy 


\begin{abstract}
Canadian jails are increasingly being used to hold pre-trial rather than sentenced prisoners. In fact, a growing number of individuals are serving a significant portion of their sentence by way of banked remand credit (Deshman and Myers 2014). This temporal reconfiguration has important implications for the very nature of 'punishment,' yet studies of jail experiences remain scarce within penal scholarship (Irwin 1985; Welch 1999; Walker 2014; Griffin 2006). This dissertation explores the experiences of men and women who spent time as a pre-trial and/or sentenced prisoner at the Ottawa-Carleton Detention Centre (OCDC), a notorious jail located in Canada's capital city. Employing Sexton's 'subjective' conceptualization of punishment, and drawing on interviews conducted with 33 participants, I consider how prisoners define, perceive and respond to conditions at OCDC. Prisoners' accounts reveal that much of what is experienced as 'punishment' in the jail context relates to unintended yet profound forms of physical and symbolic harm (Sexton 2015). Central to prisoners' accounts were the pains of 'warehouse' living, guardprisoner dynamics, medical mistreatment and health damage. The emphasis on such pains illustrates not only the salience of 'unintended' harms (Sexton 2015), but the extent to which the body remains implicated in the experience of punishment. Interestingly, these pains were not necessarily ameliorated by the social world produced by prisoners, as Sykes (1958) observed in his classic study. Instead, the institutional dynamics of the jail gave way to a culture marked by tension, mistrust and violence, while also impairing the ability of individuals to imbue the carceral experience with counter-punitive meaning. Prisoners' resistant efforts both in and outside of the jail walls, however, point the dialectical nature of power, or the ways in which objects of power can react in ways that undermine its purported objectives (Foucault 1977).
\end{abstract}




\section{ACKNOWLEDGEMENTS}

Many individuals contributed to the success of this project. First and foremost, thank you to the individuals who shared their stories in support of this research. Thank you to my supervisor, Aaron Doyle, and committee members, Michael Mopas and Justin Piché, for your support and encouragement over the course of my graduate studies. I would also like to extend gratitude to Joshua Price and Maeve McMohan for their thoughtful input. Special recognition must also be paid to the dedicated administrative support staff in the Department of Sociology and Anthropology at Carleton University.

I would also like to thank the Ontario Graduate Scholarship program, the Social Sciences and Humanities Research Council and the Department of Sociology and Anthropology at Carleton University for their generous funding support.

Finally, I would like to thank my friends and family members, including those who have passed, for their patience and love. 


\section{TABLE OF CONTENTS}

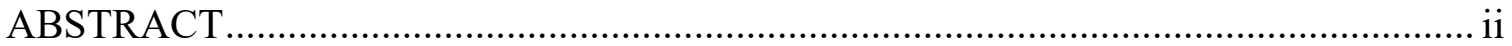

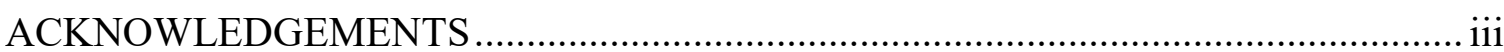

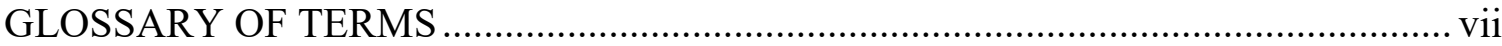

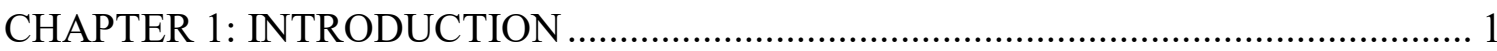

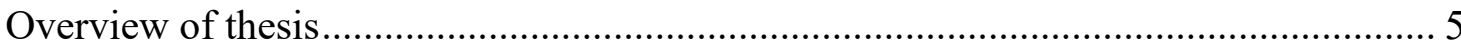

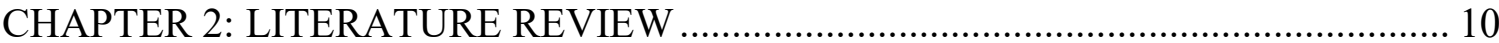

Contemporary penal theory and the state of prison research …................................. 10

Theorizing shifts in the contemporary penal context ................................................... 11

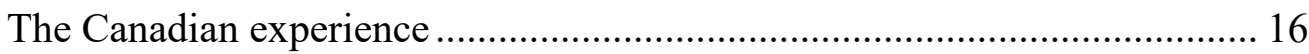

The state of prison research................................................................................... 21

The 'pains of imprisonment' ................................................................................. 24

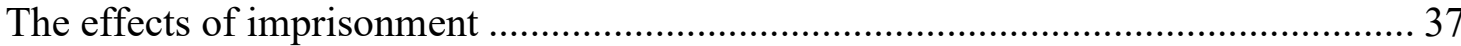

Responses to punishment: Prisoner adaptation ........................................................... 40

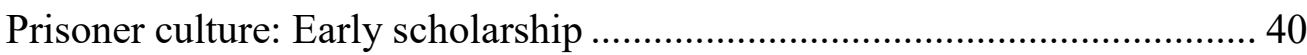

Collective responses in contemporary contexts ............................................... 44

Prisoner identity work and individual coping strategies .................................. 49

Summary of research on prisoners' experiences .......................................................... 54

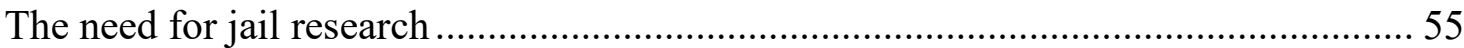

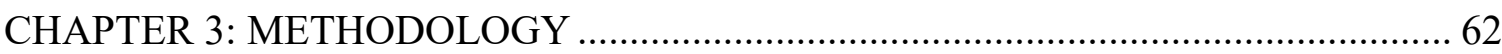

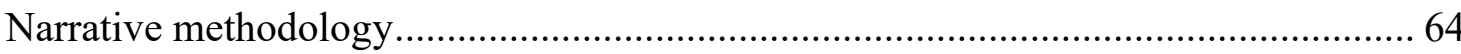

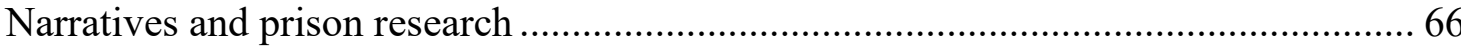

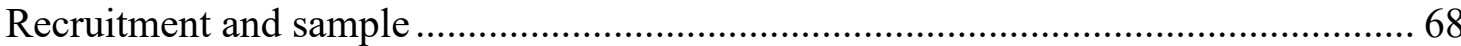

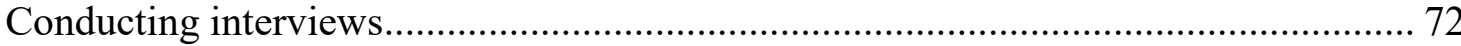

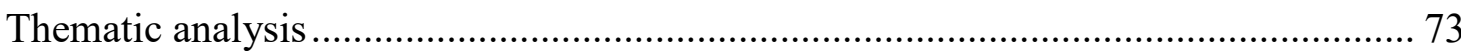

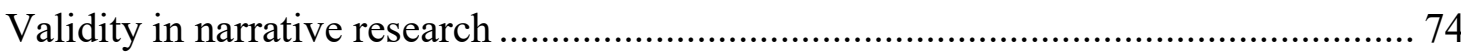

Reflexivity and the role of the researcher .................................................................. 78

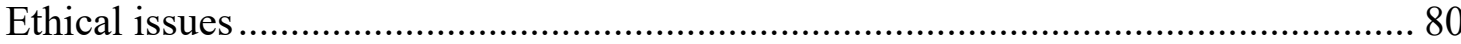

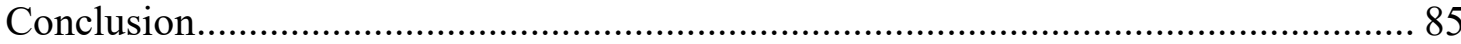




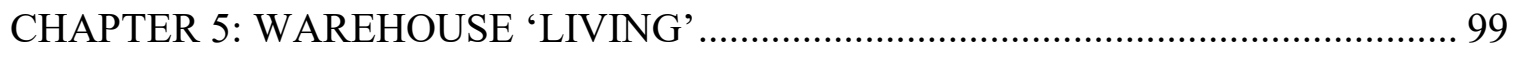

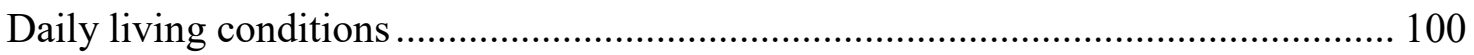

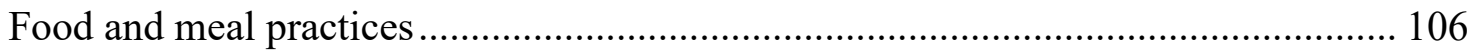

Lack of mental and physical stimulation............................................................. 111

Alienation from the outside world .................................................................... 115

Experiences in solitary confinement ................................................................ 119

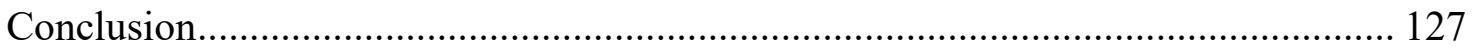

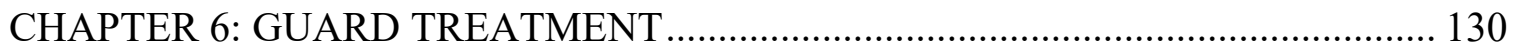

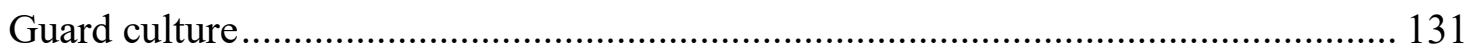

Guard practices that increase the pains of imprisonment..................................... 133

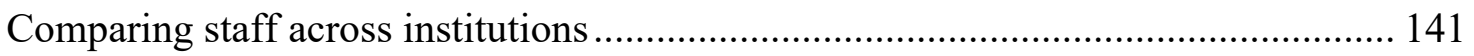

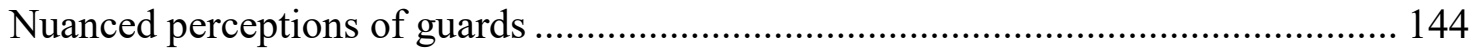

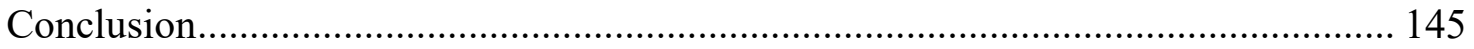

CHAPTER 7: HEALTH AS A SITE OF PUNISHMENT …................................... 147

Concerns upon admission: Denied medications and medical support ..................... 148

Inadequate healthcare and medical neglect ..................................................... 150

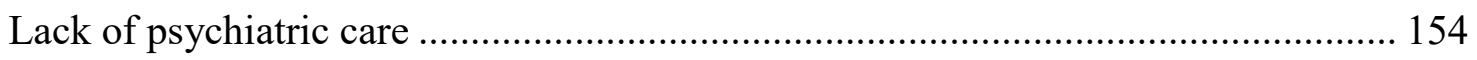

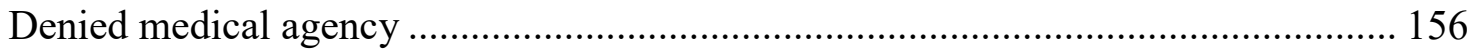

Lack of healthcare and accommodation for pregnant women ............................... 158

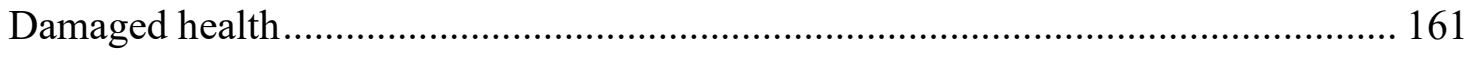

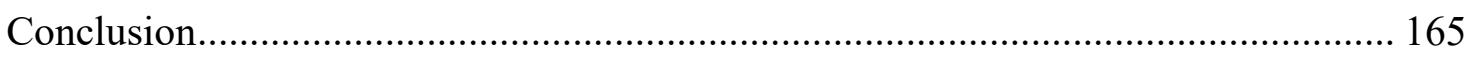

CHAPTER 8: PRISONER ADAPTATION AND RESISTANCE .............................. 168

The social qualities of the jail environment ...................................................... 170

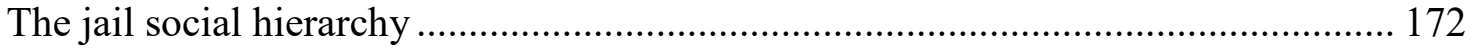

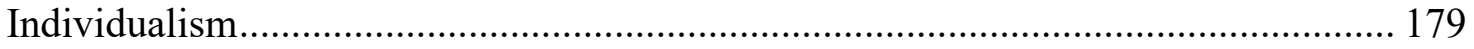

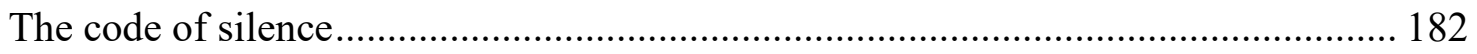

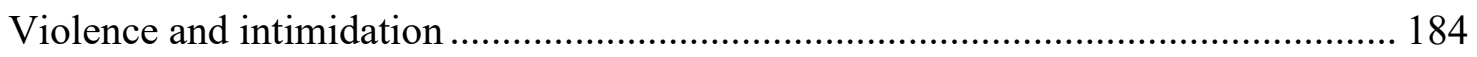

Individual strategies to reduce the pains of imprisonment..................................... 187

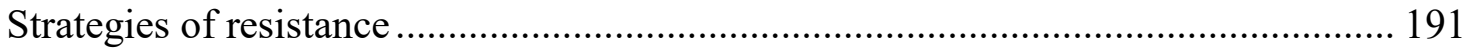

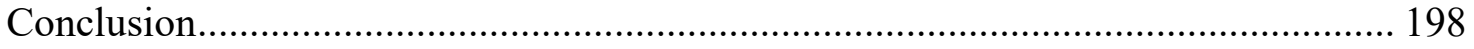


CHAPTER 9: CONCLUSION

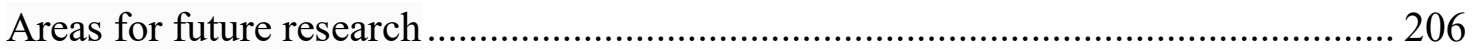

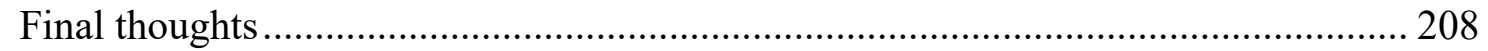

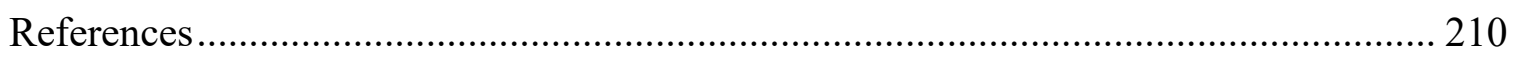




\section{GLOSSARY OF TERMS}

$\mathrm{CAB} \quad$ Community Advisory Board

CBC Canadian Broadcasting Corporation

CCLA Canadian Civil Liberties Association

CECC Central East Correctional Centre

CPEP Criminalization and Punishment Education Project

CSC Correctional Service of Canada

MCSCS Ministry of Community Safety and Correctional Services

MOMS Mothers Offering Mutual Support

MRSA Methicillin-resistant Staphylococcus aureus

OCDC Ottawa-Carleton Detention Centre

OCI Office of the Correctional Investigator

UK United Kingdom 


\section{CHAPTER 1: INTRODUCTION}

Prominent criminologists have lamented the apparent decline of carceral research in the context of tumultuous penal landscapes (Simon 2000; Wacquant 2002; Reiter 2014; Tubex 2015; Crewe 2015). Crewe (2015: 51), for example, argues that sociological depictions of penal institutions have been replaced by "big picture penal scholarship," or macro-level theorizing of broad trends and policies that shape the context of punishment. Within such scholarship, theorists have largely focused on the declining popularity of rehabilitative philosophies, and the corresponding rise of more punitive measures and forms of actuarial justice (Feeley and Simon 1992, 1994; Garland 2000). While bearing utility for understanding broad trends in the nature and scope of punishment, some scholars suggest that a macro-level focus has led to a 'pixelated' view of the prison social world (Reiter 2014). As Reiter (2014: 417) argues, with the "dearth" of prison research, the prison has become a "social black site" - "physically located outside our communities, invisible to the public and researcher alike." Given that penal rhetoric and policy are often not reflected in practices 'on the ground' (Phelps 2011; Hutchinson 2006; Moore and HannahMoffat 2005), scholars have stated the need for research examining how social control and punishment play out in specific contexts (Hannah-Moffat 2005; Comack and Silver 2008; Phelps 2011) so as to fill the 'blind spots' of macro-level accounts (Crewe 2015).

Claims that prison research has disappeared are arguably overstated. In fact, contemporary prison scholars, including convict criminologists and prisoner ethnographers (Taylor 2009), have studied a wide array of topics relating to the experience of imprisonment. Within this body of research, scholars have explored, for example, the contemporary pains of imprisonment (Crewe 2007, 2009, 2011; Sexton 2015; Terry 2000, 
2004; Richards 2014; Walker 2014), the sociological factors that mediate carceral experiences (Kruttschnitt et al. 2013; Chatrand 2015; Crewe, Hulley and Wright 2017), as well as the individual and collective ways in which prisoners adapt to and/or resist prison conditions (Schmid and Jones 1991; Terry 1997; Crewe 2007; Ricciardelli 2014a, 2014b, 2015; Ricciardelli and Memarpour 2016).

However, it remains the case, as it did several decades ago (Irwin 1985), that the jail, as a specific type of institution, remains neglected in both empirical and theoretical penal scholarship. To clarify, jails are unique from prisons in that they hold not only sentenced prisoners, but also remand prisoners (i.e. those awaiting trial, sentencing, or another court proceeding), as well as individuals awaiting transfer to another institution. The reason for the long-standing sociological neglect of jails is not clear, although Klofas (1990: 82) suggests that researchers may assume that prison and jail experiences are similar, or that "many of the issues examined in the prison research are irrelevant to jails because of the brevity of most jail stays." However, as previous authors (Irwin 1985; Welch 1999) have pointed out, the neglect of jails leads to an incomplete account of punishment, since jails are distinct from prisons in terms of the types of prisoners they hold, their underlying purpose (i.e. detainment), and the qualities of institutional conditions, which often include population transiency, minimal resources and crowding (Irwin 1985; Welch 1999; Walker 2014; Griffin 2006).

In Canada, jails have become the site of changing patterns of punishment. More specifically, around $60 \%$ percent of the provincial prisoner population is on remand, meaning they have yet to be tried and/or sentenced, and are merely awaiting a bail decision or trial date (Reitano 2017). The current situation is a marked departure from historical 
trends regarding the makeup of provincial jails. At the turn of the last century, there remained more sentenced than remanded prisoners in daily counts $(10,842$ versus 7,392), but the number of prisoners on remand has since continuously climbed each year, and in 2005/2006, surpassed the number of sentenced prisoners (10,875 versus 9,560) (Porter and Calverly 2011). In 2015/2016, there were just under 15,000 prisoners held on remand across Canada, compared to around 10,000 who were sentenced in provincial custody (Reitano 2017). This imbalance is particularly pronounced in Ontario, where $67 \%$ of provincial prisoners are on remand (Reitano 2017).

As pre-trial detention has increased relative to sentenced punishment, prisoners are increasingly 'doing time' prior to a finding of guilt. In fact, due to systemic inefficiencies in the court system, some individuals will serve their entire sentence through banked remand credit (Deshman and Myers 2014). This temporal reconfiguration has implications not only for the democratic principle of due process, but the very nature of 'punishment.' Theoretically, time spent on remand does not constitute punishment per se; rather, it is justified by a preventionist logic (i.e. the protection of the administration of justice) as opposed to retributive and/or rehabilitative concerns. In practice, however, time spent on remand retroactively becomes part of one's sentence and, at the experiential level, remand involves 'punishment-like' conditions (Walker 2014).

In fact, former prisoner Walker (2014: 16) argues that "from the viewpoint of inmates, jails are significantly more punitive than prisons." In the Canadian context, jails are notorious for featuring conditions marked by crowding, frequent lockdowns, limited programming, poor sanitation, violence and other problems (Deshman and Myers 2014; Demers 2014; John Howard Society of Ontario Standing Committee on Prison Conditions 
in Ontario 2007). As a result of the growing use of remand in Canada, and corresponding decline in sentenced punishment, provincial incarceration has become increasingly shaped by the logic of 'warehousing' (Irwin 2005; Robertson 1997), whereby individuals are merely 'stored' to await court decisions.

Some critics suggest that the growing use of pre-trial detention may reflect a culture of risk aversion (Deshman and Myers 2014), whereby the potential costs of bail release are determined to outweigh the harms caused by detention. In this context, however, notions of risk appear to be fused with classist, racist, patriarchal and ableist meanings that result in the disproportionate representation of marginalized social groups behind bars. Indeed, the overrepresentation of individuals facing poverty, homelessness, mental health problems and substance addiction (Public Services Foundation of Canada 2015; Deshman and Myers 2014), as well as the stark overrepresentation of Indigenous people (Porter and Calverley 2011; Perreault 2014), illustrate the jail's unofficial use as a repository for socially and economically marginalized groups (Irwin 1985; Welch 1999). As court statistics reveal, most of the individuals confined in jails do not conform to stereotypical images of the 'dangerous criminal.' Rather, their incarceration reflects the use of the jail to deal with social problems. Illustratively, around two-thirds of remand prisoners are facing non-violent charges, with the most common charge being administrative in nature (e.g. failure to comply with conditions) (Porter and Caverely 2011).

Exploring the experiences of men and women who previously spent time in provincial custody, I consider how subjective accounts of jail punishment can add nuance to theoretical understandings of incarceration in the contemporary context. For this research project, I conducted narrative interviews with individuals who spent time as a 
remanded and/or sentenced prisoner at the Ottawa-Carleton Detention Centre (OCDC), a notorious jail located in Canada's capital city. In analyzing their narratives, I draw on Sexton's (2015) conceptualization of punishment as that which is experienced as punishment by prisoners, rather than merely that which is intended and/or recognized as punishment by law. Such a conceptualization is useful for capturing the 'hidden' and/or unintended harms inflicted or facilitated by the penal system, which often cannot be gleaned from policy texts. As I will explain, prisoners' accounts reveal that much of what is experienced as 'punishment' in the jail context relates to seemingly unintended yet profound forms of physical and symbolic harm (Sexton 2015). The hidden pains of imprisonment (Sykes 1958) reaffirm the need to study punishment in its realized rather than articulated forms (Sexton 2015).

\section{Overview of thesis}

In the subsequent chapter, I situate this study in relation to two bodies of literature. The first is the vast body of work theorizing contemporary trends in punishment in the context of English-speaking countries. I will provide a brief overview of the 'punitive turn' and 'new penology' frameworks, before commenting on the limitations of such theorizations. As previous scholars have pointed out, empirical research examining punishment as it 'plays out' can complement the 'blind spots' of macro accounts (Crewe 2015; Sexton 2015). Several scholars have lamented the demise of such research; however, I hope to paint a more optimistic picture of the state of prison research. Hence, the second body of research I draw on is that examining punishment in its realized forms, including research done with and by prisoners. As I will explain, several scholars have considered 
how broad-level changes in the realm of punishment have corresponded with changes to the 'pains of imprisonment' and prisoner modes of adaptation.

However, a continued oversight of penal research is its lack of engagement with jails, which, as noted, are institutions marked by unique qualities in terms of their social purposes, the nature of their conditions and the populations they hold (Irwin 1985; Welch 1999). As I will argue, the neglect of jails is particularly perplexing given that jails are the site of changing patterns of punishment in Canada and other countries around the world (Webster Doob and Myers 2009; Deshman and Myers 2014; Brown 2013; Sarre and Sarre 2016; Walmsley 2014).

In the third chapter, I will lay out the methodology for this project in greater detail. I will begin by discussing the narrative interviewing format - which involves asking participants to 'tell their story'- and commenting on the utility of narratives for social researchers. As I will argue, while narrative research is useful for many projects that seek to understand the subjective realm of perceptions and emotions (Riessman 1993), it is particularly well-suited to studies exploring the experiences of those who are structurally silenced (O'Connor 2003). This is because the narrative format enables participants greater agency over the topics discussed, thereby allowing them to partially shape the research trajectory. In relation to the current project, I will discuss how the research project unfolded, describing participant recruitment, data collection, and the thematic analysis of narratives. I will also reflect critically on the project, commenting on sample limitations, issues of validity in relation to the data obtained, reflexivity and the role of the researcher, and key ethical issues that emerged. 
In chapters five through eight, I discuss the findings of this study. First, I consider how prisoners defined the pains of imprisonment at OCDC, narrowing in on three central themes that emerged across accounts, namely warehouse-like conditions, guard-prisoner dynamics, and health experiences. Interestingly, the pains that held the most salience in prisoners' accounts were seemingly unintentional facets of punishment, illustrating the need to explore punishment as it is experienced, rather than as it is articulated in policy texts (Sexton 2015). The emphasis placed on these pains also reveals an important finding for penal theory, namely the extent to which the body remains implicated in the experience of punishment. Indeed, the extent to which punishment infiltrated the body - through harms such as harsh physical conditions, hunger, violence, the contraction of disease, and denied medical care, for example - runs counter to criminological accounts suggesting that the mind has displaced the body as the primary target of contemporary punishment (Sykes 1959; Foucault 1977; Crewe 2011). Importantly, however, prisoners also emphasized the symbolism of institutional conditions, which they viewed as communicating their status as sub-human.

I also consider how prisoners responded to institutional conditions in both collective and individual ways. In discussing collective responses to institutional conditions, prisoners' accounts suggest the social world at OCDC bears important differences from the classic tenets of prison culture as articulated by classic prison sociologists like Sykes (1958) and Clemmer (1958), as well as scholars of female prisoner culture like Giallombardo (1966) and Ward and Kassebaum (1965). To be sure, some similarities with classic prison culture were evident among men, including a status hierarchy, a code of silence, and the pervasive use of violence. However, much like 
Ricciardelli (2014a) has noted at the federal level, the solidaristic underpinnings of male prisoner culture were undermined by an individual orientation that prioritized selfpreservation in the context of an unpredictable and chaotic social environment. In the absence of social solidarity, perpetual fear and uncertainty came to shape prisoners' experiences. Hence, prisoners' accounts illustrate how, in some ways, prisoner culture does not always serve an adaptive function in the Syksian sense, but can instead function to compound the pains of imprisonment.

Through prisoners' narratives, I also explore how prisoner agency and creativity were incorporated into the carceral experience at the individual level. What stood out in discussions of individual forms of adaptation, however, were the structural impediments that undermined the ability of prisoners to designate positive meanings to 'doing time.' In other penal contexts, authors have noted that prisoners engage in a variety of positive activities and/or behaviours to reduce the pains of imprisonment and claim meaning over carceral experiences (e.g. Sykes 1958; Ricciardelli and Memapour 2016; Baer 2005). At OCDC, prisoners experienced incarceration as 'hard time,' that is, with a constant awareness of their incarcerated status and the (slow) passage of time (Toch 1992). In this context, simple activities, such as reading, were the only means through which prisoners could exercise agency, designate positive meanings to the carceral experience, and simply 'pass the time.'

Importantly, OCDC prisoners do not simply accept the state of their circumstances, but engage in a variety of resistant activities to advance their rights. Complementing prisoners' narratives with reports and media articles, I will consider prisoner efforts to forge meaningful change at OCDC and within the provincial penal system more generally. 
I conclude by situating prisoners' experiences within the broader politics of punishment in Ontario and identifying areas ripe for future research. 


\section{CHAPTER 2: LITERATURE REVIEW}

\section{Contemporary penal theory and the state of prison research}

Sociologists and criminologists have spent much time analyzing current trends in the realm of punishment and social control. What Crewe (2015) dubs "big picture penal scholarship" has sought to explain how and why punishment has changed in the contemporary context. While offering different explanations, theorists generally agree that a shift has occurred in English-speaking countries, marked by a retreat from rehabilitative philosophies and the embrace of punitive measures and actuarial justice (Bottoms 1995; Garland 2000, 2001; Pratt 2000, 2007; Feeley and Simon 1992, 1994). While such accounts are useful for understanding broad shifts in penal policy, some authors argue that the booming literature on macro-level trends has corresponded with a decline in qualitative prison research (Simon 2000; Wacquant 2002; Reiter 2014; Tubex 2015; Crewe 2015). As Crewe (2015: 50) writes, “one of the striking characteristics of much of this 'big picture' penal scholarship is that it stops at the gates of the prison, or breaches its surface somewhat barely or briefly." The current situation, it is argued, is in marked departure with research orientations during the 'golden age' of prison sociology, when researchers like Sykes (1958) and Clemmer (1958) provided rich, detailed accounts of prison culture and the 'pains of imprisonment' (Reiter 2014). Today, it is argued, the disappearance of prison research has resulted in a 'pixelated' view of the prison social world (Reiter 2014).

In this chapter, I will first summarize key themes emerging from the vast literature exploring shifts in punishment in the twenty-first century, with particular attention paid to the 'punitive turn' and 'new penology' frameworks. Problematizing claims that this literature has displaced empirical prison research, I will then draw on array of prison 
studies, including prisoner writings, that document various aspects of prisoners' experiences of punishment. Within this research, focal areas of concern include the contemporary 'pains of imprisonment,' the sociological factors that mediate prisoners' experiences and the diverse ways in which prisoners cope with, adapt to and resist the qualities of prison life. Moving beyond abstract measures and discourses, these studies explore punishment as it is experienced by prisoners (Sexton 2015).

However, a continued shortcoming of both the empirical study of imprisonment, as well as macro theories of punishment, is the neglect of jails (Irwin 1985; Welch 1999; Griffin 2006; Walker 2014). As Irwin (1985) notes in his seminal work, the jail is unique from the prison in terms of its social purpose, the makeup of its population, and the institutional conditions that define it. Yet the particularities of the jail are rarely acknowledged in penal theories, and the jail has received minimal attention on the part of empirical researchers. In the final section of this chapter, I will draw on the work of Irwin and others to explore the 'unofficial' social functions of the jail. These functions, which operate somewhat independently from the prevailing punishment discourses of the day, relate to the jail's use as a catch-all solution to deal with social problems such as poverty, homelessness, drug addiction and mental illness. As I will argue, the study of jails is particularly important in the current Canadian context, where the increased use of jails to hold pre-trial rather than sentenced prisoners (Deshman and Myers 2014) has led to the temporal reconfiguration of punishment.

\section{Theorizing shifts in the contemporary penal context}

Since the late twentieth century, scholars have paid keen attention to changing penal landscapes, particularly in the United Kingdom and American settings. Much of this 
literature has focused on the apparent decline of rehabilitative approaches, and corresponding rise of punitive measures and actuarial justice (Bottoms 1995; Garland 2000, 2001; Pratt 2000, 2007; Feeley and Simon 1992, 1994). More specifically, some theorists note that punishment and social control have taken a 'punitive turn,' evidenced by the popularity of 'tough on crime' politics and related trend of mass incarceration (Garland 2000). Others have emphasized the emergence of a 'new penology' (Feeley and Simon 1992), oriented around risk-based models of population management that do not seek reformation or deterrence, but merely to contain the 'threat of crime' through the incapacitation of high-risk groups (Brownlee 1998).

The 'punitive turn' thesis, which has gained much traction in criminological thought, was presented by Garland (2000) as a way of understanding how and why approaches to punishment and social control were changing. Exemplified by the British and American cases, he described the shift as one from the welfarist and rehabilitative model, to a more harsh and expressive system of punishment. Garland (2000: 349-350) pointed to several 'tough on crime' policies that signalled a punitive turn:

“'three strikes' and mandatory minimum sentencing laws, 'truth in sentencing' and parole release restrictions; no frill prison laws and 'austere prisons'; retribution in juvenile court and the imprisonment of children; the revival of chain gangs and corporal punishment; boot camps and 'supermax' prisons; the multiplication of capital offences and executions; community notification laws and pedophile registers; zero tolerance policies and sex offender orders..."

As Matthews (2005) notes, a rare consensus has developed among criminologists that a punitive turn has, in fact, occurred. To be sure, theorists have diverse explanations as to why a shift has taken place. In the U.K. context, Garland (2000) attributes the punitive turn to changing sentiments on the part of the 'liberal elite.' He suggests that rising crime rates in the 1960s, combined with the hyper-visibility of crime facilitated by the mass 
media, led to new sensibilities on the part of the middle-class, who had once favoured a more welfarist approach to punishment. Meanwhile, Garland notes, politicians embraced "tough-on-crime" politics in an effort to appear to be 'doing something' about the crime problem. Alternatively, neo-Marxian theorists suggest that punitive policies are associated with forms of control under neoliberalism, viewing mass incarceration as the contemporary means of dealing with social problems (Wacquant 2005). Wacquant (2005: 19), for example, points to the ways in which American prisons have "partly supplanted and partly supplemented the ghetto as a mechanism of racial control."

Other authors suggest that trends in incarceration and punishment practices can be tied to the rise of risk-based management logics within the realm of public services. Feeley and Simon (1992) suggest that a 'new penology' has increasingly shaped both punishment policy and prison management. Moving away from a disciplinary form of governance that focuses on the individual and their reformation, this approach involves the management of deviance through the identification and containment of 'high risk' groups. Key to the new penology is the utilization of 'risk science,' which employs "impartial and objective criteria" to identify risky subjects (Zedner 2006: 426). Those deemed 'high risk' are contained through cost-effective incapacitation strategies, while rehabilitative efforts are abandoned due to their perceived futility (Feeley and Simon 1992). The incapacitation of 'habitual offenders' through 'three strikes laws,' as well as the growth of indeterminate sentences, exemplify the risk-containment orientation of the new penology.

In some regards, there appears to be a contradiction between the punitive turn and new penology accounts insofar as the former emphasizes the emotional and expressive ('irrational') aspects of contemporary punishment, while the latter emphasizes its 
apparently scientific, morally-neutral ('rational') character (Hallsworth 2000). Brownlee (1998: 327) writes, "the punitive language of much of the official discourse on crime is, in reality, at odds with the aims of the new penology and manageralism more generally, and threatens to undermine them." Illustratively, the cost-efficiency concern of the new penology runs counter to the excesses of punitivism (Brownlee 1998). Furthermore, while "the punitive discourse heightens the expectation among the public that a tough, unmistakably punitive response can be provided for every infraction, no matter what the cost," the new penology approach would "foster a 'normalization' strategy towards crime, seeking to play down its impact in order to promote less expensive responses" (Brownlee 1998: 328, 334).

Rather than seeing punitive forces and risk-based logics as contradictory, others see them as complementary. For example, Cheliotis (2006: 317) writes that actuarial practices can "facilitate retributive punishment" by separating out the 'unruly' populations who become subjects of expressive punishment. Moreover, punitive sentiments can help justify and perpetuate the inhumane consequences of an actuarial approach to punishment policy and prison management, whether those consequences are intentional (i.e. expressive) or the unintentional by-products of risk-based systems of decision-making. Indeed, as Hallsworth (2000) notes, both 'rational' and 'irrational' forces are at play in contemporary systems of punishment. He argues that the bureaucratic rationalism at the root of the new penology works tandem in with the anti-modern logic of punitivism.

That there could be two seemingly contradictory logics informing punishment policy aligns with the frameworks presented by Goodman, Page and Phelps (2015), as well as Hutchinson (2006). Their accounts note that, at any given time, punishment is 
simultaneously shaped by a set of forces, rather than a single all-encompassing ideology to which the myriad of actors involved in the field of punishment unanimously uphold and adhere to. Hence, in the current context, it is perhaps a combination of punitive philosophies and depersonalized risk-based social control strategies, as well as other factors, that shape the landscape of punishment.

Perhaps one locale in which the overlap between punitivism and the new penology can be seen is the 'warehouse prison.' As Robertson (1997: 1004) explains, “"warehousing" is penal confinement that provides little to no constructive activities, such as work, vocational instruction, and education, other than constitutionally prescribed exercise periods, for the great majority of general population inmates." Irwin (2005: 57) provides a similar definition, writing, "prisoners endure deeply reduced mobility, activities, and involvement in prison programs and are merely stored to serve out their sentences." In comparison to other types of penal institutions, the warehouse model does not operate under the purported logic of reformation or rehabilitation, but rather, serves the purpose of mere containment (Irwin 2005; Robertson 1997). The warehouse prison hence aligns with the population management goals of the new penology, while also satisfying punitive desires by way of exceptionally painful and dehumanizing conditions.

In the American context, the warehouse model of incarceration is emblematized by 'supermax prisons' - tightly controlled institutions that feature conditions akin to permanent solitary confinement. With minimal time spent out of cells, limited human interaction, and lack of opportunities for physical or mental stimulation, supermax confinement may, after the death penalty, constitute "the most intense type of punishment the state has at its disposal" (Ross: 2013: 1-2). Scholars have traced the rise of supermax 
prisons to the apparent desires of policymakers and prison administrators to house 'the worst of the worst,' i.e. those deemed exceptionally violent or otherwise 'unmanageable' (Pizarro and Stenius 2004; Ross 2007, 2013). In practice, however, the supermax model has become more malleable in its use, now employed to hold a wide array of individuals in the United States and other countries around the world (Ross 2013). Supermax institutions have received much criticism for their harsh and inhumane conditions; Guenther (2013: 197), for example, states that supermax confinement constitutes a "living death sentence that compounds the violence of crime."

\section{The Canadian experience}

When it comes to the question of how contemporary penal theories apply to the Canadian context, scholars have expressed divergent views. On the one hand, some suggest the analysis of punishment reforms offered by the punitive turn framework is not applicable to the Canadian experience. For example, Meyer and O'Malley (2009) argue that Canada 'missed' the punitive turn, evidenced by its continued 'balanced' sentencing approach that incorporates seemingly diverse objectives. They argue that the punitive approach emblematized by the American criminal justice system is rejected by Canadians, who have continually sought a balance between "the rights and freedoms of society, victims and offenders" (Meyer and O'Malley 2009: 8). Similarly, Doob and Webster (2006) argue that, while Canada has felt the pressure of a punitive turn, its effects have been muted for a variety of reasons. These include a more diverse array of sentencing principles embedded in our criminal justice system, lack of support for harsh measures by Canadians, as well as other historical, structural and cultural factors than have protected Canada from punitive tendencies. 
In contrast, Comack and Silver (2008) suggest that there is, in fact, evidence of a punitive turn in Canada if one looks at specific regional contexts. Drawing on the example of a 'zero-tolerance policing' model implemented in Winnipeg, they argue that claims Canada has been an exception to the punitive turn overlook variability across context, as well as the complexity of penal governance. Authors like Moore and Hannah-Moffatt (2002) and McElligott (2008) have also studied shifts in the Ontario context, where an explicit shift in punishment rhetoric occurred in the 1990s under Premier Mike Harris. The Harris government launched a so-called 'common sense revolution' that aimed to cut costs by slashing government programs and services, while simultaneously getting 'tough on crime.' As part of this agenda, existing detention centres were removed of perceived 'frills;' almost all programming was cut and prisoners were confined to cells for 16 to 23.5 hours a day (Moore and Hannah-Moffat 2002). At the same time, several local jails were closed and replaced with 'supermax' jails, which were "deliberately designed to be cheap and harsh" (McElligott 2007: 33).

Punitive rhetoric also became a key political trope under Conservative Prime Minister Stephen Harper, who came to power in 2006. Taking from the package of reforms that Garland (2000) describes as indicative of a punitive turn, the government enacted new mandatory minimum sentences, placed greater limits on parole eligibility, increased restrictions on pardons, eliminated the standard practice of granting double credit for time served on remand, and imposed harsher sentences for youth, among other reforms (Mallea 2010; Comack, Fabre and Burgher 2015). On the one hand, as Webster and Doob (2015) note, many of the reforms enacted under Harper have been mostly symbolic in their immediate effect. On the other hand, the rise of 'tough on crime' measures may have 
broader cultural implications insofar as political rhetoric is a factor influencing the nature of public opinion on crime and punishment (Webster and Doob 2015).

As critics have pointed out, many accounts of contemporary penality have taken official policy and political rhetoric as the indicators of shifts in punishment and social control, yet 'punishment in practice' can diverge quite significantly from its policy roots (Sim 2009; Phelps 2011; Hutchinson 2006; Moore and Hannah-Moffat 2005). As Moore and Hannah-Moffat (2005: 89) argue, "penal policy is best thought of as consisting of two components, rhetoric and practice," and these two components are often not mirror images. Illustratively, one of the most important trends in Canadian punishment practices, i.e. the rise of pre-trial detention relative to sentenced punishment, does not appear to be tied to formal policy changes or philosophical shifts in the politics of punishment.

To elaborate, over half of the provincial prisoner population in Canada is now comprised of remanded prisoners who have yet to be tried and/or sentenced (Weinrath 2009; Webster, Doob and Myers 2009; Friedland 2012; Piché 2014). In fact, Piché’s (2014) research on prison construction found that the remand prisoner population, as opposed to the sentenced population, is driving penal expansion in Canada. The growing use of pretrial detention, however, has occurred not as the result of punitive legal reforms or the incorporation of risk science in the realm of judicial decision-making. Rather, as Deshman and Myers (2014) note, the expanded use of use of pre-trial detention may reflect a culture of risk aversion that has emerged from within the institutional contexts where policies are interpreted.

More specifically, as Webster, Doob and Myers (2009: 99) note, "an increasing culture of risk aversion" can be seen throughout various stages of the legal system. They 
argue that a risk averse mentality begins with police, who are laying more charges (including administrative charges) and sending more cases to bail hearings rather than employing their discretionary powers of release. The mentality, they argue, is paralleled in the courts, where, for example, adjournments (which push cases to another day and potentially another judge) have become standard practice, delaying bail decisions and leaving individuals detained for longer (Webster, Doob and Myers 2009: 100). Risk aversion can also be seen in the routine application of numerous bail conditions. These conditions, which are often difficult to follow, have given way to a rise in "failure to comply' criminal charges, which in turn contribute to provincial jail crowding and court backlog (Deshman and Myers 2014).

A culture of risk aversion can also be seen in bail courts, where judges may view the potential costs of bail release (e.g. the commission of a new criminal code violation) as outweighing the potential benefits (e.g. the protection of democratic legal principles) (Webster, Doob and Myers 2009). Importantly, judicial notions of risk are not based on the depersonalized 'scientific' management schemes described by new penology theorists. Rather, it appears as though notions of risk are laced with classist, ableist and racist judgments that emerge at the level of practice.

Indeed, the remand system is used to perpetuate forms of social inequality by disproportionately targeting individuals who are poor, Indigenous, racialized, and/or suffering from mental illness and substance misuse (Deshman and Myers 2014; Novac, Hermer, Paradis and Kellen 2006; Kellough and Wortley 2002; Statistics Canada 2015; Perreault 2014; Public Services Foundation of Canada 2015; Tilley 2012; John Howard Society of Ontario 2015). Far from constituting 'high risk' subjects, such individuals are 
frequently detained on relatively minor and non-violent charges; in fact, administrative charges have become the most common type of charges among remand admissions, and such charges are often the most serious the person is facing (Porter and Calverley 2011; Deshman and Myers 2014).

The seeming inability of popular penal theories to adequately explain key trends in the realm of punishment speaks to larger disconnect between penal theory and practices on the ground. Indeed, authors have criticized contemporary penal theory for assuming the inherent congruity between the two, as well as for oversimplifying the nature of punishment (Moore and Hannah-Moffat 2005; Hutchinson 2006; Carrier 2010). Carrier (2010), for example, argues that the punitive turn thesis is totalizing in its attempts to theorize all penal practices through a monolithic lens, focusing on indicators of punitiveness, equating rhetoric with practice, and ignoring diversity within and across contexts.

Another shortcoming of the punitive turn thesis is its implied presumption that an 'appropriate' level of punishment exists, which "contributes to reinforcing the naturalization of the penal sanction" (Carrier 2010: para 48). The 'appropriate' level of punishment, however, is never defined, as the notion of 'punitiveness' remains ambiguous throughout the literature (Carrier 2010). In light of the continuity of punitiveness throughout the history of punishment, Sim (2009: 15-16) suggests that the phenomenon underpinning the punitive turn and new penology literature "is perhaps better understood as an intensification in law and order processes which were already deeply embedded in the political and cultural institutions of the state and civil society." 
The historical nostalgia evident in the punitive turn literature, from Sim's (2009: 3) point of view, may stem from the tendency of scholars to "read the social history of the prison as an account from above," relying on official discourses and texts, while ignoring "accounts from below," i.e. prisoners' subjective accounts of punishment. Walker (2014: 7), a former prisoner, expresses a similar view, noting that penal scholars rarely "situate their analyses on the lived experiences of inmates who are most vulnerable to criminal justice policies and practices." Indeed, scholars interested in understanding the nature of incarceration must go beyond official narratives of punishment to explore the perspectives of those who experience it. Even when partial information regarding institutional conditions and practices can be gleaned from policy documents and government reports, the nature of how punishment is experienced by prisoners is not self-evident. Elements of incarceration can be experienced in ways that stray from the official objectives of policymakers and legal actors (Griffin 2006; Crewe 2015), while the nature of punishment can extend beyond the law's formal intent (Sykes 1958).

\section{The state of prison research}

Prominent prison scholar Ben Crewe (2015) suggests that empirical prison research can shed light on the 'blind spots' of 'big picture' theory. He and others, however, have lamented the apparent decline of prison research in the age of mass incarceration. At the turn of the century, Simon (2000: 289) likewise noted that sociological knowledge of prison life had paradoxically faded during "the great expansion of incarceration." Turning their attention away from the prison social system, he noted, scholars began to study and theorize different aspects of punishment, including incarceration rates, sentencing measures, and public perceptions of crime. A key empirical question that remained 
unanswered, Simon argued, was how life inside prison had changed alongside prison population growth and wide-scale changes in prison management. Wacquant (2002) made a similar observation in his oft-cited article, The Curious Eclipse of Prison Ethnography in the Age of Mass Incarceration. To Wacquant, as the prison system came to take on new social functions, it became decreasingly accessible to researchers. Like Simon, Wacquant was alarmed that "observational studies depicting the everyday world of inmates all but vanished just as the United States was settling into mass incarceration" (Wacquant 2002: $385)$.

Wacquant saw the "lack of openness of correctional facilities to inquiry" as only part of the problem. Impediments within the field of social science research were also at play, including, most notably, "the social and professional organization of academic life itself" (Wacquant 2002: 387). For different reasons, he argued, the academic climate was no longer conducive to the practice of qualitative research behind bars. In a more recent account, Reiter (2014) similarly suggests that institutional factors in both the prison and university contexts have led to a shift from qualitative to quantitative studies of punishment. The effect of changing research orientations, she notes, is that "prison research is pixelated; the research exists, but the sum of the data conveys, at best, a blurry image of the institutions under scrutiny" (Reiter 2014: 417). In this context, Reiter notes, key questions regarding prison life have not been addressed by contemporary scholars.

Tubex (2015) makes an explicit connection between trends in punishment and academia. She argues that the same forces driving changes in penal philosophy, including the rise of neoliberalism and managerialism, have influenced other social institutions like the university. In the realm of punishment, neoliberalism has corresponded with a shift 
from rehabilitative to punitive policies, the politicization of punishment, and the rise of managerialist logics. In this context, performance comes to be assessed by quantitative indicators, rather than qualitative measures, and the operational goals of the prison take precedence over broader social objectives. Meanwhile, at the university, a similar inward shift has occurred, whereby academia, increasingly driven by "the private sector motto of competition and profitability," has become organized around institutional goals rather than wider social aims (Tubex 2015: 8). In particular, the pursuit of favourable rankings structures the university reward system by prizing academic productivity in the form of publications in prestigious academic journals. Internalized by researchers, this reward structure fosters academic work that is conducive to publication. This can pose limits to research, Tubex argues, since "in the area of expertise we are referring to, there are few journals within these rankings where our writings can find a home" (Tubex 2015:8).

The statements by the above scholars present a pessimistic view of the state of prison research; in the following paragraphs, however, I hope to present a different picture. While in-depth ethnographies by outside researchers in the style of Clemmer (1958) and Sykes (1958), for example, remain somewhat scarce (but not unheard of) outside of the U.K., studies investigating various aspects of prison life continue to provide rich detail of the subjective aspects of punishment and the social world of prisons. This point is also made by Taylor (2009) and Piché, Gaucher and Walby (2014) who emphasize the specific neglect of convict criminologists and prisoner ethnographers in discussions of prison research.

Below I will provide an overview of classic and contemporary prison research in an effort to capture key findings and themes that have emerged in the study of punishment 
in practice. In particular, I will focus on studies exploring the 'pains of imprisonment,' the sociological and biographical factors that mediate prisoners' experiences, and the ways in which prisoners adapt to and resist the qualities of prison life. This review does not encompass every study or empirical area under investigation, but nonetheless highlights the considerably robust and multifaceted field of prison research. By and large, however, most studies continue to focus on the experience of those within the prison, with jail research remaining on the periphery.

\section{The 'pains of imprisonment'}

Foucault's (1977) influential account in Discipline and Punish analyzed the nature of power in the contemporary prison as a means of illustrating the functioning of power in society more broadly. To Foucault, imprisonment marked a shift from the body as the site of punishment, to the mind as the site of 'correction.' This transformation reflected a more fundamental shift in the nature of social control; namely one that rested on expressions of 'top-down' power, to one that involved 'disciplinary' forms of power that activated objects into subjects of power. In the prison, he explained, the perpetual threat of surveillance by guards, combined with practices of normalizing judgement and examination, led prisoners to become self-regulating, docile bodies; hence, power operated in and through them. While the body was "no longer the constituent element of the penalty" (Foucault 1977: 11), Foucault questioned whether this shift made imprisonment more 'civilized' than the forms of physical punishment it had replaced, or instead, if it merely afforded a more effective means of social control (Crewe 2011).

Years before Foucault's influential analysis, Sykes (1958) similarly questioned whether the modern prison was, in fact, less painful than the forms of physical punishment 
that preceded it. A founding prison sociologist, Sykes discussed the "pains of imprisonment' in his analysis of the prisoner social world at a maximum security institution in New Jersey. Sykes described five types of pains, which he also called 'deprivations' or 'frustrations,' that defined the prison experience. These pains included the losses of liberty, goods and services, heterosexual relationships, autonomy and security. While, he noted, the modern prison was envisioned as a "humane alternative to the physical brutality and the neglect which constituted the major meaning of imprisonment in the past," he was convinced that prisons could be "just as painful as the physical maltreatment which they have replaced" (Sykes 1958: 64).

Goffman's (1961) work on 'total institutions' also illuminated the pains associated with institutional life. In his account, Goffman emphasized the inherent identity threats associated with life in total institutions. He defined total institutions as "place[s] of residence and work where a large number of like-situated individuals, cut off from the wider society for an appreciable period of time, together lead an enclosed, formally administered round of life" (xiii). Examples of total institutions include nursing homes, military camps, asylums, monasteries and prisons. Upon entry into the total institution of the prison, he noted, prisoners are stripped of their pre-prison selves through a series of rituals that designate uniform institutional identities. The prisoner "begins a series of abasements, degradations, humiliations, and profanations of self' (14). As Goffman wrote, the prisoner is searched, weighed, photographed, fingerprinted, given an identification number, stripped of personal possessions and given institutional clothing. Goffman described such admission procedures as "trimming" or "programming" because the 
prisoner was being "shaped and coded into an object that [could] be fed into the administrative machinery of the establishment" (16).

Since these and other classic works, researchers have considered if and how the pains of imprisonment have changed in contemporary penal landscapes. In the UK context, for example, Crewe $(2007,2009,2011)$ has considered how the prison experience has changed in light of new 'softer' forms of penal governance. He notes that various reforms in the 1990s, including the Incentives and Earned Privileges scheme, have promoted a regime of "self-government and responsibilization" (Crewe 2007: 259), whereby prisoners are encouraged to align themselves with institutional rules and objectives in the sake of their own self-interest. His account of power conjoins Foucault's notion of disciplinary power, which stresses the 'subjectification' of objects of power, with the administrative logic the new penology, whereby "[m] ovements are restricted, security has been tightened, and risk has become the trump-card of the system" (Crewe 2011: 524).

In the new prison setting, Crewe argues, the pains of imprisonment have evolved; conditions have become less harsh, but psychologically more onerous. For example, prisoners experience the 'pains of uncertainty and indeterminacy' as a result of practices such as indeterminate sentencing. Not knowing when they will be released, or where they stand on the "route-map to freedom" (Crewe 2011: 514), prisoners bear a sense of ontological insecurity. Prisoners experience the 'pains of psychological assessments' when they are placed into rigid and abstract categories of risk that obscure the nuances and complexities of personal identity (Crewe 2011: 515). Prisoners are also burdened with the 'pains of self-government' as they are expected to self-regulate all aspects of their lives in a way that achieves the approval of their watchers. In sum, Crewe states, while "power is 
exercised more softly, in a way that is less authoritarian," imprisonment "has become ‘deeper' and more burdensome" (524).

In the American context, Sexton (2015) examines how prisoners understand and define punishment in the context of the so-called punitive turn. She employs a subjective conception of punishment that focuses on that which is experienced and perceived as punishment, "regardless of whether it is intended as punishment and/or is approved or acknowledged by the penal system" (Sexton: 2015: 118). Based on her interviews with prisoners, Sexton identifies a set of 'concrete' pains that involve assaults on prisoners' material needs, including "medical neglect or mistreatment; inadequate or unhealthy food; and the inability to pay for necessities that [are] not provided by the prison" (121). Echoing Goffman, she also describes a set of 'symbolic' pains that involve assaults on the identity and humanity of prisoners, including "loss of autonomy, self, and personhood" (123). Interestingly, Sexton found that punishments with high symbolic meaning were the source of more pain than punishments viewed only in concrete terms, as they were viewed as emblematic of broader injustices.

Prisoner writings have also highlighted the symbolic pains associated with contemporary incarceration. For example, in the American context, Terry $(2000,2004)$ discusses how the new penology, oriented around principles of efficiency, management and technology, shapes the prisoner experience, and in particular, the prisoner identity. In an environment where all aspects of existence are controlled - "what they see, hear, smell, touch and do" (Terry 2000: 109) - prisoners are stripped of their identity and autonomy as human beings. Like Terry, Richards (2014) who served a life sentence in an Australian prison, emphasizes the way in which prisoners lose their sense of self when they become 
the 'property' of correctional departments and are converted into 'inmates.' As she articulates, the 'prisoner' status is perpetually reinforced through a multitude mechanisms and practices. Consequently, Richards argues, the prisoner identity eventually becomes internalized by women; "it becomes subsumed into her self-identity" (100). These accounts highlight how Goffman's analysis of the dehumanizing effects of total institutions has retained applicability in the contemporary prison context, hence illustrating the continuity of some features of punishment.

While studies of the pains of imprisonment in the context of jails are scarce, Walker's (2014) account constitutes a notable exception. Having spent time in the California jail system as a prisoner, Walker presents a rich description and sociological analysis of the jail experience. As Walker notes, for many prisoners, “jails are significantly more punitive than prisons" (16). Like Sexton, Walker distinguishes between distinct types of pains, although he focuses on those embedded in the physical infrastructure ('environmental pains') and those related to interpersonal forms of harm ('private pains'). Examples of environmental pains include inadequate clothing and bedding, issues with plumbing (including lack of hot water and toilet flooding), extreme temperatures, and lack of natural light. To Walker, such problems are not merely the result of poor physical conditions; they are perpetuated by an environment of 'malign neglect.' Private punishments, in contrast, relate to the forms of harm that prisoners experience at the hands of staff and other prisoners. To Walker, the effect of environmental and private punishments is to make the jail an unlivable space where punishment is omnipresent.

While contemporary studies of the pains of imprisonment suggest both change and continuity in the nature of punishment, it is important to recognize that punishment is not 
an 'objective' experience (Sexton 2015). Indeed, a central argument within prison sociology is that experiences of incarceration are not identical, but mediated by an array of sociological factors (Sykes 1958; Clemmer 1958; Goffman 1961; Crewe 2007). Hence, researchers have considered how experiences are shaped by social factors, such as gender, racial identity and age, biographical factors, such as previous experiences of incarceration, and contextual factors, such as institution type.

Gender has been deemed an important factor mediating experiences of punishment. While a male-centric focus shaped early works in prison sociology, women's imprisonment did not completely escape empirical attention. In an early study of women's imprisonment, Giallombardo (1966) noted that, while women's prisons were less harsh than men's, and variation existed among prisoners, "there [was] nevertheless a "hard core of consensus" among the female prisoners that prison life [was] depriving and frustrating" (Giallombardo 1966: 273). She found that the pains of imprisonment among women were similar to those identified by Sykes in relation to men (i.e. the loss of autonomy and freedom, the denial of personal property, the deprivation of heterosexual relations, and forced co-habitation). Other researches, however, emphasized the different types of pain women experienced in prison, particularly those related to the loss of traditional female roles (Ward and Kassebaum 1964; Foster 1975; Van wormer 1981). For example, in their study of female prisoners, Ward and Kassebaum (1964) found that women experienced separation from the home and family as the greatest source of pain at all stages of their prison sentences.

Subsequent research exploring women's pains of imprisonment maintained a strong focus on the loss of bonds and/or traditional female roles experienced by women, and the role of different relationships in shaping the prison experience (e.g. Propper 1982; 
Severance 2005). Motherhood in particular is a topic that has garnered the attention of prison researchers exploring women's incarceration (Datesman and Cales 1983; Clark 1995; Enos 1998; Shamai and Kochal 2008; Berry and Eigenberg 2003; Berry and SmithMahdi 2006). As Enos (1998) notes, the majority of American women in prison are mothers, and studies have found the loss of family ties and the maternal role to be at the centre of women's pains of imprisonment. Datesman and Cales (1983: 142) write, “[w]hile separation from children is also painful for men in prison, women in prison are more likely to have been the primary caretaker and, in many instances, the sole parent before incarceration." Hence mothers have been found to experience a high level of "role strain" as a result of not being able to carry out maternal practices (Berry and Eigenberg 2003).

Some authors have moved beyond normative gender roles when exploring women's experiences of imprisonment. For example, in the American context, Pogrebin and Dodge (2001), who conducted interviews with female former prisoners, found that, while separation from children is indeed a great source of pain, a host of other pains shape women's prison experiences. These pains relate to living conditions, prisoner-on-prisoner harassment and exploitation, violence, constant noise, the presence of drugs, inadequate medical care, cross-gender supervision, and sexual coercion by guards. Disturbingly, the authors found that sexual violence is embedded in the institutional environment, noting that "most of the respondents claimed that male officers sexually harassed them" (Pogrebin and Dodge 2001: 538) and many women recalled being coerced into sexual relations with guards. Based on their findings, Pogrebin and Dodge argue that the pains experienced by women are perhaps greater than suggested in previous studies. 
While some forms of violence experienced by female prisoners are direct, others are hidden in institutional practices. On this topic, Chartrand (2015) emphasizes how women in Canadian prisons are subject to various practices that constitute or give way to violence. Such practices, which are justified by security and gendered discourses, include "maximum security classifications, involuntary transfers, strip searches, segregation, solitary confinement, dry cells, special handling units, transfer to men's prisons, lack of medical attention, self-harm, and suicide" (Chartrand 2015 para. 13). Such practices are experienced as violence, even if not formally intended to be so, yet are obscured by security discourses that effectively legitimize forms of violence that would be unacceptable in nonpenal settings.

While women's prisons might be generally understood as 'landscapes of violence' (Chartrand 2015), certain elements of prison life appear to hold greater salience in women's subjective accounts. For example, several authors have noted that staff-prisoner relations factor heavily in prisoners' accounts of incarceration (Kruttschnitt et al. 2013; Liebling 2011; Micucci and Monster 2004). In a comparative study of women's experiences in the United States, England, and the Netherlands, Kruttschnitt et al. (2013) found that "interactions with staff have the largest impact" in shaping women's perceptions of autonomy. More specifically, they found that "women who feel like the correctional staff really do not care about them, and "they are just doing their jobs," are $118 \%$ more likely to feel a lack of control over their prison lives (Kruttschnitt et al. 2013: 33). Similarly, in the Canadian context, Micucci and Monster (2004) found that guards who were 'controloriented,' rather than 'rehabilitation-oriented,' contributed to the pains of imprisonment through a set of practices that were justified by logics of security and order: "They enforced 
institutional rules, responded to rule transgression with punitive responses, regularly enacted control measures such as searches, and used lock-downs" (Micucci and Monster 2004: 525). While prisoners viewed rehabilitation-oriented guards favourably, they felt they were perceived by control-oriented officers as sub-human.

In the U.K. context, Crewe, Hulley and Wright (2017) have recently argued that certain aspects of prison life may be experienced more harshly by women than men due to women's pre-prison experiences of trauma. Such aspects include the loss of contact with friends and family, the denial of autonomy and control, the experience of psychological harm, as well as lack of trust, privacy and intimacy. The way in which women experience these pains, the authors argue, is shaped by their pre-prison experiences, which were often marked by violence and abuse, intimate bereavement, and addiction issues. More specifically, imprisonment can trigger the feelings of low self-worth and shame associated with abuse, the emotional deprivation associated with abandonment, and the loss of autonomy associated with previous experiences of powerlessness. In this sense, imprisonment "interacts with and compounds the forms of trauma and degradation that almost all of the women in our study had suffered prior to their sentence" (17).

Connecting the pains of imprisonment to broader gender structures has also been deemed important in relation to research on male prisoner experiences. Norwegian prisoner researcher, Ugelvik (2014a), for example, notes that certain elements of the carceral experience, due to their gendered implications, may be experienced differently for men. More specifically, he explains that the basic features of the institutional environment constitute inherent threats to stereotypical traits of male identity: "The deprivation of liberty, of goods and services, of heterosexual relationships, of autonomy and of security 
are all experienced as challenging for men as men in a specific cultural and symbolic context where the hegemonic ideal is that men are supposed to be autonomous and assertive heterosexually active tough guys, independently wealthy and able to make their personal mark on their surroundings" (165, emphasis in original). Other authors have similarly emphasized the way in which imprisonment impairs the ability of men to perform expressions of masculinity, thereby adding a gendered layer to punishment (Jewkes 2005; Michalski 2015; Rymhs 2012).

In addition to exploring the gendered pains of imprisonment, prison sociologists have also considered how race and ethnicity shape carceral experiences. In some studies, authors have emphasized how social inequalities are reproduced in the prison. For example, British and American researchers have noted that, for Islamic prisoners, discrimination is embedded in the prison experience, exemplified by the unavailability of appropriate chaplaincy services, the absence of Muslim staff members, denied access to religious texts, lack of meal accommodation, obstacles to worshipping practices, as well as discriminatory and racist treatment by staff (Spalek and Wilson 2002; Joly and Beckford 2005; Marcus 2009). Researchers have also found that Black prisoners are subject to structural discrimination in carceral spaces on the basis of racial identity; for example, Richmond and Johnson (2009), who studied the experiences of prisoners in California, found that white prisoners were more likely to have a prison job and were given preferential treatment by staff; hence they "carried the privilege of whiteness from the outside into the prison system" (573).

Although social constructions of race are, to a certain extent, 'imported' from the outside cultural context, racial identities can also take on new meaning in the prison 
context. Kruttschnitt and Hussemann (2008) explored this theme in California and England, contexts marked by distinct racial dynamics. In the U.K. context, where white prisoners outnumbered racialized prisoners, they found that non-racialized women focused on the deprivations and frustrations of prison life, whereas racialized women, especially foreign nationals, focused more on the loss of personal identity and the experience of feeling like an 'outsider.' Different findings emerged in the California context, where racialized women outnumber white women. There, they found the topic of race to be less prominent in the accounts of racialized women, while salient in the accounts of white women, and particularly those with no previous experience of incarceration. Nonracialized women in this context were not accustomed to being members of a racial numerical minority and hence, "the prison forced them to confront, perhaps for the first time in their lives, their own racial identity and the salience of 'the others' that now inhabited their world" (Kruttschnitt and Hussemann 2008: 718). Hence, while racial meanings in prison may be imported from outside cultural contexts, for some, racial identities can take on unique meanings in carceral environments.

In the Canadian context, very few studies have considered how racial and ethnic identities mediate experiences of imprisonment. This is surprising given the vast overrepresentation of racialized and Indigenous people in both jails and prisons (Sapers 2013; Statistics Canada 2015; Perreault 2014; Kellough and Wortley 2002). More specifically, despite constituting only 3 to 4 percent of the population, Indigenous people account for around a quarter of the federal prison and provincial jail populations (Reitano 2017). To be sure, some research has explored the role of Indigenous programming for federallyincarcerated women. For example, Waldram (1993) conducted research in the early 1990s 
with federally-incarcerated Indigenous women on the topic of Indigenous spirituality. He found that spirituality programs provide women with meaning and cultural knowledge and facilitate symbolic healing. More recently, Yuen (2011) conducted similar research, considering the role of leisure experiences among federally-incarcerated Indigenous women. She found cultural practices (such as Sweat Lodges, Pow Wows, Drum Circles and Talking Circles) provide women with an opportunity for healing in the otherwise punitive environment of the prison. Aside from these works, little scholarly work has been produced on the experience of racialized and Indigenous prisoners in Canada's provincial jails and federal prisons.

While gender, ethnicity and race are key factors shaping experiences of imprisonment, other sociological and biographical factors also play a role. Some authors have considered the role of age, for example, in mediating carceral experiences. In the U.K., Crawley and Sparks (2005) explored the experience of older (aged 65 and up) male prisoners using ethnographic methods. They suggest that imprisonment inflicts a set of 'hidden injuries' on this population; this can be traced to the fact that "prisons have never been designed with older people and their needs in mind" (350). More specifically, the authors found that older men were treated in an identical fashion to younger prisoners subject to the "same timetables, same physical layout, same practices, same rules and same activities" (352) - without accommodation on the part of staff. From the authors' view, this "institutional thoughtlessness" (353) serves to compound the pains of imprisonment experienced by older prisoners. In the Australian context, Trotter and Baidawi (2014) similarly found that the institutional environment presents exceptional difficulties for 
elderly prisoners; these difficulties relate not only to the lack of accessibility in the built environment, but older prisoners' physical vulnerability within the prisoner population.

One's pre-prison living circumstances and other biographical factors can also mediate the experience of imprisonment. For example, those who lack previous experience of incarceration may sense greater fear for their physical safety in comparison to those with prior experience (Souza and Dhami 2010). However, while many prisoners experience physical insecurity due to constant threat of violence in prison (Rowe 2011; Caputo-Levine 2012), others may experience relief from the insecurity of their outside lives (Rowe 2011). In fact, Weston-Henriques and Jones-Brown (2000: 267) argue that prisons may even be viewed as "safe havens" for those who experience various threats to their security in the outside world. Bradley and Davino (2002) found this to be true for certain women who experienced interpersonal victimization before prison. Crewe (2007: 270) also found certain prisoners, mostly addicts, sensed "a respite from the temptations of the free community." These studies illustrate how biographical factors fundamentally shape individual experiences of incarceration.

Experiences of imprisonment are also shaped by the institutional setting. While studies of remand prisoners are rare, there are exceptions. For example, Ashkar and Kenny (2007) explored the experience of incarcerated youth (aged 16 to 19 years old) in an Australian detention centre. They found that young prisoners' experiences were shaped by a negative prisoner culture, antagonistic relations with staff, lack of programming and services, as well as the loss of autonomy and control. In the U.K., Freeman and Seymour (2010) also conducted research with youth on remand to explore how the pre-trial detention setting gives way to a particular type of carceral experience. For many young people, they 
found, the worst pain of imprisonment is the sense of uncertainty that characterizes their situation; prisoners experienced considerable anxiety as a result of being unaware of their release date or the outcome of their legal case. Their research confirms the notion that remand is "one of the most taxing and unstable prison experiences" (138).

\section{The effects of imprisonment}

In addition to exploring the pains of imprisonment during incarceration, researchers have also explored the adverse consequences of incarceration that often extend beyond the institutional setting. By and large, 'prison effects' research emphasizes the negative and sometimes long-lasting impacts of incarceration, including mental health problems and physical health damage. As Haney (2012: 1) notes, in the current context of mass incarceration and the warehouse prison, the question is no longer "whether and how prisons can achieve to elusive goal of rehabilitation," but "how much debilitation they bring about."

DeVeaux (2013: 257), who spent 25 years in prison, argues that "[ $t]$ he experience of being locked in a cage has a psychological effect upon everyone made to endure it. No one leaves unscarred." Research from the field of psychology and psychiatry confirm his assertion. For example, based on their interviews with former life prisoners, Liem and Kunst (2013) argue that prisoners experience a specific type of post-traumatic stress disorder (PTSD), called post-incarceration syndrome. Symptoms of post-traumatic stress among former lifers include nightmares, hyper-arousal, avoidance strategies and emotional numbing. In addition to these symptoms of PTSD, prisoners may also experience effects unique to prison trauma, including difficulty making decisions and trusting others, socialsensory deprivation syndrome, and social and temporal alienation. Schnittker (2014) also 
found that former prisoners experience high levels of anxiety, depression and social uncertainty.

Some researchers have looked specifically at the effects of solitary confinement on prisoners. In his professional capacity, Grassian $(1983,2006)$ studied the effects of solitary confinement in over 200 prisoners. Based on years of observation, he argues that solitary confinement produces a unique psychiatric condition. Symptoms include hyper-sensitivity to stimuli, perceptual distortions and hallucinations, panic attacks, reduced cognitive functioning, obsessive thoughts, paranoia, psychosis and lack of impulse control. Grassian found that damaging psychiatric effects occur even among prisoners with no pre-existing mental health conditions, and that the effects of isolation can be long-lasting. Despite evidence showing the harms of isolation, the 'supermax' prison houses prisoners in conditions akin to solitary confinement, leading authors to comment on the potentially damaging psychological effects of this style of institution (Pizarro and Stenius 2004; Haney 2003; Arrigo and Bullock 2008).

Researchers have also analyzed the various health consequences associated with incarceration. In general, scholars have found that incarceration adversely impacts health, particularly when conditions are marked by severe deprivation, crowding, unsanitary conditions, limited opportunities for exercise, poor quality food and inadequate healthcare services (De Viggiani 2007; Bernier and MacLellan 2011; Brinkley-Rubinstein 2013). In such contexts, prisoners' health may suffer due to exposure to infectious diseases, chronic stress, violence, inactivity, malnutrition as well as structural barriers to accessing healthcare (Massoglia and Pridemore 2015; Brinkley-Rubinstein 2013; Harner and Riley 2013; Fleury-Steiner 2015). For pregnant women, the institutional environment, in 
conjunction with pre-existing risk factors, has been found to have a negative impact on pregnancy outcomes in some cases (van den Bergh, Plugge and Aguirre 2014; Bernier and MacLellan 2011; Hatton, Kleffel and Fisher 2006; Ferszt and Clarke 2012).

The literature examining the effects of imprisonment illustrates how punishment does not end upon release; rather, the pains of imprisonment can extend back into society in ways that extend the 'breadth' of punishment (Crewe 2015). That the experience of incarceration can have long-lasting physical and psychological impacts raises key concerns regarding the proportionality principle, or the notion that the harms of punishment should not exceed the harms caused by the original criminalized act (Von Hirsch 1992). Furthermore, prisoners who are adversely impacted by institutional conditions may return to societies with low perceptions of system legitimacy (Smoyer, Kershaw and Blankenship 2015). Perceptions of legitimacy in turn mediate the effect of punishment; in particular, punishment seen as unjust can have the effect of increasing the likelihood of future criminalized behaviour (Sherman 1993), thereby undermining the reformative, deterrent and public safety goals of incarceration.

In summary, contrary to claims that prison research has disappeared, researchers studying the contemporary pains of imprisonment have provided rich descriptions of the experience of punishment in diverse settings. Contemporary prison scholars have illuminated the 'hidden' elements of punishment that cannot necessarily be gleaned from policy texts. Researchers have also noted the ways in which different sociological, biographical and institutional factors mediate carceral experiences in ways that often compound the pains of imprisonment. The above accounts hence illustrate the need to 
examine punishment in its realized forms from the point of view of those who experience it, rather than in its idealized forms as articulated in official discourses (Sexton 2015).

\section{Responses to punishment: Prisoner adaptation}

Writings on the pains of imprisonment describe the forms of harm experienced by prisoners in penal settings; however, prison sociologists typically do not view prisoners as passive beings who merely accept their circumstances. In fact, researchers have paid considerable attention to understanding the various ways in which prisoners collectively and individually respond to the pains of imprisonment. As Schmid and Jones (1993: 439) write, 'doing time' is "a creative process through which inmates must invent or learn a repertoire of adaptation tactics that address the varying problems they confront during particular phases of their prison careers." Previous authors have conceptualized prisoners' collective and individual responses using different concepts, including prisonization (Clemmer 1958), modes of adaptation (Sykes 1958), secondary adjustments (Goffman 1961), and 'tactics' that reclaim meaning over carceral spaces (Baer 2005). Prisoners' responses illustrate the dialectical nature of power in carceral settings, or the way in which objects of control respond back in a variety of ways that demonstrate agency.

Prisoner culture: Early scholarship

Scholarship examining collective responses to punishment has focused largely on the characteristics of prisoner culture. A founding prison sociologist, Clemmer (1958), suggested that, much like members of any society, prisoners became 'socialized' into prison culture. He developed the concept of 'prisonization' to explain how prisoners became habituated to prison culture (Clemmer 1958: 299). He defined prisonization as "the taking on in greater or less degree of the folkways, mores, customs, and general culture of 
the penitentiary." He argued that prisonization equipped prisoners with the social knowledge required to navigate, and hence survive, the prison social world.

Sykes (1958) analyzed the features of prison culture in his classic sociological work on men's imprisonment. Influenced by structural functionalism, Sykes argued that prisoners adapted to imprisonment through the development and maintenance of a prison social system, complete with its own set of symbols and roles. With his colleague (Sykes and Messinger 1960: 5), Sykes discussed the five main tenets of the 'inmate code,' which they viewed as structuring prison culture. These included: 1. "Don't interfere with inmate interests," which encompassed "no ratting" and maintaining a "unified front" against guards; 2. 'Don’t lose your head;" i.e. stay out of unnecessary conflict, 'play it cool,' and ‘do your own time;' 3. "Don’t exploit inmates;" 4. "Don’t weaken;" and 5. "Be sharp," or do not trust or align with prison staff (Sykes and Messinger 1960: 6-9).

To Sykes and Messinger, the code was largely oriented around an in-group mentality that stood opposite to institutional power. The solidarity born from the code, they suggested, lessened the pains of imprisonment and enabled the formation of social identities. In practice, prisoners adhered to the code to varying degrees, giving way to different social roles (e.g. the "right guy," "rat," "tough," "gorilla," "merchant," “weakling," "fag," and "square John”). However, all prisoners consistently and uniformly paid verbal allegiance to the code. This was because, Sykes and Messinger argued, all prisoners stood to benefit from the social cohesion that the code ensured.

Likes Sykes, Goffman (1961) also considered how prisoner culture emerged in response to institutional conditions. Goffman emphasized how institutional practices attempted to turn individuals into 'inmates;' however, he did not see prisoners as simply 
accepting their institutional identities. He was also interested in understanding the ways in which prisoners re-established some level of control through 'secondary adjustments.' Goffman defined secondary adjustments as "practices that do not directly challenge staff but allow inmates to obtain forbidden satisfactions or to obtain permitted ones through forbidden means" (54). Goffman saw secondary adjustments as governed by the 'inmate code,' which provided 'some means of informal social control to prevent one inmate from informing staff about the secondary adjustments of another" (55). Like Sykes, he saw prisoner roles (e.g. squealers, finks, rats, stoolies and right guys) as being partially tied to adherence to the code.

As Crewe (2016) writes, Sykes and Goffman can be understood as 'deprivation' or 'indigenous' theorists, meaning that they understood the internal qualities of the prison as shaping prisoner culture. In this sense, they viewed the prison as a unique social institution that was somewhat autonomous from broader society. Other theorists, however, have drawn connections between the nature of prisoner culture and outside sub-cultures. For example, Irwin and Cressey (1962) suggested that prisoner culture had its roots in 'criminal sub-cultures' that existed beyond the prison. Similarly, Jacobs (1974) noted that the parallels between prison gangs and street gangs illustrated 'cultural drift,' whereby outside cultural dynamics are imported into the prison. To him, the fundamental connections between prison culture and outside forces called into question the ability of prisons to achieve their goal of reformation.

Classic authors studying women's prisons also felt that prison culture was shaped by outside social forces pertaining to gender roles. Giallombardo (1966), for example, noted that while women and men were confronted with similar prison pains, the social 
environments that emerged in response revealed important differences, which Giallombardo attributed to the importation of broader gender roles into the prison. For example, she found that the violent roles that emerged in men's prison were absent among women, which she attributed to women's 'less aggressive' nature. While Giallombardo did find several social roles that paralleled those described by Sykes in relation to male prisoners (e.g. the snitch, the inmate cop, and the square) she also found more friendshipbased roles, as well as a set of roles she dubbed the 'homosexual cluster.' Giallombardo argued that in the prison, same-sex partnerships served as a "meaningful personal and social relationship," noting that, "[f]or the vast majority of the inmates, adjustment to the prison world is made by establishing a homosexual alliance with a compatible partner as a marriage unit" (282).

Since these early works, studies have focused both on the unique qualities of the prison environment and the role of pre-existing factors and outside forces in shaping prisoner adaptation. Today, as Ricciardelli (2014a) notes, "most scholars concede that both attributes of prisoners and the prison environment play a role," giving way to the 'integration model.' For the most part, recent literature suggests that forms of collective forms of adaptation have evolved alongside broader changes shaping the context of punishment (Crewe 2005; Terry 2000, 2004; Ricciardelli 2014a; Greer 2000), although some authors have noted parallels with early depictions of prisoner culture (Melde 2008). Incorporating prisoner agency into discussions of adaptation, authors have also considered the ways in which prisoners adapt to prisoner culture through identity work, impression management techniques and other strategies, and attempt to mitigate the pains of imprisonment through individual coping strategies. 


\section{Collective responses in contemporary contexts}

Crewe (2005) provides a detailed picture of male prison culture in the contemporary U.K. context. Having spent a lengthy period of time in a medium-security institution as a researcher, he was able, like his historical counterparts, to see the prison social world "in action" (179). Based on his fieldwork, Crewe suggests that the 'inmate code' has undergone significant changes since early depictions, which emphasized prisoners' opposition to the prison system, loyalty among prisoners, as well as personal strength, manliness, and keeping to one's self. More specifically, he suggests that the prisoner code has become "diluted," and that in-group solidarity and anti-staff values have become less pronounced.

Crewe attributes these changes to different factors, including improved conditions of confinement, which have "reduced the confrontational and depriving nature of prison life" (180), the rise of prison drug use, as well as new administrative schemes, including the Incentives and Earned Privileges scheme, which incentivizes individual conformity to institutional rules. In this sense, physical, social and administrative changes in prisons have altered the nature and role of prison culture and the apparent need for in-group solidarity. While he notes that some solidarity is expressed among smaller groups, including ethnic and regional-based groups, and that prisoners generally display more acceptance and empathy, he suggests that a focus on one's own situation has become central to the experience of imprisonment.

In the Canadian context, Ricciardelli (2014a: 235) has also explored how the prisoner code has evolved in light of "the new realities of penal living." Based on her interviews with former federal prisoners in Ontario, she also found that prisoner code has 
become more "individualistic in nature and removed from notions of inmate solidarity and brotherly love among prisoners" (Ricciardelli 2014a: 249). However, in contrast to Crewe's account, she suggests that concern for personal risk is at the root of this individualized re-orientation of the prisoner code. Adhering to the code of conduct, she found, enables prisoners to mitigate threats to their safety. She articulates the five main tenets of the prison code as revealed in prisoners' accounts: 1. "'Never rat on a con' and don't get friendly with the staff;" 2. "Be dependable (not loyal);" 3. "Follow daily behaviour rules or else;" 4. "I won't see you, don't see me and shut up already;" 5. "Be fearless or at least act tough.”

In the American context, former prisoner Terry $(2000,2004)$ also sees prisoner culture as changing alongside broader transformations shaping the context of imprisonment. Previously, Terry notes, status in prison was obtained through strict adherence to the prisoner code. In practice, this meant prisoners portrayed fearlessness, condemned snitches and sex offenders, offered trustworthiness to close acquaintances, 'minded their own business' and did not interact with guards or prisoners of other 'races.' This culture changed, Terry notes, as the politics of punishment, and corresponding prisoner population, underwent transformation. "As the years passed I noticed that the "convict" as I knew him seemed to be disappearing. In its place came inner-city gang members, drunk drivers, and mentally ill individuals with little understanding or appreciation for traditional prison values" (Terry 2004: 48). Changes in prison administration and in the prisoner population gave way to new prisoner culture. Lacking the cohesion of earlier iterations, he suggests the new prison culture bears greater similarity 
to the culture of 'street life,' i.e. it is "divided by gang affiliations and neighbourhoods" and is marked by greater violence.

Some authors have described contemporary prison culture as specifically fragmented along racial lines. For example, Richmond and Johnson (2009), who conducted interviews with former prisoners in California, found that racial identity was a key factor shaping male prisoners' experiences. More specifically, they found that racial segregation was embedded in daily practices and reinforced by prisoners and staff alike. Illustratively, distinct 'racial groups' had different sinks, telephones and living areas, for example, and prisoners were expected to not associate with members of other 'races.' Also writing in the Californian context, former prisoner Walker $(2014,2016)$ describes a similar system of racial segregation, whereby day-to-day routines are structured so as to avoid the risk of 'racial contamination.' As Walker notes, racial segregation is not only perpetuated by prisoner culture; it is reinforced and maintained by institutional practices. He notes that racial segregation as an organizational logic is justified on the grounds that separation reduces gang-based violence and is preferred by prisoners; in this sense, it operates as a "legitimate form of risk management" (2014: 78).

While some authors emphasize how broader social and political developments have influenced the day-to-day experiences of prisoners, others have emphasized continuities across time. For example, Melde (2008), who conducted interviews with men in a Missouri prison, concluded that "the parallels found between life in prison today and those described in previous prison ethnographies are striking" (67). The similarities he found included the division between older and younger prisoners, the rules of 'doing your own time' and 'no snitching,' and the perceived necessity of 'sticking up for yourself.' Based on these 
continuities in prison culture, Melde argues that "macro-level changes in the manner in which we as a society believe prisons should function does very little to change the dayto-day lives of the inmates we choose to incarcerate" (75).

Across different contexts, patriarchal norms are another feature of prisoner culture that remain evident in contemporary accounts of prisoner culture (Toch 1998; Jewkes 2005; Evans and Wallace 2007; Haney 2011). In their classic account, Sykes and Messinger (1960) noted a central aspect of the prisoner code was 'being a man,' demonstrated by strength, resilience, courage, and the ability to "take it" (withstand conditions of confinement). As Ricciardelli (2015: 173) notes, "internationally, researchers have found that the norms of patriarchy still apply in prisons and in such predominantly male environments, men can be both victims and perpetrators of the discourses or norms of dominant masculinities."

Ricciardelli (2015) has analyzed the topic of prison masculinity in her research on men's federal incarceration in Canada. She found that a status hierarchy divides prisoners in terms their ability to enact masculine ideals. At the top of the hierarchy is the 'hegemonic' prisoner, who '[has] 'solid' charges, [is] 'tough', perhaps even sentenced to life, and criminally connected (e.g. [knows] other criminals with status)." In contrast are 'inferior' prisoners, who '[have] victimized women or children, snitched on other prisoners or [are] 'weak'; they [fail] to embody traits promoted in the hypermasculine environment" (Ricciardelli 2015: 179). One way in which prisoners express their masculinity is through the disparaging of sex offenders: "this [allows] prisoners to redeem themselves by 'standing up for the ladies,' prove their solid-ness' and demonstrate their masculinity" 
(180). The continued importance of patriarchal ideals hence provides another example of continuity in the nature of prison culture.

Contemporary studies of women's incarceration also reveal competing interpretations regarding if and how prisoner culture has changed alongside broader social developments. American scholar Greer (2000) argues that female prisoner culture has, in fact, changed for several reasons, including evolving gender norms, changes in the physical infrastructure of women's prisons (i.e. the replacement of the cottage system with a more institutional-like environment), changes in average sentence lengths, growing diversity in prisoner populations, as well as the increased social openness of contemporary prisons relative to the total institutions of days past. As a result of these factors, Greer (2000) argues that the pseudo-familial networks described by early prison sociologists (e.g. Giallombardo 1966; Ward and Kassebaum 1965) no longer characterize female prisoner culture. Paralleling the findings of researchers studying men's prisoners, she also observed a more individualistic approach to 'doing time' among women.

In contrast, several other American studies have emphasized the continued importance of social relationships in women's experiences of incarceration. Based on interviews and surveys conducted with incarcerated women, Bender (2015), for example, notes the continued importance of interpersonal dynamics in alleviating the pains of imprisonment. In particular, she found that "memorable messages" (e.g. advice or words of encourage) from other prisoners were key in women's experiences. Similarly, Huggins et al. (2006), who studied women's experiences of incarceration in Texas, found that dyads and pseudo-family groups provided women with companionship, affection and compassion. Likewise, Severance (2005: 350) found that women's social relationships 
helped them survive the deprivations of prison life. She notes, "[i]solated from family and friends, inmates must forge functional equivalents from those available to them - other inmates." Offering a prisoner perspective, Olson (2006, Olson and Kunselman 2007), notes that immersion in prisoner culture can help female prisoners 'do time.' More specifically, positive prisoner relationships, including friendships, family-like dynamics, and romantic relationships, enable women to find humanity in a place where it is structurally denied.

In summary, building on the works of classic authors, recent scholars have considered if and how prisoner culture has changed in the contemporary penal context. This research has produced mixed findings, suggesting both change and continuity in the realm in prison culture, as well as variation across context. The research of some British, American and Canadian authors suggests that male and female prisoner culture have undergone significant change since classic studies of prison culture, becoming more individualistic rather than solidaristic in nature (Crewe 2005; Terry 2000, 2004; Ricciardelli 2014a; Greer 2000). While wider social, cultural and political changes have influenced prison life, however, certain features remain prominent; these include select rules of the prisoner code, hyper-masculine values among men, and the importance of interpersonal relationships among women (Melde 2008; Ricciardelli 2015; Jewkes 2005; de Viggiani 2012; Olson 2006, 2007; Bender 2015; Huggins et al. 2006; Severance 2005).

\section{Prisoner identity work and individual coping strategies}

In addition to studying the broad elements of prisoner culture, researchers have also explored the interplay between structure and agency by examining how prisoners learn to navigate the prison social world. As noted, classic prison scholar Clemmer (1958) noted that prisoners became socialized into prison culture through prisonization. More recent 
authors, however, have explored prisoner identity as a cultural performance. For example, Schmid and Jones (1991) note that the prisoner identity is a "false identity created for survival" (150). In other words, it is not that the individual's identity becomes that of a prisoner, but that they are able to convey the prisoner identity through sophisticated impression management skills.

The 'prison mentality' is also explored by Caputo-Levine (2012). Conceptualizing the prison as a social field in the Bourdieusian sense, she explores the nature of the 'carceral habitus.' In relation to any social field, the habitus consists of a variety of behaviours, mannerisms and dispositions that, together, enable actors to navigate social relations in ways that are contextually specific and appropriate, and to "perform acts of 'practical knowledge' without conscious planning" (169). In relation to the prison, she argues that the habitus is fundamentally orientated around managing the constant threat of violence. In her research with former prisoners, Caputo-Levine observed various dimensions of the carceral habitus, including a permanent 'yard face' (blank expression), hyper-sensitivity to physical surroundings, an automatic response to perceived forms of disrespect, and difficulty speaking with strangers. Embodying these features of the carceral habitus, she notes, enables prisoners to manage the threat of violence in prison.

Other researchers have similarly explored the identity work undertaken by male prisoners in an effort to navigate prisoner culture and reduce the threat of violence. A key dimension of this research has been understanding how 'doing time' involves 'doing gender.' For example, Jewkes (2005) explores the strategies undertaken by prisoners to construct reputations of aggressiveness and strength so as to avoid victimization. Based on her ethnographic fieldwork in four U.K. prisons, she argues that asserting 'manliness' is a 
survival mechanism for men in prison. Similarly, de Viggiani (2012: 2) notes that the need to fit into the prison social world can "mean actively reconfiguring one's public persona and learning to integrate socially with what can be perceived as an excessively performance-orientated masculine culture." He describes a range of "front management tactics" employed by prisoners to maintain a masculine image, including prison banter and one upmanship, body-building, displays of toughness, gaining respect from other prisoners, proving the 'legitimacy' of one's charges, asserting heterosexuality, and repressing one's emotions.

Individual forms of identity work are not only used to adapt to prison social relations, but to exert agency and find meaning in the context of tightly-controlled institutions. Hence another body of research concerns the day-to-day strategies employed by prisoners to reduce the disempowering and dehumanizing qualities of imprisonment. Within this research, authors have examined the seemingly mundane but important 'tactics' (Baer 2005) prisoners use to exert agency and control over their bodies and environments. Some authors view such exercises of agency as resistant insofar as they contest the qualities of prison life. For example, Ricciardelli and Memapour (2016) found that daily routines self-designed by prisoners not only enable them to enact agency and choice, but to resist the punitive nature of imprisonment. In their study, prisoners described adhering to structured daily routines comprised of activities such as "going to school, work, reading, drawing, and the gym" (185). The authors state, "[b]y mirroring the actions of an "everyday free person,' prisoners oppose institutional practices originally established to strip them of their identity and life pre-incarceration" (189). 
Other accounts similarly suggest that seemingly routine and mundane activities can gain new meaning amidst the harsh conditions that characterize carceral living. For example, Sloan (2012), who conducted 31 interviews with male prisoners, found that cleaning practices have highly symbolic functions in prison. More specifically, cleaning practices enable prisoners to reject the prisoner status projected on the body and environment, differentiate themselves from other prisoners, and exert control over their environment. Similarly, Labotka (2014), who studied the experiences of incarcerated women in Arizona, found that hair care rituals were a central way in which women constructed a sense of self in the humiliating environment of the prison.

Although cleaning and grooming practices seem trivial, Sloan suggests that for prisoners who lack opportunities to assert control and enact gendered identities, "the manipulation of those aspects of autonomy and control that are available to them is of the utmost importance" (408). Much like Ricciardelli and Memapour describe routine activities as holding symbolic meaning, Sloan suggests that cleaning practices can help prisoners move beyond the prisoner identity and imbue their surroundings with a sense of normalcy.

Several authors have also considered how food practices become the site of identity work and resistance in prison (Godderis 2006a; Brisman 2008; Ugelvik 2011; Murguia 2015; de Graaf and Kilty 2016; Smoyer 2015a, 2015b). On the one hand, prison food regimes are often a component of punishment. As Brisman (2008) notes, the lack of control prisoners are granted over the basic human practice of eating is emblematic of the prison experience. Nearly all aspects of the food experience are determined by institutional authorities, including the nature and quantity of food, as well as when and where food is 
eaten. On the other hand, insofar as food operates as a site of power, so too does it provide opportunities for resistance. For example, based on his ethnographic research in a Norwegian men's prison, Ugelvik (2011) found that everyday acts of resistance, such as modifying food to improve its taste, can "bring rewards that may be used as a resource for identity work purposes" (55). In his account, food-based resistance is central to the construction of identities that symbolically distance the prisoner from the institution; "by everyday rule bending or breaking, the prisoners position themselves as autonomous subjects able to resist the powerful prison, rather than docile objects of the prison's power" (57).

In the Canadian context, de Graaf and Kilty (2016) also consider the role of food in the experience of punishment, drawing on interviews with women who spent time at the Grand Valley Institution (GVI), a federal prison, and the Ottawa-Carleton Detention Centre (OCDC). Whereas women have greater control over food practices in prison, in OCDC, women have no say over what, when or where they eat. While jail food is a component of punishment, however, it is also used in strategies of coping and resistance. For example, women share and gift food to provide comfort and support to one another, which allows them to "generate a sense of togetherness that [makes] incarceration more manageable for all" (38). Women also store, trade, and modify food to enact greater control over their diets. Hence, the authors argue, the symbolic power of food plays an important role in the jail context, allowing women to confront institutional power and engage in identity work.

The extent to which the above noted and other practices intended to improve conditions of confinement can be conceptualized as forms of resistance is a matter of debate. As Rubin (2015) notes, a wide array of secondary adjustment activities has been 
described as resistant by scholars. However, insofar as resistance is defined as "consciously disruptive, intentionally political actions" (24, emphasis in original), she argues that many secondary adjustments described by scholars do not meet this definition. She proposes the concept of 'friction' instead be used to capture the "reactive behaviors that occur when people find themselves in highly controlled environments" (24, emphasis in original). These behaviours may violate institutional rules or objectives, but lack political will.

Of course, resistance as politically-motivated action also occurs, and prisoners themselves can become critical opponents of the prison system (Ugelvik 2014b). In responding to issues such as poor food, unsanitary living conditions, poor health care, crowding, violence, and denial of religious freedom or legal rights, prisoners have engaged in a variety of responses, including passive-aggressive behaviour, insubordination, violence, recruitment of outside allies and lawsuits (Ross 2010). However, it is arguably the everyday forms of resistance that have captured the greatest attention from prison sociologists.

\section{Summary of research on prisoners' experiences}

Prominent scholars have argued that shifts in penal philosophy in the late twentieth century corresponded with changing research orientations among criminologists and sociologists. The apparent decline of prison research is attributed to different factors, including the increased opacity of penal institutions as well as changing management logics in the university (Simon 2000; Wacquant 2002; Reiter 2014; Tubex 2015). However, together, the studies described throughout this chapter suggest claims that prison research has disappeared might be overstated. Indeed, since the contributions of early prison sociologists, researchers in diverse settings have considered the impact of policy shifts and 
broader social changes on the nature of prison pains and prisoner adaptation. This literature provides a rich understanding of how prisoners experience imprisonment, how their experiences are mediated by sociological and biographical factors, and how they respond to the pains of imprisonment in collective and individual ways.

With exceptions, however, research on the subjective dimensions of punishment remains prison-centric in focus. The experience of those in jails, including pre-trial prisoners, remains on the periphery of penal scholarship. Given the growing importance of jails in the overall practice of punishment in countries like Canada, the empirical and theoretical neglect of jails is surprising. This neglect, however, is not new. In his 1985 book, The Jail, Irwin noted that "[s]ocial scientists, like the general public have shown a great interest in the prison but have almost completely ignored the jail"' (Irwin 1985: xxiii). In an article punished over 20 years ago, Klofas (1990: 69) noted two prominent themes in the limited literature of jails; "the first is their importance; paradoxically, the second is their neglect by social scientists." Years later, scholars such as Griffin (2006) and Walker (2014) have remarked on the continued neglect of jail within prison sociology. Below, I draw on the works of Irwin (1985) and others to impress the continued need to examine experiences inside jails.

\section{The need for jail research}

In his seminal text, Irwin (1985) suggests that the jail serves an unofficial social function that cannot be gleaned from formal policy texts. To Irwin, the jail primarily operates to manage society's 'underclass' or 'rabble,' a group comprised of highly visible yet relatively non-dangerous social groups. Based on his research and first-hand experience as a prisoner, he states, "instead of "criminals," the jail receives and confines mostly 
detached and disreputable persons who are arrested more because they are offensive than because they have committed crimes" (Irwin 1985). In his view, few jail prisoners fit the stereotypes embedded in popular consciousness; rather they are socially detached (i.e. not well-integrated into conventional social groups or networks) and socially disreputable (i.e. they generate hostility for being offensive). In his questionable terminology, the rabble includes "petty hustlers," "derelicts," "junkies," “outlaws," “crazies," "corner boys," "lowriders," "aliens," "gays," and "square Johns."

Welch (1999: 89) similarly argues that the jail serves as a "warehouse reserved mostly for the urban underclass." He argues that jails facilitate a process of "social sanitation' by housing street-involved people who are 'offensive,' but not 'dangerous.' This process is underpinned by a desire to remove city streets of 'undesirables' (e.g. homeless persons and drug users) so as to present an image of social cleanliness. Despite the harsh nature of conditions in jails, Welch (1999: 92) argues that "like the persons detained there, jails are the most neglected institutions within the criminal justice system." This neglect is paralleled within penal scholarship, which, by and large, does not analyze or account for the particularities of the jail within broader theories of punishment.

The sociological accounts of the jail put forth by Irwin and Welch are germane to the contemporary Canadian context, where jails are largely used to warehouse society's most disempowered and marginalized groups, including those facing poverty, mental illness and addiction, as well as those affected by racist and colonialist social practices. Indeed, the 'risk averse' culture driving rising remand rates (Deshman and Myers 2014) is better understood in conjunction with a social analysis of the jail. As Irwin would predict, individuals are not being detained because they are 'dangerous criminals.' In fact, most 
individuals on remand are facing non-violent charges, with one in five being detained on 'failure to comply' charges (Porter and Calverley 2011; Deshman and Myers 2014). As the Canadian Civil Liberties Association states, "[t]he revolving door of pre-trial detention arrest, release with conditions, re-arrest for breach of conditions - has its most devastating impact on individuals with marginal social support, who are already struggling with addiction, health problems, poverty and discrimination" (Deshman and Myers 2014: 72).

By design, bail is largely inaccessible to individuals living in poverty. As noted by the CCLA, the average bail is set at an average of $\$ 2,669$, and bail requirements often include having a fixed address and surety supervision. Hence, bail is out of reach for "[i]ndividuals without a job, property, strong family support or ties to middle-class social networks" (Deshman and Myers 2014: 74). At the same time, impoverished individuals are increasingly likely to come into contact with the criminal justice system. A study in Toronto found that the number of people jailed with 'no fixed address' had increased by $64 \%$ between 2001 and 2004 . The study also found the jail to be a revolving door for homeless people; 4 out of 10 of those jailed had been jailed before (Novac et al. 2006).

Jail detention practices are also fused with racial and ethnic implications. A study of bail practices in Ontario found that the rate of pre-trial detention was $35.5 \%$ for Black individuals, compared to $23.4 \%$ for non-Black individuals (Kellough and Wortley 2002). Indigenous people are also vastly overrepresented in jails, representing one out of every four admissions to remand, despite constituting only 3 to 4 percent of the Canadian population (Statistics Canada 2015; Reitano 2017). This overrepresentation is particularly pronounced among Indigenous women, who represent 37 percent of women on remand (Perreault 2014). Deshman and Myers (2014) identify the overuse of bail conditions - 
which serve to criminalize behaviours that are otherwise legal - as a major contributing factor to the over-policing and incarceration of Indigenous people. As a recent report by the Public Services Foundation of Canada (2015: 47) states, "the over-representation of Aboriginal men and women in correctional centres is an indictment of the Canadian justice system that tells us something is deeply wrong in how our society treats Aboriginal people."

Provincial jails are also increasingly being used to house those with mental health problems. Deinstitutionalization in Canada in the late twentieth century was not met with the development of adequate social alternatives, leading to the increased criminalization of mental illness (Tilley 2012; Public Services Foundation of Canada 2015). Although deinstitutionalization reflected the idea that "persons with mental illness would be better served in the community," an adverse consequence has been "the increased contact between persons with mental health issues and the police" (John Howard Society of Ontario 2015: 7). A recent report produced by the Public Services Foundation of Canada (2015) states, "as community-based mental health services have disappeared, far too many people with serious to severe mental health problems have been scooped up into the criminal justice system." Because those suffering mental health issues have a high likelihood of encountering police, jails have become de facto "warehouses for the internment of the mentally ill," and places where individuals are punished, not treated (Tilley 2012: 18).

While the relationship between jails and social inequality is not new (Irwin 1985), there are also historically-specific factors that render the jail in particular need of sociological examination in the current Canadian context. As noted, Canadian jails are the 
site of changing punishment practices, as an increasing proportion of provincial prisoners have not been tried or sentenced, but are simply awaiting their day in court. Rising rates of pre-trial detention, combined with long court delays, mean that a greater portion of one's sentence is now pre-emptively served through pre-trial detention (Deshman and Myers 2014). In fact, some individuals will serve their entire sentence via banked remand credit (Deshman and Myers 2014). To be sure, pre-trial detention technically lacks certain key normative underpinnings associated with punishment, including both utilitarian and retributive objectives (Frase 2005). Theoretically, it is simply intended to hold accused persons until their court date. However, given that time spent on remand retroactively becomes one's partial or complete sentence (Deshman and Myers 2014), many provincial prisoners now overwhelmingly 'do time' prior to a formal finding of guilt.

Furthermore, at the experiential level, time spent on remand looks and feels like punishment (Walker 2014). Perhaps contrary to what one might expect, the legally presumed innocent status of remanded prisoners does not result in treatment that is less 'punishment-like' in nature; in fact, remand centres are notorious for being the harshest places in the system (Walker 2014). In many jails, there are no distinguishing features that shape the treatment of those being 'detained' (remand prisoners) and those being 'punished' (sentenced prisoners). As Walker (2014: 51-51) notes "while in the custody of a jail, they [pre-trial prisoners] are "penal inmates," facing the same degradations and punishments that inmates who have been found guilty of a crime must face." In the contemporary Canadian context, reports indicate that jails are plagued by structural problems such as crowding, lack of programming, limited access to medical and psychiatric care, excessive use of solitary confinement, violence and poor food (Deshman 
and Myers 2014; Tilley 2012; John Howard Society of Ontario Standing Committee on Prison Conditions in Ontario 2007; Marin 2013; Public Services Foundation of Canada 2015; Jesseman et al. 2017).

The temporal reconfiguration of punishment undermines not only the presumption of innocence; it may also threaten the right to a fair trial. For example, Euvard and Leclerc (2016) found that the experience of pre-trial detention can pressure accused persons to plea guilty and/or accept offers they otherwise would not. Even when prisoners withstand remand conditions so as to exercise their right to a trial, research has found that remanded accused persons are more likely to be found guilty and receive harsher sentences in comparison to their non-remanded counterparts (Koza and Doob 1975; Manns 2005).

In sum, provincial remand centres are the site of changing punishment practices, which are disproportionately targeting socially vulnerable groups. In this context, the scholarly neglect of the jail leaves key questions regarding the nature of contemporary punishment unanswered. Indeed, sociologists have yet to consider the extent to which concepts developed in prison sociology apply to the jail, or how jail prisoners' experiences can add nuance to macro theories of punishment. In the subsequent chapters, I aim to contribute to penal theory and prison scholarship by focusing on the experiences of prisoners at the Ottawa-Carleton Detention Centre. Given the wide array of topics studied by previous researchers, I employed a 'narrative' interviewing approach to enable prisoners themselves to determine which aspects of their experience were of importance and worthy of discussion. In discussing how they experienced, perceived and responded to conditions at OCDC, prisoners accounts reveal important insights regarding the nature and effects of 
jail punishment. In the next chapter, I will describe the methodology for this project in greater detail. 


\section{CHAPTER 3: METHODOLOGY}

To explore men and women's experiences of jail incarceration, I conducted qualitative interviews with former prisoners who had been housed at the Ottawa-Carleton Detention Centre. Given the complex nature of imprisonment, evidenced by the array of themes that previous authors have explored within prison sociology, narrative methodology seemed well-suited to a project seeking to understand the aspects of imprisonment that held importance to prisoners themselves, as well as the meanings and interpretations attributed to experiences. In this chapter, I will outline the narrative methodology approach and discuss its usefulness for interpretive research in general, and prisoner research in particular. I will then describe the research stages of the study at hand, including participant recruitment, data collection, and narrative analysis. Reflecting critically on the project, I will comment on issues of validity in relation to the data obtained, reflexivity and the role of the researcher, and ethical issues that emerged.

My introduction to OCDC began when I joined the advocacy efforts of a local prisoners' rights group, the Criminalization and Punishment Education Project (CPEP) in early 2014. CPEP's OCDC campaign has involved efforts to promote better living conditions at the institution, as well as strategies to reduce the provincial prisoner population. My involvement in the OCDC campaign primarily involved informationgathering, community organizing, and public awareness actions. In the course of this research and advocacy work, I met with several dozen individuals who had been jailed at the institution, worked or volunteered there, or had a loved one inside. I helped organize public events, produced media materials and attended meetings with institutional management, ministerial representatives and other stakeholders. After nearly two years of 
engaging in advocacy work, I began a formal research project. The purpose of this research was to explore prisoners' experiences at $\mathrm{OCDC}$ so as to contribute both to advocacy efforts as well as sociological knowledge on the subjective dimensions of jail imprisonment.

As will be explored in the proceeding section, notwithstanding recent improvements (Jesseman et al. 2017), conditions at OCDC are notoriously harsh, featuring crowded cells, frequent lockdowns, dirty living conditions, poor food, violence and inadequate medical and psychiatric care (O’Neill 2004; Cockburn 2009; Hurley 2010; the Ottawa Citizen 2004; Porter et al. 2015, 2016; Jesseman et al. 2017; Pilieci 2017). While perhaps constituting an 'extreme' case, OCDC does not represent an anomaly for the Canadian penal system, but rather, illuminates systemic problems that permeate throughout it. For example, the institution highlights the larger tendency for provincial jails to feature some of the worst conditions in the system. Moreover, the blatantly harsh nature of conditions makes visible the fundamental contradiction between the government's stated goal of "building stronger, safer communities" (Ontario Ministry of Community Safety and Correctional Services 2017a), and the actual nature and effects of punishment in practice. The makeup of the population at OCDC also reflects changing practices in the realm of provincial incarceration; more specifically, over 60 percent of OCDC prisoners are on remand (Lofaro 2016a), meaning they have yet to be tried and/or sentenced. OCDC's population also exemplifies the jail's use to deal with social problems such as mental illness and addiction; illustratively, in 2016, it was noted that 22 percent of men and 50 percent of women at OCDC had mental health alerts, and 40 percent of men and 62 percent of women had substance abuse alerts (Welch et al. 2016). Hence, exploring the 
experiences and effects of confinement at OCDC can help shed light on the problems and inherent contradictions that form the basis of the entire penal system.

\section{Narrative methodology}

To explore prisoners' experiences at OCDC, I opted to study their narratives of incarceration. Narrative research is not tied to one particular methodology (Riessman 1993), but is most commonly associated with research interviews (Spector-Mersel 2010). As noted by Spector-Mersel (2010), narrative interviews typically begin with the researcher asking participants to 'tell their story,' or posing a similar open-ended question. The resulting narratives become the topic of inquiry, with researchers often studying both the content (i.e. what is told) and form (i.e. how) of participants' stories.

A narrative approach can be used to study a range of topics, but is typically associated with studies exploring experiences and identity (Riessman 1993). While not as common as other qualitative research approaches, narrative methodology is practiced across diverse fields of study, including nursing, occupational therapy, cultural studies, education research, anthropology, sociology, criminology, psychology and social work (Clandinin et al. 2007; Riessman and Quinney 2005; Ewick and Silbey 1995; Franzosi 1998; Sandberg 2010; Presser 2009). For some researchers, the purpose of inquiry is to develop a deeper understanding of the issue they are studying, "while others take a further step by striving for personal, social or political change" Spector-Mersel (2010: 215). Those seeking change as a fundamental aspect of research seek to 'give voice' to narrators (Spector-Mersel 2010).

According to Spector-Mersel (2010), the narrative approach is more than a methodology; it is a research paradigm or framework through which to see the world. 
Ontologically, the narrative paradigm assumes individuals tend to make sense of realities that are "constructed, fluid and multifaceted" (Spector-Mersel 2010: 211) by building narratives. These narratives can give lived experience a sense of structure, meaning and cohesion that are not given to it by 'nature' (Riessman 1993). For researchers, stories can serve as rich data sources shedding light on human experiences, and in particular, those aspects of it which are otherwise invisible, including interpretations, perceptions and understandings. Hence the subjectivity embedded in interpretive accounts is not seen as impediment to research; indeed, narrative researchers assume there is no objective, essential 'truth' waiting to be discovered, but merely "different subjective positions from which we experience and interpret the world" (Moen 2006: 63). As Riessman (2005: 6) notes, "[n]arratives are useful in research precisely because storytellers interpret the past rather than reproduce it as it was."

As Szczepanik and Siebert (2015, drawing on the work of Schütze 1983, 1984) note, narratives are bound by the requirement to close, to condense and to provide detail. This 'triple bind of narration' renders the narrative an insightful means of conveying experience. In particular, the requirement to condense means that narrators, because they cannot describe every detail of their experiences, tend to focus on key events and 'turning points' (Szczepanik and Siebert 2015). Hence, the researcher gains an understanding of which topics, themes and events, by virtue of attention paid to them, are viewed as important by participants. The narrative format can also produce an "atmosphere of 'ordinary conversation"” which may reduce boundaries between the researcher and narrator (Szczepanik and Siebert 2015: 5). 
Narrative research "is not meant to be governed by formulas or recipes" (Fraser 2004) and analysis of narratives can take different forms (Bold 2012). Researchers undertake different types of analysis depending on their focus and the type of texts under study (Riessman 2005). In the study at hand, the goal was primarily to explore how former prisoners experienced jail incarceration; hence, narratives collected for this project were examined using thematic analysis (Riessman 1993, 2005; Fraser 2004). Thematic analysis involves exploring "the content of a text, "what" is said more than "how" it is said, the "told" rather than the "telling"” (Riessman 2005: 2).

\section{Narratives and prison research}

I wish to elaborate on the usefulness of using a narrative approach to study imprisonment in particular. To a certain extent, information regarding penal conditions can be gleaned from inquiries and reports, such as ombudsman and correctional investigator reports, legal cases, media investigations, and internal files obtained through access to information requests. However, the 'public transcript' reveals little about prisoner experiences (Crewe 2007, drawing on Scott 1990) and "subjective meanings of imprisonment are key to understanding prisoners' responses to the experience" (Rowe 2011: 575, drawing on Cohen and Taylor 1972). Access to such meanings requires the examination of 'hidden transcripts,' or sources of information not presented to the public eye (Crewe 2007). Narratives can allow researchers into the 'backstage areas' (Crewe 2007) that are invisible in both public records and front stage prison settings. They can also provide a sense of the 'carceral habitus' or the subjectivities, dispositions and mentalities that emerge within the social world of penal institutions, but tend to be taken-for-granted 
by actors (Caputo-Levine 2012; Neuber 2011). In essence, narrative methodology can help answer the question of what it is like to experience imprisonment.

While the narrative approach is useful for any study that seeks to understand the subjective meanings attached to sociological phenomenon, it is particularly useful to explore the experiences of those who are systematically silenced. Prisoners as a social group are silenced by a myriad of forces that operate both within and outside carceral settings (O'Connor 2003). During the various stages of the legal process - i.e. policing, trial, sentencing and punishment - accused people are placed in the position of least power (Weinrath 2009). While they may be granted opportunities to speak, the "discursive spaces that the system opens up, [and] the kinds of positions it provides" are extremely limiting in terms of allowing "real dialogue" and a chance for actors to tell their stories (McKendy 1999: 238-9). This structural silencing may occur because the recognition of the humanity and biography of accused persons might render the practice of punishment more difficult to undertake (McKendy 2006).

In addition to this form of silencing that occurs during the legal process, prisoners are physically silenced from the world via their physical and symbolic isolation. As O'Connor (2003: 140), writes, “[w]hat happens after conviction (i.e. the punishment) slips quietly into the community unconscious" (O'Connor 2003: 140). Indeed, penal institutions are located symbolically 'outside' of society; apart from volunteers and occasional 'tourists,' most free people will never step inside a penal institution (O'Connor 2003), while prisoner communication with the outside world is highly restricted. Of course, prisoners can penetrate the silence of incarceration through writings and other techniques (Taylor 2009; Piché, Gaucher and Walby 2014). However, by and large, penal institutions 
enforce social dislocation and disconnection. Even following release, formal restrictions placed on those with a criminal record, as well as "unofficial civic disadvantages" (Crewe 2015: 60), serve to socially impair former prisoners in the community, illustrating how the stigma of criminalization is etched on the prisoner in different ways that extend the ‘breadth' of punishment (Crewe 2015).

Prisoners' narratives can "break a cultural silence enforced through incarceration" (O'Connor 2003:144). The narrative interviewing format, which, unlike traditional interviews, is not informed by a predetermined set of questions, encourages participants to direct the trajectory of conversation. By enabling prisoners to determine which aspects of their experience are worthy of narration, the approach draws on their experiential knowledge to shape the thematic content of research data. In this sense, the approach acknowledges the fact that those who experience incarceration may be best-suited to determine the topics and themes worthy of analytical attention.

\section{Recruitment and sample}

Ethical clearance for this project was obtained from the university's research ethics board in late 2015 and participant recruitment began soon after. Five semi-structured interviews were conducted under earlier ethical clearance in order to collect background information on conditions and experiences at the jail. Recruitment for participation primarily involved the placement of advertisements at locations frequented by former prisoners, including community centres, halfway houses and social service agencies. Interested individuals contacted me and decided a time and location for the interview. Some word of mouth sampling also occurred. A subset of interviews were video-recorded 
with the informed consent of participants and utilized in a mini-documentary series that was produced in the context of an undergraduate course (McKendy 2016).

Self-selection was important in order to reduce the likelihood of harm to participants. As Hebenstreit and DePrince (2012: 65) note, "individuals who self-select into studies - and therefore know in advance that the research focuses on violence (or other traumatic events) - may be better prepared to tolerate potential negative emotional reactions." In total, 33 interviews were conducted. In terms of demographic characteristics, 16 participants were women, 17 were men and 26 out of 33 were white. The age of both men and women ranged from early twenties to mid-fifties.

The research sample for this study is not representative of the population at OCDC. Most notably, women constitute nearly 50 percent of the sample, but only around 10 percent of the population at OCDC. The inclusion of women's voices, however, is important for several reasons: women's carceral experiences are shaped by gendered forces that operate both in and outside of penal settings, women represent a growing segment of the incarcerated population (Kong and AuCoin 2008) and women's experiences are often left out of theoretical accounts of punishment (Kruttschnitt et al. 2013).

As Bosworth et al. (2005: 261) note, women "not only are often incarcerated for different crimes... but also arrive with different needs and life experiences," yet much prison research has been male-centric in focus. In the Canadian context, information available on federally-incarcerated women, including reports produced by the Correctional Service of Canada (CSC) and the Office of the Correctional Investigator (OCI), reveal a number of concerns related to female imprisonment. For example, among federallyincarcerated women, nearly 70 percent have experienced sexual abuse, while 86 percent 
have experienced physical abuse (Sapers 2015). Approximately three-quarters are mothers to children under the age of 18 , and around two-thirds of mothers were single parents prior to arrest (Sapers 2014). Women in prison are also prone to problematic types of institutional control; for example, more than 60 percent of federally-incarcerated women are prescribed psychotropic medication (Sapers 2014), which some have criticized as a control technique (Sawa 2014). Strip-searches, solitary confinement and use of force have also been used in problematic ways in women's prisons (Arbour 1995). Corresponding with rising rates of female imprisonment, the use of double-bunking, solitary confinement, and violence have also increased in women's prisons (Sapers 2015). Self-harm is also more prevalent among women in Canadian federal prisons (Gordon 2010), and has increased in recent years (Office of the Correctional Investigator 2013, Sapers 2014).

That there is less information available on provincially-incarcerated women points to the need for research examining their experiences. While women continue to represent only a small percentage of the incarcerated population, their growing rate of imprisonment significantly outpaces that of men (Perreault 2014). Furthermore, while the carceral experiences of men and women overlap in some regards, women may face pains that are tied to gendered structures operating both in and outside of penal institutions. For example, researchers have found that women experience pains due to separation from children (Berry and Eigenberg 2003), structural forms of violence (Chartrand 2015), exploitative relations with staff (Pogrebin and Dodge 2001), as well as the parallels between incarceration and previous experiences of trauma (Crewe, Hulley and Wright 2017). In summary, the inclusion of women's voices in this study reflects the intention to study how 
sociological factors such as gender shape penal experiences, as well as to uncover sociallyneglected voices.

One limitation of the research sample was its racial and ethnic homogeneity; 11 women and 15 men were white (two women and two men were Indigenous, and three women were Black). The unintentional exclusion of Black male prisoners constitutes a notable shortcoming of this study, particularly given the salience attached to race among male interviewees. As I will explain, non-racialized men often confronted new racial meanings in the context of the jail, where the privilege of whiteness was perceived to be overturned. The inclusion of Black men's perceptions of prisoner culture would have provided a greater understanding of how racial identities influence prisoners' perceptions and experiences of jail incarceration.

As the relative racial and ethnic homogeneity of the male sample became evident, I began to informally discuss this matter with former prisoners and others involved prison advocacy work. The suggestion arouse that cultural factors may discourage prisoners from certain ethnic groups from discussing their jail experiences, given the stigma attached to incarceration. However, in retrospect, greater efforts could have been made to recruit diverse participants. It was an oversight on the part of myself, the researcher, to not engage in more targeted forms of recruitment by, for example, connecting with organizations that provide services to racialized groups affected by criminalization. In effect, the homogeneity embedded in this study unintentionally perpetuates the exclusion of racialized prisoners; this bias should be kept in mind as the reader moves forward. 


\section{Conducting interviews}

At the discretion of participants, interviews took place in halfway houses, transition houses, community centres and coffee shops, and participants were compensated with $\$ 20$. Interviews were recorded and transcribed verbatim. In keeping with the narrative format, I approached interviewees with a single question: "Can you tell me about your experience at OCDC?" While additional prompts and questions were employed where necessary, I did not have a predetermined list of questions or themes for discussion. Underpinning this interviewing format was a desire to understand the aspects of incarceration that mattered most to prisoners themselves.

Borrowing from the feminist interviewing approach (Hesse-Biber 2013), efforts were made to "reduce the hierarchy of the interviewer-interviewee relationship by engaging in mutual dialog and disclosure" (Campbell 2010: 62). Rather than taking a neutral and detached stance, I assumed the feminist researcher position of playing an empathetic and supportive role to those who have experienced trauma. "In feminist interviewing, interviewers make the point of saying to the confused, tentative, or unsure interviewee: "You're not alone, this happens to others, I've heard this before"" (Campbell et al. 2010: 62). The relational dynamic that emerged often led narrators to turn the focus on me, posing questions about my own life experiences. Mutual divulgence can not only help reduce barriers between the researcher and participant (Campbell 2010), but, as I experienced, allow the researcher to better understand and appreciate what it is like to be interviewed. 


\section{Thematic analysis}

After interviews were completed and transcribed, narratives were thematically analyzed. As Riessman (2005: 3) notes, thematic analysis "is useful for theorising across a number of cases - finding common thematic elements across research participants and the events they report." Before comparisons were made across narratives, individual narratives were studied in isolation. For analytical purposes, core narratives were constructed in skeleton plots (Bell 1988). As Riessman (1993: 43) explains, “[t]he core narrative, a kind of radical surgery, is a way of rendering the "whole story" into a form that allows for comparison." Within individual narratives, particular attention was paid to recurring themes, points of emphasis and contradictions (Fraser 2004). After individual narratives were analyzed, commonalities and differences across narratives were explored, and narrative components were organized by theme (Bold 2012). Given the amount of rich data associated with narrative interviews, the thematic organization of interview data was not a simple undertaking. However, as Bold (2012: 121) notes, "in the process of organising [information], the researcher is finding answers to questions, deciding on the significance of specific pieces of data and beginning to shape the analysis."

In analyzing narratives, I paid particular attention to how narrators defined and understood the pains of imprisonment; hence, I explored punishment as it experienced, irrespective of the intentionality behind measures deemed painful. I also considered how former prisoners responded to the pains of imprisonment through individual and collective forms of adaptation. In general, attention was paid to unexpected themes, following the guidance of Riessman (1993), as well as the ways in which sociological and biographical factors mediated prisoners' experiences. 


\section{Validity in narrative research}

Narrative research allows for an in-depth look into people's lives and often involves highly rich and detailed data (Larsson and Sjöblom 2009). In relation to the content of narratives, Moen (2006) raises the question of how researchers can be sure that materials hold validity. As Riessman (1993) notes, people can lie, they may forget how they actually felt or experienced something, they may exaggerate, and so on. Since there have yet to be any established means of ensuring the quality of narrative research studies, Moen suggests researchers find the criteria most appropriate to their specific work, although she presents four ways in which the quality of qualitative research is assessed more generally. These include prolonged engagement and persistent observation, triangulation (where different sources of data are drawn upon), negative case analysis (where the researcher actively seeks disconfirming evidence), and member checks (in which the researcher shares findings with participants so as to garner feedback). Moen also notes that because narrative research is a double-interpretive process, a distinction should be made in research reports between the perspectives of the narrator and the researcher.

Of course, it is difficult to ensure or even define 'validity' in studies of perceptions, understandings and feelings. As Moen (2006) notes, the basic assumption of interpretive research is that there is no single 'truth,' only interpretations of experiences. Furthermore, Frank (2002) suggests that it is in the context of dialogue that meaning is produced; therefore, authenticity is created in the process of telling stories. Hence, the question for narrative researchers is not whether people's accounts are 'true,' but how they are influenced by the narrative setting. On this topic, Clandinin and Connelly (Clandinin and Connelly 2000; Connelly and Clandinin 2006) discuss 'unpacking' the three qualities of a 
narrative inquiry space, namely temporality, sociality and place, or when, with whom and where narrative construction unfolds.

In relation to temporality, Clandinin et al. (2007: 23) remark, "it is important to always try to understand people, places, and events as in process, as always in transition." For prison researchers, concern with temporality relates to, among other factors, where a person is situated in relation to their experience of incarceration (e.g. how much time they have served or how long they have been free). Sociality refers to the social context in which a narrative is constructed, while place refers to the physical location (Clandinin et al. 2007). By exploring how temporality, sociality and place influence narrative construction, researchers acknowledge that people's stories can never occur in isolation; rather, stories are intimately tied to the particular social, cultural, and physical settings in which they are told (Clandinin et al. 2007; Moen 2006).

Previous researchers have commented on the qualities of research conducted in prison, noting how immersion in the carceral setting can influence one's perspective. For example, the qualities of prison life and institutional power dynamics can shape prisoners' presentations of the self (Drake and Harvey 2014), how prisoners perceive the role of research (Copes, Hochstetler and Brown 2013), how prisoners view the researcher (Schlosser 2008), as well as how prisoners act, think and speak (Szczepanik and Siebert 2015; Schlosser 2008). Conducting research with former prisoners who are no longer incarcerated may eliminate some of the problems associated with institutional interviews, particularly by removing immediate power dynamics and institutional forces. Retrospectivity may also grant former prisoners the ability to more fully contemplate the longer-term impacts of incarceration. However, new issues emerge in relation to 
temporality. For example, individuals may not clearly remember events and experiences or how they felt during them (Riessman 1993). Hence, one must bear in mind how a post factum orientation may affect narrative construction.

As Moen (2006) and Clandinin et al. (2007) note, the research setting itself can partially shape how stories are told, since it becomes part of the participant's social context. Therefore, the researcher should be mindful of how the setting, including the physical location and dynamic between the researcher and narrator, influence narrative construction. Regarding place, participants in the study at hand were asked to choose locations for interviews that were comfortable to them. In relation to the researcher-participant dynamic, the questions, prompts, responses and reactions I provided, as well as how I related (or did not relate) to the narrator, undeniably influenced how prisoners' stories unfolded. This dynamic illustrates how narratives, in addition to being shaped by broader social and cultural forces, are also influenced by the research experience. Given that the research process becomes embedded in the research product, the findings of this study must be interpreted in light of the specific spatial, social and temporal qualities that shaped them.

Moreover, given that experiences of punishment are inherently subjective, influenced by an array of sociological and biographical factors that vary from prisoner to prisoner, this research is not meant to capture the particularities of experience beyond the individual narratives that are examined. Of course, the non-generalizability of narratives begs the question: of what use is studying prisoners' stories? As I hope to articulate, OCDC prisoners' narratives can shed light on the nuances of the jail experience that are not revealed in abstract depictions of incarceration, whether official policy texts, political discourses, or broad theories of punishment. It is not so much the particularities of 
prisoners' experiences that hold theoretical importance, but rather, the broader themes that emerge from prisoners' socially-situated knowledge positions (Haraway 1988). For example, prisoners' medical stories may be loaded with idiosyncratic and contextual meanings; however, such stories may also illuminate a broader process whereby medical practices become fused with punishment.

At the same time, the uniqueness of OCDC prisoners' experiences should not be overstated. The pains experienced by OCDC prisoners stem from an array of factors that emanate from different structural, institutional and situational sources, as articulated by Doyle and Walby (unpublished). For example, some of the pains experienced by OCDC prisoners are common to most all penal institutions, such as lack of privacy, restricted contact with the outside world and chronic boredom. Some pains are related to political, legislative and judicial trends in Ontario and federally that have contributed to jail crowding. In other cases, institutional-level problems common to jails are at play; for example, many jails are minimally resourced, marked by little programming, inadequate health and psychiatric care and few to no work or educational opportunities. Finally, institution-specific factors, such as the physical infrastructure and nature of guard culture, also shape conditions at OCDC. Operating at different levels, these factors interact to create a situation where the pains of imprisonment are compounded by 'layers' of problems (Doyle and Walby unpublished). The magnitude of penal harm at OCDC perhaps makes the qualities and effects of punishment more 'knowable' to the researcher; hence, as an 'extreme' case, OCDC may provide a vivid opportunity to contemplate the nuances of contemporary punishment more broadly. 


\section{Reflexivity and the role of the researcher}

As Riessman (1993) notes, narrative research is not just about listening to people's stories; it also involves the researcher him or herself producing a narrative with the research materials they obtain. Hence, not only do researchers play a partial role in shaping how narratives unfold, we also "tell stories of our own" when we re-interpret and re-construct narratives during the analysis and reporting stages (Fraser 2004: 195). To what extent should the researcher write themselves in as a 'character' in research narratives? Some authors suggest that much like the humanity of prisoners must be written into research reports (Bosworth et al. 2005), so too must the author "reintroduce the humanity of the researcher" and provide a critical and reflexive account of their role (Ferrell 1998: 24). Reflexivity, and writing oneself into the research, involves consideration of how one's own experiences, views and values have shaped the research process.

Reflecting on my own biography can assist in maintaining a keen awareness of how my own perspective as the researcher may affect the research process. Perhaps most notably, I come to this research from a social vantage point that is dissimilar to that of most participants. I occupy a position of privilege in most social and economic categories and, by and large, have not been adversely impacted by the social structures that perpetuate criminalization, including poverty, ableism, colonialism and racism. I am also an 'outsider,' having never experienced incarceration or other forms of state intervention firsthand. While I come to this research with a critical understanding of issues related to criminalization and punishment, my standpoint is nonetheless embedded in privilege. This privilege cannot be erased or bracketed during the research process; rather, it is infused throughout it, shaping the questions I ask, how I interpret responses, and the means by 
which I present participants' stories. The narrative approach may allow the perspective of the participant to shape the interview process; however, it cannot eliminate the standpoint of the researcher.

I also come to this research project with values and political orientations shaped by my experience engaging in prisoner advocacy work. As a member of the Criminalization and Punishment Education Project, I was involved in researching and spreading awareness about conditions at OCDC for around two years prior to conducting this research. In engaging in this work, I developed relationships with countless individuals who experienced the harms of incarceration first-hand. This experience provided me with a critical awareness of issues facing criminalized persons in the local context and undoubtedly shaped my normative and philosophical views on incarceration. In the course of this advocacy work, my views were informed by an 'abolitionist stance,' i.e. "a constant and deeply critical attitude towards prisons and penal systems as human (and inhumane) solutions" (Mathiesen 2008: 59). In practice, this meant promoting immediate reforms that were compatible with the more longer-term goal of decarceration.

The question of if and how our pre-existing political commitments can be separated from social inquiry continues to be a matter of debate among social scientists. As Bosworth et al. (2005: 258) note, “[d]espite Howard Becker's early claim that we need to be clear about "whose side are we on," criminologists and sociologists alike tend to feel more comfortable representing their work as objective, scientific, and precise." Researchers from the positivist tradition believe that academic inquiry can and should be 'objective' and value-free. Feminist critics, however, have convincingly argued that all knowledge claims are socially-situated and partial in nature (Haraway 1988). As Nelund (2014: 73) notes, 
"[t]he idea that we can have scholarship that has no political allegiance and comes from no particular position has been critiqued for substituting an idealized liberal and largely masculinist or androcentric perspective, in lieu of material and situated perspectives."

Indeed, engaged traditions understand political commitments as underpinning inquiry. Feminist scholars, for example, have never debated if and how research could be value-free; rather their work "is by definition about providing the intellectual scaffolding for social change" (Risman 2006: 283). Like feminism, penal abolitionism has also produced knowledge for the central purpose of assisting in social struggles (Ruggiero 2012), while prioritizing the voices of criminalized people and promoting alternatives to existing social institutions (Bell 2014; Piché 2016).

Nonetheless, it is important to maintain an awareness of how my own perspective has influenced the co-construction, interpretation and analysis of prisoners' narratives. By committing to a stance of critical reflexivity, I must confront and engage with data that challenges or complicates my assumptions or normative views regarding imprisonment. Rather than selectively choosing data that confirms my pre-existing beliefs, I must meaningfully explore data that challenges the theoretical and political underpinnings of the project.

\section{Ethical issues}

As this project involves research with human beings and relates to a sensitive subject, standard ethical procedures were followed so as to mitigate the possibility of harm to participants. Audio and data files were carefully stored and the privacy of participants was protected through the use of pseudonyms in all written documents. However, as I discovered first-hand, the ethical concerns associated with prisoner research may extend 
beyond considerations identified by research ethic boards. As Bosworth et al. (2005: 258) write, "academics tend to be taught to seek refuge in procedures such as "informed consent" to deal with any responsibility they may have toward their research participants." On this topic, Roberts and Indermaur (2007: 311) note the importance of the distinction between 'procedural ethics' and 'ethics in practice' in relation to prisoner research. Procedural ethics, they note, relate to the formal procedures deemed necessary to receive ethical clearance from research ethic boards, whereas ethics in practice "refers to a researcher's responses to ethical issues that arise during the research process."

The vulnerability of participants in this study led to an ongoing reflection of what it means to be ethical as a social researcher studying penal harms. To elaborate, the sample was disproportionately comprised of economically and socially marginalized individuals, many of whom experienced poverty, homelessness, disability, and mental health and substance misuse issues. While these characteristics are observable in the general incarcerated population (Deshman and Myers 2014; Public Services Foundation of Canada 2015; Kellen et al. 2010; John Howard Society of Ontario 2016) there are two factors that may have contributed to this representation. These include the locations where recruitment materials were advertised, which are frequented by homeless and impoverished individuals, as well as the incentive of financial compensation. Given that jails disproportionately hold socially marginalized individuals (Kellen et al. 2010), which Irwin (1985) identifies as an engrained characteristic, I did not view the characteristics of the sample as a methodological problem. What did emerge as an issue, however, was the potential for exploitation, and in particular, the seemingly coercive impact of compensation. 
While most participants expressed enthusiasm and even gratitude at the chance to tell their story, a small number (three) appeared to be, from my assessment, uncomfortable with participation. Their discomfort was evident in both verbal and non-verbal communication cues that indicated anxiousness. In such cases, I quickly ended the interviews. It is my sense that such participants may have taken part in the research interview out of economic need. In addition to constituting a form of exploitation, such interviews did not produce substantial data. These situations illuminate how participant coercion can occur in unintended ways.

As Roberts and Indermaur (2007) note, researchers have mixed views on paying prisoners in exchange for research participation. On the one hand, it is argued, prisoners, like participants in any study, should be compensated for the time they give to researchers. On the other hand, some authors have criticized compensation on the grounds that 'payment may provide 'undue inducement' to participate, that payments may be seen as rewarding offending, or that payments may be used to fund additional offending" (Roberts and Indermaur 2007: 315). Of particular concern during the research project at hand was the extent to which financial compensation played a coercive function in relation to participation.

Different researchers have studied motivations for research participation among vulnerable groups. For example, Campbell and Adams (2009) explored why victims of sexual assault participate in research interviews, and found that monetary payment was one reason. However, they found participants were more concerned with helping others, helping themselves, and contributing to research. Similarly, Hebenstreit and DePrince (2012) found compensation to be a motivating factor for research participation among 
female victims of intimate partner abuse, but more common reasons included curiosity, the desire to help others, and the desire to help oneself. In their study on the benefits and harms of prison interviews from the point of view of participants, Copes, Hochstetler and Brown (2013) found that prisoners did not identify financial compensation as the sole or primary reason for participation. In fact, all 40 of their participants indicated they would have participated in interviews even if they had not been compensated.

While there may be several motivating factors for participation in research, the practice of issuing compensation raises an ethical dilemma; on the one hand, compensation recognizes the contribution made by the participant and communicates the value of this contribution; on the other hand, compensation can lead to exploitation of those in economic need, who might not necessarily wish to discuss their painful experiences. For future researchers, a possible solution to overcoming the potentially coercive impact of compensation might be to not advertise payment on recruitment posters, even if offered. Given that various researchers have found that interview participation is motivated by factors other than payment, non-advertisement of compensation might not necessarily lead to lack of participation.

Even when participants are self-recruited and intrinsically motivated to contribute to research, they may experience emotional harm as a result of participation, given that incarceration can be a form of trauma (DeVeaux 2013). As Campbell et al. (2010: 61) note, "[a] key concern for trauma researchers has been whether, and to what extent, victims of violence become upset or distressed by participating in survey and interview research." However, researchers studying the impacts of interviews on sensitive topics have tended to emphasize the benefits identified by participants. For example, Campbell et al. (2010:70) 
found that rape survivors experienced research interviews in positive ways: "For many, the experience of having someone listen with patience and real engagement as they talked freely, and sometimes cried freely, was very impactful.” Similarly, Dyregrov et al. (2010) found those affected by suicide identified benefits to interview participation, including the ability to help others, being able to talk to someone and gaining insight. Copes, Hochstetler and Brown (2013) found that prisoners also viewed interviews in a positive light due to perceived emotional benefits and the value of being able to talk to someone.

In the study at hand, I strove to allow participants to guide their narratives as much as possible so as to avoid causing them emotional harm. In most cases, I was taken by the extent to which many participants revealed intimate details of their life, including stories of victimization, family trauma, drug and substance use and mental and physical health issues. Those who recounted particularly painful stories were often the same ones who expressed gratitude for the chance to tell their story.

However, a notable difference emerged between interviews with men and women; although there were exceptions, interviews with men tended to be much longer and more detailed. From my perspective, most men approached the narrative interview as a chance to finally tell their story. Although I can only speculate as to the cause of the gender differences that emerged, I suspect it could relate to the lack of social spaces for criminalized men to discuss the harms they have experienced. Insofar as incarceration is a form of trauma (DeVeaux 2013), the development of post-incarceration support programs could prove to be of great social value in the local context and beyond. 


\section{Conclusion}

While different methodologies can be used to study experiences of incarceration, narrative methodology seemed well-suited to the project at hand. As noted, narrative interviews enable narrators to have greater agency over the nature and scope of topics and events discussed. Insofar as “the act of telling one's story is an enactment of personal agency" (Enck and McDaniel 2014: 46), the narrative approach reduces the power asymmetries between the researcher and participant. For interpretive researchers, the subjectivity embedded in narratives is viewed not as a shortcoming, but a resource, given that the objective is to explore the inherently subjective domains of experience, meaning and understanding. Questions of truth and accuracy in narrative research are hence displaced with how the narrative setting, including temporality, sociality and place, influence narrative construction (Clandinin and Connelly 2000; Connelly and Clandinin 2006).

Because the researcher is involved in co-constructing and re-writing narratives (Riessman 1993; Fraser 2004), reflexivity is required to situate and understand the researcher's role. In the research at hand, reflexivity involves consideration of how the various stages of the research process are shaped by personal values and politics. In line with feminist and abolitionist approaches, I do not assume values can (or should) be suspended for the sake of researcher 'neutrality.' As Risman (2006: 190) points out, “integrating one's moral beliefs with one's professional work keeps both alive and lively." However, it is important to maintain a stance of openness to views and data that challenge the theoretical underpinnings of the project. 
In the subsequent chapter, I will contextualize this study by providing a brief historical overview of OCDC. Following this, I will describe the data that emerged from this study by providing a thematic analysis of narrative interviews. This analysis will explore the prominent and recurring topics that emerged across narratives. Key guiding questions for this analysis include: How did former prisoners define and understand the pains of imprisonment? What aspects of imprisonment were granted salience in their accounts? How did they adapt to, cope with and resist the pains of imprisonment? How are sociological and biographical identities drawn into their narratives? Connecting this data with existing penal scholarship, I will also consider how their narratives overlap with, challenge or otherwise provide nuance to prison sociology and penal theory, thereby highlighting if and how studies of the jail, as a particular carceral milieu, can help inform sociological understandings of punishment. 


\section{CHAPTER 4: THE OTTAWA-CARLETON DETENTION CENTRE}

This study focuses on the experiences of men and women who spent time at the Ottawa-Carleton Detention Centre. Before analyzing prisoners' narratives, I will provide a brief overview of the institution's history so as to contextualize the current study. The jail, which holds just under 600 prisoners, serves primarily as a remand facility, with well over half of the prisoner population having not yet been tried and/or sentenced (Welch et al. 2016). The institution is divided between lower security dormitories (dorms) and maximum security cells. Dorms are self-contained units that house approximately 30 prisoners. Each dorm contains bunkbeds, a television, a washroom and set of telephones. In contrast, maximum security ranges are comprised of small cells located in two distinct sections of the institution: "old max," made up of separate wings, and "the pods," a podular section that was added during a renovation period in the early 2000s. Cells, which range in size from approximately 8'5' by 10' feet, to 7'5" by 14'4"' (Dadshani v. Ministry of Community Safety and Correctional Services and Defence Counsel Association of Ottawa 2006), are equipped with a toilet, sink and one bunk bed. Frequent lockdowns at the institution, particularly in recent years (Pilieci 2017), mean that prisoners can be confined to dorms and cells for up to 24 hours a day.

Problems at the institution date back to the 1970s, shortly after it opened. During its first few years, a series of escapes led local journalists to report on conditions at the jail, which were already being described as crowded. In 1975, guards reported that an armedescape could not be thwarted because the jail was "packed to the roof" (The Globe and Mail 1975). The next year, in 1976, a Member of Parliament, Evelyn Gigantes, called for 
an inquiry into conditions at the centre due to a series of breakouts, suicides and riots. Her call was rejected, however, despite the admission of the Minister of Community Safety and Correctional Services at the time, John Smith, that lack of programming at the jail was breeding an atmosphere of boredom and tension (The Globe and Mail 1976). Over the next few years, OCDC continued to make news headlines due to escapes, violence, and crowding. A report on public institutions released in 1987 revealed that three people were being held in cells designed for two (Evenson 1987).

In early 1989, the guards' union protested against conditions at the institution, stating that the jail was crowded, understaffed and unsafe. A union representative, Joe Benard, stated the jail was "like a powderkeg waiting to go off" (Blanchfield and Doran 1989). A short time after guards' warnings, a tragedy occurred when a 27-year-old prisoner, Michael Sienkiewicz, was violently beaten to death by six other prisoners. Sienkiewicz, who was in jail on a break-and-enter charge and for unpaid highway traffic fines, was found dead in the shower area of the jail shortly after he had been transferred to maximum security (Marleau 1989; Marleau and Ibbitson 1989). A guards' union representative stated that the killing may have been a consequence of problems at the institution. However, the superintendent at the time, Bill Barr, brushed off the potential roles of crowding and other institutional problems in contributing to the death (Marleau and Ibbitson 1989).

Throughout 1989, guards remained vocal proponents of conditions at the institution. In the summer months, the union continued protests, stating that the jail was holding up to 100 prisoners more than the 176 it was designed to hold (The Ottawa Citizen 1989). Local media also reported that cells designed for two prisoners continued to hold 
three, forcing some to sleep on the floor (The Ottawa Citizen 1989). During the fall season, Ontario guards staged a work strike to protest understaffing and dangerous conditions in jails across the province (Ward and Hall 1989).

By the end of 1989, Ontario jail guards appeared to amp up their tactics. The Ottawa Citizen reported that guards' actions included "confining inmates to their cells, denying management access to cell blocks, booking off sick en masse, [and] work-to-rule and picketing" (Hall 1989). In response to their actions, the province announced it would hire more jail guards and expand infrastructure to alleviate crowding across the province. The province also announced it would establish 'health and safety committees' in provincial institutions, including OCDC, as requested by guards (Hall 1989). However, the tensions between the government and the guards' union did not seem to improve, as evidenced by continued guard protests in the ensuing years (Vis 1993).

Prisoners have also historically been opponents of jail conditions at OCDC. In the summer of 1989, prisoners captured media attention when they staged a hunger strike to protest crowding, insufficient clothing changes, and lack of telephone and yard privileges. At its peak, the protest was reported to include around half of the prisoner population. The media reported that prisoners stated they were punished for speaking to journalists by being placed in solitary confinement (Blanchfield 1989). The following year, nine prisoners again staged a week-long hunger strike to protest involuntary transfers (The Ottawa Citizen 1990). Media reports indicate that hunger strikes and protests were also staged in 1997 and 1998 to protest the poor quality of food (The Ottawa Citizen 1997; The Ottawa Citizen 1998). 
The politics of punishment in Ontario underwent a shift beginning the mid 1990s, when the Progressive Conservative government embraced a 'no frills' efficiency model (Moore and Hannah-Moffat 2002; McElligot 2007). The corrections minister, Rob Sampson, expressed an explicit intention to make the provincial penal system 'harder' than its federal counterpart. "[T]his is not the federal equivalent of the penal system. We want jails to be places where people don't want to go and don't want to stay ... We're very much focused on a no-frills facility" (Harris 2000). To this end, several local jails were closed and replaced with 'supermax' jails, while conditions in remaining detentions were 'leaned out.' As McElligott (2007: 43) explains, “[r]ehabilitative programmes, recreational facilities and 'perks' such as TVs, video games and smoking - and even time spent outside the cell - were drastically curtailed in provincial institutions."

Relations between the guards' union and government worsened over the next few years, with guards continuing to engage in work actions that affected prisoners in mixed ways. A general public service strike in 1996, which included OCDC guards, resulted in weekend prisoners being sent home (Bell 1996). Further work actions unfolded in 1998, after the government announced that several smaller jails in Ontario would be closed and that OCDC would be expanded (from a capacity of 286 to 486), but that additional guards would not be hired, as electronic monitoring would replace them (Ibbitson 1998). Guard work actions at this time reportedly created an institutional atmosphere of fear and tension among prisoners (Dimmock 1999). In 2002, during an actual strike, prisoners protested worsening conditions, including "late meals, poor sanitary conditions, no clean clothes, no toiletries and no yard time" (Canadian Press Newswire 2002). One prisoner told the media, 
"[t]here were no showers, no medication, and the water was out half the time. They fed us lunch and our breakfast in one meal. It was the worst I'd seen" (Zimonjic 2002).

In 2004, a local newspaper published a story entitled, "Ottawa's jail is a disgrace" (The Ottawa Citizen 2004). The article commenced by articulating the disconnect between idealized versions of Canadian values and actual human rights practices. "Canadians enjoy preaching to the world about the humane treatment of others, but we have a prime example of inhumane treatment here in our capital: the Ottawa-Carleton Detention Centre." The article went on to detail daily living conditions at the jail. "Prisoners jam-packed in cells and sleeping on floors. Prisoners deprived of proper access to legal counsel. Prisoners deprived of exercise and showers for many days. Prisoners being carted around the Ottawa Valley in a "meat truck" and housed in bug-infested, dirty cells. Prisoners losing all privacy. Working conditions described by guards at the detention centre evoke a jail that has become a pigsty held together by duct tape." The newspaper also reported that its journalists were denied access to the facility to investigate conditions first-hand.

OCDC has also come under fire in the legal system. In 2004, a human rights case was launched on the basis that conditions at the institution violated the Canadian Charter of Rights and Freedoms. A lawyer representing a prisoner at OCDC stated that the jail was akin to an 'Iraqi prison camp' (O'Neill 2004). By this time, judges began awarding prisoners triple credit for time served at OCDC, effectively putting pressure on the government to improve conditions at the jail (O'Neill 2004). In a benchmark ruling, Judge Denis Power granted a man triple credit for time served at OCDC (meaning he was awarded three days for every one day served) because conditions at the institution contravened United Nations standards and brought the justice system into disrepute. The lawyer 
representing the man stated, "[w]e in the Western world are always quick to point fingers at other regimes that mistreat inmates, say in Central or South America or the Middle East or Abu Ghraib, or places like that. But when it's right here in our own city in a capital of a country like Canada, for the public to be complacent about it is something that I just can't understand" (O’Neill 2004).

In subsequent years, OCDC remained in the spotlight, receiving periodic bouts of media attention for chronic problems (Cockburn 2009; Hurley 2010). Media attention exploded in the fall of 2012, when Julie Bilotta gave birth in a cell at OCDC. After screaming in pain and pleading with staff to take her to the hospital, she was placed in solitary confinement, where she ultimately gave birth. Bilotta is now suing institutional staff and the province, attributing the ultimate death of her son to the treatment she endured (Bilotta v. Her Majesty to the Queen of Right in Ontario et al. 2014; CBC News 2014).

Her experience, which sparked widespread condemnation from local advocacy organizations and mothers (Pedwell 2012; CBC News 2012), occurred around the same time as a human rights case emerged involving Christina Jahn, a woman with mental health problems and terminal cancer who was kept in solitary confinement for over 200 days over a one year period. Her settlement required the province to implement a series of remedies (the 'Jahn remedies') relating to the treatment of incarcerated women with mental health problems (Ontario Human Rights Commission 2013), although such remedies were quickly contravened (Dempsey 2015).

In the past few years, OCDC has remained in the spotlight partially due to the advocacy efforts of prisoners and their allies, including the Criminalization and Punishment and Education Project (CPEP) and Mothers Offering Mutual Support 
(MOMS). CPEP is an Ottawa-based prisoner advocacy organization comprised of academics, students, prisoners and other allies, while MOMS is a local support and advocacy group comprised of relatives of prisoners and community allies. As an active member in these groups for over two years, I engaged in a variety of research and advocacy activities intended to push for change at OCDC. With many others, I helped organize a series of large-scale public forums, developed petitions, met with ministerial and institutional representatives, participated in news media interviews, produced minidocumentary style videos, wrote blog pieces and opinion editorials, and engaged in various other actions in an effort to publicize and challenge conditions at the jail.

While problems persist at the institution, there have been notable accomplishments made in the last three years, which can be partially attributed to the ongoing efforts of local activists. Such accomplishments include the establishment of a Community Advisory Board (CAB), the establishment of a government task force, as well as reported improvements in the areas of mental health services, healthcare, crowding, yard time, access to showers and access to visits (Ontario Ministry of Community Safety and Correctional Services 2016a, 2017b, 2017c; Seymour 2017a, 2017b).

The OCDC CAB was established in 2014 to foster transparency and public oversight. According to the Ontario Ministry of Community Safety and Correctional Services (2017d), CABs "are mandated to provide advice and recommendations to the ministry and the government on all aspects of the operations of the individual correctional facilities they serve." The OCDC board is comprised of a handful of volunteers who participate in routine visits to inspect conditions (Porter et al. 2015). Since its inception, the $\mathrm{CAB}$ has released three annual reports (Porter et al. 2015; Porter et al. 2016; Jesseman 
et al. 2017) which have documented ongoing problems at the institution. The reports produced by the $\mathrm{CAB}$ have generated significant media attention and appear to have contributed to some improvements, although many highlighted issues remain unaddressed, as noted in their most recent annual report (Jesseman et al. 2017).

The OCDC task force emerged following the 'shower cell' scandal in April of 2016. After local media revealed that OCDC prisoners were being confined in shower stalls, the corrections Minister first denied the practice was occurring, then subsequently retracted his statement and called for an end to the practice (Provencher and Mah 2016; Reevely 2016; Doyle, McKendy and Mathias 2016). In response to the scandal, the Minister also established a task force "to develop an action plan to address overcrowding and capacity issues, the resulting impacts at OCDC in the near term, and to identify long-term solutions to improve the health and safety of all inmates and staff' (Ontario Ministry of Community Safety and Correctional Services 2016b).

The task force was composed of diverse members, with representation from the Ministry, institutional management, the guards' union, criminal defence lawyers, crown attorneys, advocacy organizations, the $\mathrm{CAB}$, and others. Members worked together to develop 42 recommendations intended to address immediate problems at the jail, but also larger problems surrounding bail and remand in Ontario. The government committed to implementing the recommendations and, so far, has released three progress reports outlining their efforts (Ontario Ministry of Community Safety and Correctional Services 2016a, 2017b, 2017c). After the final report was released in July of 2017, a total of 21 of the 42 recommendations were said to have been implemented. 
Another pivotal moment occurred in May of 2016 when OCDC prisoners launched a class action lawsuit against the province for the degrading treatment they endured at OCDC. The lawsuit involves prisoners who spent time in OCDC between 2014 and 2016 and who experienced the effects of crowding and/or dehumanizing conditions. The case argues that conditions at OCDC constitute cruel and unusual punishment, against the Canadian Charter of Rights and Freedoms. The lawsuit, which is still ongoing, seeks not only compensation for the parties affected, but also a series of remedies that will address conditions at OCDC (Champ and Associates 2016). The human rights lawyer leading the lawsuit, who also led the Jahn case, has stated that he hopes the class action suit will push the government to fix problems at the jail (Lofaro 2017).

The issue of solitary confinement regained attention in 2017, when former federal correctional investigator, Howard Sapers, was appointed by the Ministry to conduct an independent review of segregation practices in Ontario institutions. In his report, released in the spring of 2017, Sapers condemned solitary confinement practices in the province, stating, "segregation has become the multi-purpose default to respond to diverse correctional challenges. This inappropriate use of segregation must stop" (Sapers et al. 2017: 66). The report noted that OCDC had the longest segregation placements in the province in 2016, with an average stay of 26 days. It was also noted that segregation practices were increasing at OCDC; 2016 saw an increase of $110 \%$ in the average daily counts of segregated prisoners. Sapers outlined a 63 point plan to reduce the use of solitary confinement and improve conditions in Ontario institutions. Recommendations included infrastructural improvements to OCDC and other jails. 
The establishment of the $\mathrm{CAB}$, launch of the task force, and commissioning of federal Correctional Investigator Howard Sapers are efforts that reflect the Ontario government's stated intention to 'transform' the Ontario correctional system. A central figure behind this transformation agenda was Yasir Naqvi, who was the Minister of Community Safety and Correctional Services from 2014 to 2016, following which time, he became the Attorney General of Ontario. During his period in power, he has repeatedly proclaimed the need to ameliorate conditions at OCDC and address the bail and remand crisis in Ontario. Offering statements such as the following, Naqvi has insisted that change is needed and on its way.

"The Ottawa-Carleton Detention Centre has faced long-standing capacity pressures and I have been clear that the status quo at this institution, and throughout our correctional system, cannot continue. That is why we are moving forward on transforming Ontario's correctional system. This transformation is focused on enhanced mental health supports, increased rehabilitation and reintegration programing, alternatives to incarceration, and staff and inmate safety to truly build safer communities for all" (Naqvi 2016).

In response to public calls to build a new jail (e.g. Marin 2016), Naqvi has stated that expansion will not address the root causes of crowding. "[T]here are more people in our correctional institutions than there should be," he asserted. "By building more jails, you are essentially building more capacity, and five years from now you'll be at square one. You haven't really addressed the real problem. What we need to focus on is to reduce the demand for jails. That's where my focus is. That's where real transformation takes place" (Seymour 2016b). While attempts to address the root causes of crowding in Ontario's provincial jail system have been slow, a series of changes were announced in early 2017. Among these changes include the establishment of 20 new community 'bail beds,' the expansion of Bail Verification Supervision Programs, the presence of duty 
counsel at OCDC and the hiring of more court personnel to speed up the bail process (Ministry of the Attorney General 2017).

For those invested in conditions at OCDC and the politics of punishment in Ontario, it appeared that positive change was finally underway. However, on May 4th, 2017, the same day as the Sapers report was released, the government made a shocking announcement that appeared to contradict its previous commitment to decarceration.

"[F]unding has been approved for the construction of a new 325-bed multipurpose correctional centre to replace the existing Thunder Bay Jail and Thunder Bay Correctional Centre, as well as a new 725-bed multi-purpose correctional centre to replace the existing Ottawa-Carleton Detention Centre. This investment will help increase capacity and reduce overcrowding at provincial institutions" (Ontario Ministry of Community Safety and Correctional Services 2017e).

This announcement was met with diverse public reactions. On the one hand, some feel that the construction of a new jail is necessary due to the deplorable physical state of OCDC, which renders it irreparable (Tossounian 2017). On the other hand, some are concerned that the construction of a new jail will simply provide the infrastructure necessary to continue current practices of mass detention and the use of jails to deal with social problems, hence leaving the root causes of jail crowding unaddressed (Piché 2017; Gilbert 2017). Furthermore, fears have been expressed that a new jail will 'induce demand,' and hence, ultimately lead to the same crowding issues evident at OCDC (Shore Davis Johnston 2017). Consequently, prisoner advocates in the local context, including the Criminalization and Punishment Education Project, have launched a campaign to undercut plans to construct a new jail.

As can be gleaned from the brief overview of OCDC presented above, the jail is situated within a dynamic social and political environment. The continually evolving 
nature of this subject matter does present a challenge for sociological research. Illustratively, since the data collection process for this project, which began in late 2015, several developments have occurred that may have changed the day-to-day experiences of prisoners. Consequently, it is important to clearly note that some details of prisoners' accounts may not reflect the current situation at OCDC. However, the underlying purpose of this research is not to provide an 'objective' account of jail conditions, but to highlight the utility of incorporating subjectivity into theoretical understandings of punishment.

In the following section, I explore incarceration at OCDC as a subjective experience (Sexton 2015), considering how prisoners define, understand and respond to the pains of imprisonment. First, I narrow in on the 'concrete' and 'symbolic' pains of imprisonment (Sexton 2015) that held salience in prisoners' accounts. In three key areas of institutional life, including physical conditions, guard treatment and healthcare, prisoners discussed experiencing both physical and symbolic types of harm. These harms were not always intentional, but were nonetheless enabled by a combination of forces operating within the institution (e.g. physical conditions and institutional culture) and beyond it (e.g. court and judicial trends and government policy). The salience of unofficial harms in prisoners' accounts reaffirms the need to explore punishment as it is experienced, rather than as simply articulated in policy discourses (Sexton 2015). 


\section{CHAPTER 5: WAREHOUSE 'LIVING'}

As noted, the Ottawa-Carleton Detention Centre theoretically operates as a temporary holding facility. Well over half of the individuals at the jail are on remand, meaning that they have yet to be tried and/or sentenced (Welch et al. 2016). The logic of pre-trial detention, i.e. detainment, lacks the same normative underpinnings as sentenced punishment. In fact, pre-trial detention does not constitute 'punishment' per se; it serves not as a legal response to past actions, but as a pre-emptive strategy that seeks to contain the risk of future harm. As noted, however, pre-trial detention retroactively becomes part of one's formal sentence, rendering its legal function temporally-dependent. Moreoever, conditions are 'punishment-like' in nature, with no distinguishing features setting apart the experiences of remand and sentenced prisoners. In fact, prisoners' accounts of daily life at OCDC resonate with the harsh characteristics of the 'warehouse prison,' most often discussed in relation to American supermax facilities (Irwin 2005; Robertson 1997).

In this section, I will explore prisoners' depictions of daily living conditions, which emphasize both the embodied and symbolic aspects of 'human warehousing.' Included in the pains of everyday living are those related to crowded conditions, lack of privacy, unsanitary living conditions, the inability to maintain personal hygiene, frigid temperatures and poor food. Such pains were not only experienced as embodied aspects of punishment, but also as 'symbolic pains' (Sexton 2015) that communicated to prisoners their depreciated level of humanity. The loss of human identity was compounded by the depletion of mental and physical stimulation and erasure of social connections. The pains related to one's estrangement from humanity were exacerbated for those placed in solitary confinement. 
As most of the prisoners in this study had served time as both a remanded and sentenced prisoner, it is difficult to discern which experience they are speaking from, or if they are in fact speaking on the basis of their amalgamated experience. In general, the distinction between remand and sentenced time is blurry, as the two groups are mixed together at OCDC. Given the ambiguities surrounding the distinction between pre-trial and sentenced time, I will refer to prisoners' general experiences as related to their 'punishment.'

It is important to reiterate that problems at the institution are likely attributable to overlapping 'layers' of problems (Doyle and Walby unpublished). These factors include institutional features (e.g. infrastructural issues and staff culture), problems common to all penal institutions (e.g. lack of privacy and restricted contact with outside world), problems unique to jails (e.g. lack of programming and crowding), and broader trends in the legal system in the province of Ontario (e.g. trends in bail and remand practices). Hence, penal harms may play out in a particular way at OCDC, but the nature of these harms is tied to certain underlying forces that may shape the broader landscape of punishment.

\section{"They're treating us like dogs." Daily living conditions}

Mass numbers of prisoners are stored at OCDC, with seemingly little attention paid to their comfort or privacy. Prisoners typically live either in maximum security cells or in minimum security communal units called dormitories. Although cells are intended to hold a maximum of two individuals, many prisoners stated that triple-bunking, or worse, was a regular occurrence, forcing many to sleep on the floor. In describing the pains of daily living, there was considerable overlap between the accounts of men and women, illustrating how certain aspects of punishment may be experienced similarly by male and 
female prisoners (Jones and Schmid 2003). In their accounts, prisoners emphasized not only the physical discomfort associated with their living conditions, but the feeling of being dehumanized and degraded. The complete loss of privacy, epitomized by close proximity to the communal toilet, had particular salience in prisoners' accounts.

"If you're the third person that got into the cell, you're like basically on the floor, and you basically have to sleep by the toilet, whether you have your feet where the toilet is, or your head where the toilet is, but it's really uncomfortable because if a guy gotta get up in the middle of the night to go for a pee, you're sleeping there, he's like peeing over you, so it's like very uncomfortable" (Dale).

"Well you're sleeping right next to the toilet. It's not very sanitary, especially when you're flushing the toilet, and your bed's next to the toilet. Gets over everything. It's a known fact, right? When the toilet flushes, it sprays up all kinds of bacteria. I'm sure if you took a blue light and swabbed it, you'd see all kinds of nasty shit in max. Max is just disgusting” (Stan).

"I was in one time, there was a cell, and there was five of us in one cell. Three on the floor and one on each bed. And people that like, literally, I was sleeping with people stepping over me to go to the washroom in the cells, stepping over me, and I'd have to move my head so that they could stand there and urinate. And I mean when they're urinating, some of it's going on the floor, right where I'm sleeping, there's no doubt about it" (Floyd).

"I remember sleeping on the floor myself. You're afraid to even sit there, even going to the bathroom, with two other women and they're looking at you like, you know, it just makes you feel degraded" (Bethany).

"You gotta piss in there, you gotta poo in there, you gotta eat in there, three meals a day. That's terrible" (Annie).

As noted by Garfinkel (1956: 420), through status degradation ceremonies, "the public identity of an actor is transformed into something looked on as lower in the local scheme of social types." The nature of cell conditions serves not only as a source of material discomfort, but as a status degradation ceremony, whereby prisoners are symbolically stripped of their dignity as human beings. The communal toilet disrupts normal expectations of privacy, while the use of a single space to eat, sleep and use the washroom contravenes social standards of hygiene. As several male prisoners noted, close 
proximity to the toilet could result in the highly humiliating experience of being urinated on. The dehumanizing quality of these living conditions was often emphasized through the use of non-human referents. For example, Annie stated, "they're treating us like dogs. Not even, dogs are better. They're like treating us like, like, you know what I mean, we're not human or something."

Although cell conditions were described as crammed and dehumanizing, many prisoners stated that they nonetheless preferred cells to dorms. This is interesting given that the institutional reward structure designates dorms as privileged areas (see: Ontario Ministry of Community Safety and Correctional Services 2015). In comparison to cell ranges, dorms are less tightly-controlled and offer regular access to showers, phones, and a communal television. However, dorms, which hold around 16 women or 30 men, are emblematic of Goffman's (1961: 6) articulation of 'batch living' insofar as "each phase of the member's daily activity is carried out in the immediate company of a large batch of others, all of whom are treated alike, and required to do the same things together." Even more so than cells, dorms provided prisoners with little privacy or space to call their own. As one man explained, "I prefer being in max 'cause having a cell, you have a bit more of your own kind of space, you know? In the dorms, you don't have really any privacy whatsoever" (Noah). "I can't handle the dorm, because too young, loud. I like to do my own in max" (Loretta). From the point of view of many prisoners, the perks of dorm life were outweighed by the problems of forced mass cohabitation and lack of personal space.

Issues of privacy and crowding were tantamount in shaping prisoners' experiences in dorms. The crammed physical space was experienced as dehumanizing and, to some, reminiscent of animal-like living conditions. 
"You're sleeping side by side and you're sharing a common bathroom. There's like two urinals, two toilets and you share that between 24 guys" (Dale).

"In a dorm, you're with 16 girls, you cannot go anywhere" (Kristin).

"It's not a privilege. I mean it's like 16 women talking to you. You got your little gang there and this gang" (Cora).

"You're living in this small space that's like maybe half the size of this room, with 16 bunks, so you barely have any space to walk around, and you know, you have women that are spitting on the floor, you know, wiping bodily fluids places, throwing garbage everywhere" (Lucy).

"There's a bed, and then there's another two feet, and then another bed. And they're bunk beds. You're cramped. You're in like a barn" (Joseph).

In relation to privacy, both men and women felt degraded by lacking privacy when

showering.

"It's all glass, our washroom, there's no privacy. If you're showering, you have to get changed in front of another girl to get in the shower. That's not okay" (Kristin).

"If you're a woman, like if you're taking a shower and you're having your period, everybody can see that, right? And you feel very uncomfortable like someone looking at you. The guards are looking at you... It's embarrassing" (Bethany).

"There's like two showers that are like side by side, which is very uncomfortable when you go to take a shower because the other person's right next to you and it's an experience in itself" (Dale).

"The shower areas in the pods are - you have to shower in front of 40 people. Like you have to take your shower in front of 40 people... You take off your clothes and there's people walking around, they're watching TV and you have to shower in front of them, all doing whatever they're doing. And women guards too walking. They're watching us. The women guards, in minimum, they just walk by and there you are showering and it's an open glass" (Floyd).

"You're having a shower in front of how many other guys are in that area? That's very intimidating... It's an invasion of privacy. So you're in the shower with ten other guys who you've never met" (Joseph). 
In addition to facing crowding and lack of privacy, all living sections were described by prisoners as unsanitary, fraught with dirt, mould and bug-infestations.

"It's not right the way, like the place is filthy. Ugh. It's filthy. It doesn't matter how many times you sit there and mop the floors and wash the walls" (Tammy).

"There's ants on the floor, I've seen cockroaches there the last time I was there. At one point the shower in one of the dorms, tiles would fall off the wall in the shower while you were in there and there'd be all this dried glue I guess and dust behind it" (Lucy).

Floyd recalled that some shower stalls were covered in mould.

"I wouldn't let my dog shower in there, it was so bad, the mould was just everywhere. I never showered... I mean there's no way would you walk on what was on that floor in your bare feet. You were going to catch a disease!... I said, the guard, I said, "you gotta be joking me!" I said, "I'm not showering in this!" And I said to the guard, I said, "would you shower in that?" He said [laughs], "absolutely not."

Prisoners also recalled the poor air quality that characterized the overpopulated institution.

"The air vents in the dorms is like, you can see the dirt, the dust all in the vents, you know? You can see it, there's like a steel grill on them, you know? You can see the dirt, and it looks terrible" (Noah).

"The air in there is so stale, and I mean there's no air flow or whatever, and it sucks with not being able to go outside" (Grayson).

Prisoners also described problems with the infrastructure and plumbing in the building. For example, some noted that sinks and showers sometimes did not work properly.

"In my minimum range for example, you get two sinks. One of them worked for half the time I was there, and the other one worked for the other half of the time I was there. But when one was working, the other one wouldn't. Like, we had two showers. One of them worked. The other one sprayed water all over the toilet stall next to it" (Blake).

Some experienced flooding in their cells while incarcerated. For example, Kale recalled that the toilet in his cell overflowed twice while he was incarcerated, and he was 
forced to remain inside. "You don't get a mop for like two hours." Pierre, who was triplebunked in the medical unit, also recounted being forced to stay in a flooded cell.

"One morning our toilet overflowed. And all day long, our cell was full of shit water about that high, right up to our knees. In medical, man. And they made us - they gave us our meals, we had to eat in that. At about eight o'clock that night, they came in, they put us all in the bathroom next door, all four of us, the wheelchair guy and everything, we couldn't even barely even fit in there, in the shower room... I got cellulitis from that" (Pierre).

In all parts of the institution, men and women also faced difficulties in maintaining basic hygiene. For those held in cells, access to showers was sometimes irregular due to lockdowns.

"They were letting you shower once every three to four days. Yeah. You'd say, you know, "can I take a shower?" "Not today"” (Floyd).

"Sometimes you go without a shower for two or three few days" (Kale).

Some prisoners also noted they lacked access to toilet paper on occasion.

"Multiple times, you would have no toilet paper for sometimes 24 hours" (Kevin).

"There's 32 guys and they give us six rolls of toilet paper a day and you're banging on the window looking for some TP and they're like, "just fuck off"”' (Blake).

"You'd always have to ask for toilet paper. It like, it would never be enough toilet paper and you'd have to say "hey, I need toilet paper." "Yeah, we'll get back to ya." And they'd be two days later... If you're mouthy with them, they just won't give you anything. They'll say, "use your shirt"” (Floyd).

Two women recalled even being denied access to menstrual hygiene supplies.

"I started my period during the three days I was there [in suicide watch]. They refused to give me pads or even underwear. So I just had to sit there with this baby doll, no underwear on, lying on the floor like, just bleeding all over myself, like I couldn't believe that they were treating me like this" (Lucy).

"I remember when I had my period and I remember I asked the guard, I said, "excuse me, can I at least get a maxi pad." And they told me to use my shirt for a pad. And it was so bad like - you have to use your clothing" (Bethany) 
Several prisoners also recalled the painful experience of living in constant frigid temperatures, without proper clothing or blankets. Lucy recalled, "there were times in the winter where it was - actually the summer too - it was like freezing in there. So you're wearing like all your clothes, you're wrapping sweaters around your head to make a hat sort of, and you're just, under your blankets, just freezing." Ethan recalled, "it's actually so cold you can't even sleep there in the winter." From his point of view, cold temperatures were a control tactic employed by staff to 'cool prisoners down.' "The inmates are just like animals. You cool down the temperature around them and they'll calm and slow down. The body will just automatically slow down because it's cold" (Ethan).

Ethan also recalled how the dehumanizing environment of the jail led some prisoners to internalize their non-human status. In his words, "sooner or later, you give up and now you're an animal." He recalled the practice of smearing feces as a response to animal-like treatment.

"There's times you walk down the hall, all you smell is shit and you walk by and somebody's shit on the window. Like his own shit... Then on the wall and just like pushing it under the door to put it out in the hallway, like "fuck you," you know, "you wanna treat me like an animal? Here you go. I'll be a monkey, here's my feces",' (Ethan).

\section{"It's like you're eating out of a dog dish"}

\section{Food and meal practices}

Given the centrality and recurring role of food in everyday life, it is perhaps unsurprising that prisoners often discussed their experiences with food at OCDC. To prisoners, food was infused with punitive meaning; the poor quality and scarce quantity of food, as well as the lack of accommodation and choice available to prisoners, rendered it a site of punishment. To draw on Sexton's (2015) framework, and paralleling the findings of Smoyer and Lopes (2017), punishment in relation to food was both 'concrete' and 
'symbolic;' at a physical level, the institutional diet implicated the body in the experience of punishment, while, at a symbolic level, it communicated to prisoners their loss of human status.

The quality of food was discussed extensively by both men and women. Food was generally described as being unpalatable, lacking nutrients, and sometimes unfit for human consumption. In prisoners' words, food was "garbage" (Blake), "disgusting," (Kevin), "crap" (Leo), "horrible" (Noah), "awful" (Cora) and "terrible" (Sandy). Lucy recalled that meals were sometimes unidentifiable: "The food all looks like vomit to me, like it it's been so processed and re-heated and frozen and re-heated so many times that sometimes you can't even tell what it was."

Some reported receiving mouldy or raw food, or finding foreign objects in their meals.

"I saw mould on my food one time, and it was like, one time I was eating my food I found a bug in my food... And sometimes the food wasn't even cooked" (Bethany).

"When I was there, there was a snail in my peas, and I had to put a complaint in. A snail. And there was one other girl, she had glass in her food" (Kristin).

"I seen mouldy bread. Fingernails. Eye lashes inside of your food. Horrible" (Floyd).

Food was described as sometimes being poorly cooked and/or served cold. Grayson recalled, "sometimes the meals would come freezing," while June noted, "sometimes it would be raw or not even cooked."

Of equal concern to the poor quality of food was the amount of food given to prisoners, which was described by many as insufficient. Three small meals are provided to prisoners per day, with last meal being served around 4:30 PM. As will be explored in a 
later chapter, meals in dorms were distributed by prisoners themselves, meaning that some prisoners could be denied meals altogether.

Prisoners with the financial means sometimes subsisted on canteen items. For example, Floyd recalled, "I was basically trying to survive on was the canteen 'cause I hated the food so much, so I'd rather just eat chips and chocolate bars." Kristin stated, "I rarely ate it, I always bought canteen. After I found a snail in my food, I wasn't so fond of eating their food." However, since there are no paid work opportunities at the jail, canteen items were only available to those with outside contacts who could deposit funds into their canteen account. Those who lived entirely off of institutional food faced issues of hunger, particularly in the evenings. Indeed, many prisoners described feeling like they were starving.

"It's just barely enough to pretty much get you through the day. If you don't have money for canteen, you're pretty much feeling like you're starving all the time" (Blake).

"You didn't get much, they just, they just give you enough so you don't, so you don't starve I guess, you know, so you don't fall over and die on them" (Leo).

"You don't get much. From supper time, which they fed you early, it's 4:30, to quarter to five, and you stay hungry from that time until like 7:30 the next morning. It's hard" (June).

"It's not very big portions. You pretty much starve in there" (Bethany).

"It's just enough to keep you alive, it's not very much.... You starve in there basically" (Floyd).

“There was never enough, like we'd get a small tray like this, I mean it's gone in like three bites" (Grayson).

For some prisoners, living in a state of chronic hunger took its toll on the body. "I'd lose weight when I go to jail" (Floyd).

"I'll put it this way, I went in and I was like 225 pounds, and I left, I was about 190" (Brock). 
Unlike in institutions where prisoners can take part in the processes of food production and meal preparation, OCDC prisoners are deprived of the agency to control their diet. In relation to daily meals, questions of what, when and how much food is eaten are determined by institutional authorities. As noted by de Graaf and Kilty (2016: 31), such a food system "contributes to the breaking down of the self by disrupting one's sense of autonomy and control over the body." While the rigid food structure at OCDC denies all prisoners agency over their bodies, it had particularly negative impacts on those with special diets. Individuals with food allergies or dietary restrictions stated they were often not properly accommodated, and/or that alternative meals were nutritionally insufficient.

For example, Grayson noted he was sometimes served meals containing fish despite his documented allergy.

"I'm on a no-fish diet, and my diet wouldn't come, and they were like, "well what do you want us to do, go cook you another meal?" Well it's on the sheet, recorded, like, you know, you guys are supposed to follow it, you're not following it, so. "Oh well, eat that." Well I'm gonna, like my throat's gonna swell up and everything. "Oh well, die"," (Grayson).

Annie described similar problems:

"I'm on no onion, no potato. If they end up bringing me anything that has that in that, they won't take it back. The odd guard might. But at least 75 percent of them won't take that meal back."

Lucy, who was on a meat-free diet, recalled the lack of options available to vegetarians.

"It was a constant struggle with the diet because I'm a vegetarian, and like the whole vegetarian diet consists of soy and I'm allergic to soy, like I just have an intolerance to it. So they were you know, like after a while, giving me Styrofoam containers with crackers and peanut butter in it, or rice cakes, and that's all I was eating" (Lucy).

The insufficient diet took a toll on Lucy's health. 
"I left there anemic, I've never been anemic in my life. I've been a vegetarian 13 years" (Lucy).

At the same time as food consumption was experienced as an embodied punishment, food also served as the source of symbolic punishment, communicating to prisoners their sub-human status. As theorists in the field of cultural studies have noted, eating practices are not only shaped by biological needs, but are fundamentally tied to socio-cultural meanings within a given social context. In this sense, eating and food bear a deep symbolic dimension, communicating "a much larger set of themes and situations" (Barthes 2013: 26). Insofar as food practices can serve as a microcosm for understanding broader social systems (Simmel 1997), food at OCDC is emblematic of prisoners' loss of humanity. The sense that food symbolized prisoners' reduced human status was exemplified by the use of non-human referents to describe their food experiences. "It's like you're eating out of a dog dish" (Jessica). "I wouldn't feed half the stuff to my pets" (Blake). "I've seen like farm animals eat better food than that" (Lucy).

Importantly, it was not only the quality of food that communicated to prisoners a sense of inhumanity; the practices and circumstances surrounding eating were also highly symbolic. For example, prisoners were given a limited amount of time to finish their meals, forcing them to rush through their food. "Our meals were served by the guards and we only had a 15 minute limit on eating and if we didn't finish by then, they would open the cells and take our trays" (Grayson). Furthermore, during lockdowns, those held in cell ranges could be forced to eat their meals in their cells, either on their bed or on the floor. "Eating your meals on the floor, you know, it's filthy in there to begin with" (Floyd). "People are going to the washroom while you're eating food" (Sasha). 
Prisoners also did not always receive proper cutlery, compounding the sense of inhumanity they experienced while eating. As Floyd recalled, "we were eating on the floor, we were eating like dogs with our hands, because there was no forks, no knives, because I guess, the overcrowding. You're supposed to get a plastic spoon. We'd say, "where's our spoon?" "We don't have any." Lucy similarly recalled the dehumanizing experience of lacking proper cutlery. "Eating everything with a plastic spoon, it's like, you know, you're a baby, and certain things, like salad, you know, you can't eat with a spoon, so you have to eat with your hands. You feel like a cave person" (Lucy).

As prisoners' accounts reveal, food serves as a site of punishment in different ways. The poor quality and small quantity of meals, as well as the lack of accommodation available, render food the source of 'concrete punishment' (Sexton 2015). At the same time, the nature of meals also served as a highly symbolic type of punishment. Mealtimes served not only as a mechanism through which prisoners were stripped of their preinstitutional identities through the denial of agency and choice; given the centrality of adequate food to human life, meals served as symbolic indicators of prisoners' loss of humanity.

\section{"You're basically forced to sit there and not better yourself." Lack of mental and physical stimulation}

In addition to living in cramped, unsanitary and uncomfortable conditions, OCDC prisoners were provided with few opportunities for meaningful activity. The Ontario Ministry of Community Safety and Correctional Services (2017f) proclaims there is "a variety of programs and services available to inmates and offenders who are remanded or sentenced in correctional facilities," including programs relating to life skills, rehabilitation, education and work. During court appearances, prisoners may even be asked 
by their sentencing judge whether or not they have participated in programming while on remand, with participation potentially influencing the nature of their sentence. However, prisoners noted that very few programs were offered, and that sessions were often cancelled due to lockdowns and/or staff shortages. Indeed, prisoners were forced into a warehouselike existence, unable to "compensate for the pains of imprisonment by "doing time" in a constructive manner via work, training, or education" (Robertson 1997: 1031). As one man recalled, "you're basically forced to sit there and not better yourself" (Kale).

Some indicated that they would have welcomed the opportunity to take part in programs, particularly those geared towards substance abuse and mental illness. The lack of programs available led some prisoners to contemplate the purpose of incarceration. As Jessica explained, “you're shut off. You don't get any help. You don't get any rehabilitation. You don't get counselling. And I mean, when you're in there, that's when you should be getting it, right?" She noted the irony whereby prisoners were being held accountable in an institution that failed to achieve its own purported objectives. "If you're gonna lock someone up and hold them accountable for their crimes and expect them to rehabilitate, then why don't you step up to the plate and give them something?" Brock similarly questioned the utility of incarceration: "You separate people from society and then you stick them right back in society without any treatment or nothing. How is that supposed to help people?"

For those held in maximum security ranges, cell confinement for extended periods of time was described as the painful norm. As noted by the jail's Community Advisory Board, lockdowns, which involve prisoners being confined to their cells or dorms, are regularly used at the institution due to staff shortages (Porter et al. 2015). During 
lockdowns, prisoners housed in cells may be unable to access showers, phones, visits, yard time and programs. The chronic boredom associated with cell confinement came to define some prisoners' existence. Dale noted, "you have to get accustomed to doing nothing." Jessica recalled, “it's obscene. It's not even livable. You're in your cell 23 and a half hours a day pretty much."

As Brock recalled, cell confinement took its toll on prisoners, leading to anxiety and frustration.

"I remember one time, I was locked down for three days. And it's just me and my cellie. There's a toilet there, there's bunk beds, and yeah, we were locked down for three days straight. And that's pretty stressful. I can't explain it. I don't wish that upon anybody. Like him and I were friends. Towards the end, we were ready to like go at it, like fist fight, and that was just because of the stress. We didn't have any beef with each other. It was just stress... You can't call your lawyer, you have no access to the phones, you got no access to nothing. You just had to sit there in your cell, waiting for the guard to say, you know, "lockdown's over"”, (Brock).

Prisoners lamented only sporadically being let outside for fresh air. According to the corrections ministry, yard time is typically held every day unless security or weather concerns arise (Ontario Ministry of Community Safety and Correctional Services 2015). As the $\mathrm{CAB}$ has noted, however, up to two weeks can pass without yard time (Porter et al. 2015). The lack of yard time increased the symbolic distance between prisoners and the outside world. As Lucy recalled, "the whole summer I had no idea, everyone's like, "it's a heat wave." I had no idea. Because we were on [lockdown] so often, we barely got yard."

As prisoners noted, even when the 20-minute yard time stints were offered, they took place in small, enclosed spaces with little in the way of equipment. Noah explained, “it's kind of a small space, and it's screened right in. There's no equipment at all. I think in max, there was one, like a pull up thing, like, you know, a bar, you know? " Similarly, the yard in the women's section, which is enclosed and roofed in, was described as a "bird 
cage" (Britney) and "concrete square" (Jessica). Not only did prisoners lack access to basic equipment, they were also not provided with adequate clothing to withstand the harsh winter temperatures. Kale recalled, "during my time, it was winter time, so they give you this little coat that's falling apart sort of thing and not very warm. So most of the times, I just didn't go to yard, cause it was so cold outside."

Nonetheless, as an escape from their captivity, yard took on symbolic meaning for some prisoners. Britney recalled, "I remember winter times walking around in there [the enclosed yard], and you'd close your eyes and you'd smell the air, and it was the only thing that would remind you of, I'm still a person, I'm still outside, I'm still breathing." In her case, the ability to breathe fresh air was a reminder of her humanity and experienced as a positive thing. For others, like Ethan, the taste of freedom was bittersweet, serving as a reminder of one's captive status.

"Sometimes you don't want to see the light of day. It reminds you of your freedom that you don't have anymore and it will drive guys crazy going out in yard and it's like, fuck there's a fence stopping from you from just walking across the street and enjoying my day. You be enjoying it and then you notice the fence, with all the barbed wire and that's when you're like, "oh yeah, fuck, you know, what's the point of enjoying the day now"” (Ethan).

Like yard time, windows also came to play a symbolic role in prisoners' experiences. As Kale noted, there are no windows in some areas of the institution, leaving prisoners unable to estimate the time of day. Combined with the lack of clocks, some prisoners became time-disoriented, and hence, further alienated from the outside world. In other areas of the institution, windows are present but coated with a frost overlay so that prisoners cannot see outside. Lucy recalled being at the jail when the frost coating was installed on some of the windows. To her, the inability to see outside increased the symbolic distance between herself and the world outside. 
"They just came one day, took us in the yard, and they put this stuff on the windows. So now, like now it's starting to peel so you could look at little cracks and see the parking lot but it just makes you feel even more like locked in. Like, you're not just there serving your time; there's always other issues. You have kids at home, you know, bills aren't getting paid, you're getting stressed, you don't know what you're gonna do, you have no control over anything. Sometimes it's nice to look at a tree, you know, or a squirrel running in the grass, like anything that just takes your mind away. So having them blocked like that, it's just, it just makes you feel more trapped... little things like that, I find, make a big difference, like being able to look at the sky makes a big difference" (Lucy).

\section{“It's like you're not even on the same planet anymore." Alienation from the outside world}

While reduced contact with the outside world is a fundamental feature of incarceration, the Ontario Ministry of Community Safety and Correctional Services (2016c) claims that contact with the outside community is important for prisoners. According to their website, “Ontario's Correctional Services recognizes that communication between inmates, family members and members of the community is important for their rehabilitation and successful reintegration into society." Despite the government's recognition of the importance of external social contact, prisoners at OCDC described being 'shut off' from society.

A sense of social alienation was exacerbated by structural problems with prisoners' key mechanisms of outside communication, namely the phone and visiting systems. For prisoners confined in cells, access to a limited number of phones was provided for brief periods of time when the institution was not on lockdown. As Grayson explained, "everybody who was there prior got seniority over the phone, so I mean, they'd only give us an hour, phones are 20 minutes in length, you know what I mean, like it only gives three guys time on two phones, so that's six guys total out of 30." Because only collect calls are

permitted, calls cannot be placed to cell phones. This further restricted communication with friends and family due to the growing use of cell phones in place of landlines. "You gotta 
do collect calls now. Who owns a home phone? Do you own a home phone? No? How am I supposed to call you if I go to jail? They take everything out of your hands" (Blake).

The expensive cost associated with collect calls, particularly in relation to longdistance calls, also served as a communication barrier for some prisoners. As Lucy noted, "even if you're not long distance, if you're more than I think 20 kilometers from the jail, it's considered long distance, and it charges you long distance... so if you don't live in like the immediate area like Blackburn or Orleans, or Gloucester, forget it, it's charging you long-distance and you're paying like \$20 a call. It's crazy. " For those with contacts outside the immediate region, the high cost of calls deterred them from connecting with family. As Ethan explained, 'I wasn't going to be making long distance calls where it costs like 10 bucks for two minutes, what's the fucking point?"

Like phone calls, the Ministry recognizes the importance of visits for prisoners, stating, "visits improve inmate morale and can help contribute to their rehabilitation and successful reintegration into the community" (Ontario Ministry of Community Safety and Correctional Services 2016d). According to ministerial policy, while limits can be placed on visits by the institution's superintendent, visiting hours are said to be normally held daily for five hours. At OCDC, prisoners are theoretically entitled to two twenty minute visits, or one forty-minute visit, per week. However, prisoners noted that the visiting system was fraught with barriers that made meaningful communication difficult.

For instance, several prisoners noted that visits were routinely cancelled without notice. As noted by the $\mathrm{CAB}$, visits are most often cancelled due to lockdowns (Porter et al. 2015). Prisoners recalled instances where their family members came to see them, only to be turned away at the gate. As Grayson recalled, "my family would come to visit me and 
they'd have to call them first, and they'd say, "yeah come on out," but by the time they get there, like drive 45 minutes to an hour, they get to the gate, "oh, we don't have enough staff to have you visit." As Grayson noted, visits were not only an opportunity for prisoners to see their loved ones, but a chance to get out of their cells and experience a break from idleness: “[visits provide] just a little bit of freedom 'cause you don't get yard, you know?"

Another barrier to visits is the setting in which they occur, which not only inhibits meaningful contact, but can bring about shame and embarrassment to prisoners. Prisoners in their jail-issued clothes are lined up in the visiting area as they await their seat. They are then seated in a row facing their visitor, but separated through glass. The prisoner and visitor must speak through a phone set. While this style of visiting is not unique to OCDC, it differs from the more open-style of visits that occurs in many federal institutions. As Dale explained, “you're in a visiting room, there's like ten other people there getting visits and everyone's like talking over each other so it's really hard to understand what the person's saying in front of you." This can be particularly painful for visits with children. As Sasha, a mother of a newborn baby recalled, "the first time I see my son, it's behind glass." A few prisoners said that they preferred not to experience visits. "I'd rather not see my family in jail. My daughter didn't wanna see me like that" (Annie). "Nobody ever comes to see me. I don't want them to" (Blake).

The institutional structures that restricted contact with the outside world became a source of frustration, as Chloe explained.

"You're not getting out to do your programs, you're not able to have your visits come, like what do you expect people to react like? The loved ones that you don't get to see much, so they drive all the way for a visit, they're not allowed to come in and then, you know what I 
mean, you need to talk someone or get out of your cell or something for a program that gets cancelled, like what do you expect?" (Chloe).

As Robertson (1997: 1032) argues, warehouse-like institutions treat prisoners as "living corpses." Disconnected from societal structures, and unable to take on meaningful roles, prisoners became estranged from their social identities. The analogy of a social death was not far from the surface in some prisoners' narratives. Lucy, for example, described feeling like a "zombie."

"For me, it's like, you're in a coma, and everybody's around, you call outside and everybody's just talking around you, over your lifeless body, and you can't even respond or answer or do anything, because you're there and you know, you're completely helpless... I ended up having to be there for a year at one point, and I realized what people were talking about, like it's like you become a zombie. You're just going through the motions, but you're not even thinking about it anymore. And then when you go home, you don't even know what to do with yourself"' (Lucy).

Blake also described the loss of identity. "You can't communicate with anybody. You lose your sense of self. You're literally sitting, staring at a wall for 24 hours a day." Joseph also described feeling socially alienated. "It's like a hell. It's like being in a dark hole. In a way, it's like being in confinement." Jessica recalled how this sense of seclusion resulted in feelings of powerlessness: "you're so secluded and cut off from everyone and everything in there. You can't do nothing. You're at their mercy completely."

As prisoners' accounts reveal, warehouse-like institutions subject human beings to “coerced and regimented idleness" (Robertson 1997: 1004). The state of their existence is fraught with a deep symbolism; "the zoo-like confinement of idle inmates symbolizes that they are undeserving of anything but daily survival and in many prisons not even that is assured" (Robertson 1997: 1031). For OCDC prisoners, the absence of mental and physical stimulation symbolized the loss of humanity. As Britney stated, "when you're 
incarcerated, you're not supposed to be treated like a caged animal, and that's exactly what Innes Road detention centre is."

The structural denial of mental and physical stimulation is emblematic of the containment logic of the warehouse style of imprisonment (Robertson 1997). While coerced idleness may seem more humane than the forms of corporal punishment that modern penal institutions have theoretically replaced, some scholars argue that human warehousing constitutes an exceedingly harsh form of punishment that depletes prisoners of human worth (Robertson 1997; Guenther 2013). In describing life in the American supermax prison, Guenther (2013: 197) writes, "[t]he extreme boredom produced and reinforced by social and sensory deprivation can amount to a living death sentence." While the warehousing style of incarceration in Canada may lack the political intentionality underpinning the development of 'supermax' prisons in the United States, prisoners' accounts nonetheless suggest warehousing is a key characteristic of the jail experience.

\section{"I still feel the cold cement on the floor." Experiences in solitary confinement}

While general conditions at OCDC are harsh and austere, staff members have the ability to add an extra layer to prisoners' punishment by placing them into solitary confinement. Solitary confinement, also referred to as 'isolation' or 'segregation,' is 'a form of confinement where prisoners spend 22 to 24 hours a day alone in their cell in separation from each other" (Shalev 2008: 2). The United Nations Special Rapporteur Juan Méndez has called for a ban on the use of solitary confinement but for exceptional circumstances, and a complete ban on its use in excess of 15 days, for indefinite periods of time, and to house young people and those with mental illness (United Nations News Centre 2011). Others have called for the complete abolition of solitary confinement due to 
its inhumane nature and adverse consequences (West Coast Prison Justice Society 2016; College of Family Physicians of Canada 2016; Ontario Human Rights Commission 2016a). As Shalev (2008: 2) notes, after the death penalty, solitary confinement is "the most extreme penalty which can legally be imposed on prisoners." The adverse effects of isolation on prisoners have been well-documented (Shalev 2008; Haney 2003). As Haney (2003: 130-131) notes, a robust body of research has found that that solitary confinement inflicts significant psychological harm. In his review of this extensive research, Haney notes the following effects have been documented: negative attitudes and affect, insomnia, anxiety, withdrawal, hypersensitivity, ruminations, cognitive dysfunction, hallucinations, loss of control, irritability, aggression, rage, paranoia, hopelessness, lethargy, depression, a sense of impending emotional breakdown, self-mutilation, and suicidal ideation and behavior.

According to the Ontario corrections ministry, solitary confinement is officially used for both 'disciplinary' and 'administrative' purposes. Administrative segregation, which is said to characterize the majority of cases, is non-disciplinary and hence, prisoners are theoretically entitled to the same provisions as prisoners in the general population (Ontario Ministry of Community Safety and Correctional Services 2016e). All prisoners held in solitary confinement are entitled to "as much as possible, the same rights and privileges as all other inmates such as healthcare and programs within the institution" (Ontario Ministry of Community Safety and Correctional Services 2015: 40). As I will explain in this section, prisoners' accounts reveal a fundamental gap between policy and practice. 
As solitary confinement has come to characterize the nature of confinement in supermax, 'special security' and other warehouse-like institutions (Shalev 2008), the qualities that differentiate solitary confinement from general population are often minimal. Illustratively, at OCDC, frequent lockdowns can mean that prisoners are confined to their cells for 24 hours a day, with limited opportunities for physical or mental stimulation. Solitary confinement cells are theoretically different from regular cells in that they are intended to house a single prisoner. However, in practice, prisoners note that even solitary confinement cells may be subject to double-bunking, undermining their distinguishing feature of isolation.

As Blake explained, the punishment of isolation is lost when segregation cells are double-bunked.

"I was put on 18 days administrative segregation for refusing to follow a command from a guard. So administrative segregation is the hole. It's solitary confinement. I had a cellmate the entire 18 days because they didn't have a cell to put me in by myself for 18 days. They just didn't have the room. So they're punishing people by just basically switching them from one cell to another from one cellmate to another it's not really, it doesn't make any sense."

Notwithstanding the blending of general population and solitary confinement at the institution, the 'hole,' as prisoners call it, continues to carry great importance as an extreme form of punishment due to the 'loss of all privileges' that may accompany it.

Of the 33 participants in this study, 19 (8 women and 11 men) had experienced at least one stay in solitary confinement, reflecting broader trends in the use of solitary confinement at the institution and in Ontario more generally (Ontario Human Rights Commission 2016b). A study conducted by the Ontario Human Rights Commission in 2015 found that approximately 23 percent of prisoners at OCDC were placed in solitary confinement over a three month period (Ontario Human Rights Commission 2016b). 
However, a survey of OCDC prisoners conducted by the OCDC task force found that an astonishing 79 percent of respondents had spent time in segregation (Welch et al. 2016). Figures from the institution indicate that solitary confinement was used 'officially' 555 times between April and September of 2015 (Cox 2016). Indeed, reports indicate that solitary confinement has come to serve "as a routine management strategy" in Ontario institutions (Ontario Human Rights Commission 2016b, see also: Sapers 2017). This is true despite legal stipulations that restrict the use of solitary confinement to rare circumstances (see: Ministry of Correctional Services Act 1990).

Prisoners described being involuntarily placed in solitary confinement for a range of reasons, including disobedience, fighting with other prisoners, trading medications and possession of contraband. More generally, segregation was said to be used for "people they didn't know how to handle" (Lucy), including prisoners with mental health problems. Prisoners stated isolation was freely used a punishment tactic, rather than being reserved for extreme cases. Sasha stated, "if you look at them [the guards] wrong, you go to the hole." The use of solitary confinement in such a way parallels the findings of Piché and Major (2015: 15), who note that solitary confinement is not only used for 'official' purposes related to disciplinary and administrative aims; rather, "solitary confinement cells are malleable spaces, serving multiple (un)official purposes."

Prisoners who spent time in solitary confinement, regardless of the reasons that brought them there, recalled conditions marked by an extreme level of deprivation. Kept in small cells for days at a time, those in solitary confinement may be denied access to toilet paper, reading materials and other 'privileges' such as canteen and yard time. 
"Whatever luxury you had on the range are gonna be diminished greatly being in the hole... your basics, like toilet paper, like a toothbrush, like having a shower, like a change of clothes, you know, like underwear, t-shirt, you know, things like that, a blanket" (Kevin).

"When you go to solitary confinement, there's no yard, like you get no privileges at all, like no books to read, no nothing, no windows to look out of, no nothing. It's pretty horrible" (Leo).

"No communication, shower once a week, no yard, no outside time, no telephone calls, no visits, nothing... In seg., 'cause it's supposed to be punishment, right?" (Pierre).

Prisoners also noted that they were denied regular showers while housed in solitary confinement. June recalled that she only was allowed out of her segregation cell "every three to four days for a shower." Men recalled similar experiences.

"I've gone in there, I haven't had a shower for a week" (Pierre).

"You're lucky if you got to shower once a week" (Kevin).

"It was once a week if I was lucky. Sometimes I'd gone there almost three weeks without a shower, you know. And you gotta beg 'em, like you have to beg them, and kiss their ass" (Leo).

Physical conditions in solitary confinement cells were described as even worse than conditions in regular cells. For example, prisoners described being forced to withstand even colder temperatures in solitary confinement. "You literally fucking freeze to death almost" (Ethan). Solitary confinement cells were also described as being unsanitary and unkept. Leo recalled, "I had them put me in solitary confinement where the cell was so disgusting that it was like you'd gag from like the smell, you know?" Several prisoners who experienced isolation, including a pregnant woman, stated that their mattress was removed during the day. "No bed, just a cement floor, that's it. In the evening around nine or 11 they'll bring in like a little thin mat. But I mean it's crap for somebody my size. I mean I still feel, I still feel the cold cement on the floor" (Leo). One prisoner recalled being placed in a 'dry cell,' i.e. a cell that lacks a flushable toilet. "They end up dry celling me, cut off 
all water, took my mattress from nine a.m. to nine p.m., leave me with a blanket and bible" (Sasha). Prisoners also described being exposed to constant noise, including the screams of other prisoners in cells nearby.

As noted, solitary confinement cells sometimes hold more than a single person. As Floyd recalled, "there's people sleeping on the floors in the hole too." Leo recalled being triple-bunked in solitary confinement: "I've been in that jail in solitary confinement when there was three of us in one little fucking, one little cell." From Floyd's point of view, double-bunking in solitary confinement could exacerbate the stress experienced by prisoners.

"You know, most guys in the hole are in there for fighting, so they're like, they're hyper and... they're the type of guys that don't like to take shit anyway, and that's why the end up in the hole. Well if you overcrowd them in the hole, it makes things worse" (Floyd).

In isolation, most of prisoners' time is spent idle, with minimal physical or mental stimulation.

"[You] just sit there and you wait for your meals. That's it. That's all you can do. I mean, it's not like you can say, "ok it's time for me to go home now" (Leo).

"You sit there and count the fucking lines in the wall and holes in the wall" (Pierre).

Leo described having little social contact and few means to pass the time.

"I mean solitary confinement, you don't get the phone. I got no family here so I never get any visits when I go inside. I don't know how to write, so I don't write letters. So when I go, it's very boring, the whole time. I mean I read a bit, but I mean there, they don't give ya nothing to read. Like you go in there, if something happens to be in there already, you're alright, you gotta read it over and over and over. If not, you're just-you're lucky if you get a pencil and a paper."

The United Nations' Standard Minimum Rules for the Treatment of Prisoners identifies indefinite and prolonged solitary confinement (over 15 consecutive days) as falling under the category of "cruel, inhuman or degrading treatment or punishment" 
(United Nations Office on Drugs and Crime 2015). In direct contravention to this principle, some former prisoners spent the entire duration of their stay - sometimes months - in solitary confinement. In some cases, they were housed in isolation simply because the institution was not designed to accommodate their needs, yet they were subject to the punitive measures associated with placement in solitary confinement (e.g. the removal of one's mattress during the day).

For example, Leo, who was incarcerated several times at OCDC, recalled he was housed in solitary confinement because his health issues, including loud snoring, sleep apnea, gastrointestinal issues and night terrors, made it difficult to live with others. Another man, Pierre, who suffered from fetal alcohol syndrome and other physical health problems, spent six months in solitary confinement because he faced difficulties in the general population.

The meanings attributed to solitary confinement by prisoners were complex. In general, solitary confinement was experienced as an extreme form of punishment. Sasha described feeling like she was "going insane" after 21 days of isolation. June, who was placed in isolation upon admission, stated she talked to herself and felt as though she was experiencing hallucinations. Pierre, who spent six months in isolation, stated that he was diagnosed as having post-traumatic stress disorder as a result of prolonged isolation.

For some, however, solitary confinement was viewed as preferable to the harsh and crowded conditions of general population. Indeed, some viewed solitary confinement as a safe haven insofar as it provided prisoners with privacy and safety. Pierre, who even described suffering psychological harm as a result of isolation stated, "it's not punishment. It's relieffrom the rest of the [prisoners] that are in there." Leo also stated that he felt safer 
in solitary confinement: "you know, when you wake up two o'clock in the morning and you get a fist in the face and you think, you know, you're - you end up there anyway, so this way, you know, you're not getting attacked."

Two men stated that they intentionally behaved in a way that would lead to their placement in solitary confinement. Ethan, who lived with schizophrenia, stated:

"I wanted to go in so I started a fight. I just wanted to be alone. I'm one of those people, if I'm gonna go in jail, I wanna be alone. More safer for me and anyone around. It wasn't that hard to start a fight with somebody, I'd just walk up to somebody and give them a shot right in front of the guards."

Similarly, Pierre, who also suffered from mental illness stated, "I go, "put me in seg. "If they don't, I smash a guard in the head, and they put me in seg." One woman also said she regularly threatened suicide during her jail visits in order to be placed in isolation. "Usually I'm on suicide watch 'cause I want to be alone. In order to be alone, you have to say you're like suicidal or cause a fight... In order to be alone, instead of three in a cell, then you cause shit, or you say, "I'm suicidal", (Jolene).

The experience of isolation as a safe haven illustrates how the meanings granted to punitive measures can differ quite significantly not only between prisoners and staff, but among prisoners themselves. Despite constituting an extreme form of deprivation, the isolation and privacy associated with solitary confinement can come to be valued in a context marked by extreme insecurity and crowding. Importantly, statements regarding the safety and security provided by solitary confinement speak to the harshness of general conditions, and should be read within this context. As noted, even prisoners who preferred solitary confinement to the general population described isolation as a highly punitive experience.

As revealed in prisoners' statements, solitary confinement is used in ways that stray from both international legal frameworks and ministerial policies. In its application, 
solitary confinement is used as a punishment tactic and an inhumane way to house prisoners who have difficulties in the general population. Reduced social contact, both with other prisoners and outside contacts, increases the social alienation experienced by prisoners to the utmost degree. The harsh nature of conditions - marked by sporadic showers, occasional unavailability of toilet paper, frigid temperatures, the removal of the mattress during the day, and lack of mental and physical stimulation - symbolizes an animalistic-like state of existence. As Piché and Major 2015 (23-24) note, solitary confinement "reduces human beings to a brutalizing, degrading, dehumanizing, lonely and meager existence."

Guenther's (2013) articulation of solitary confinement as a "social death" is emblematic of prisoners' experiences in isolation at OCDC. Guenther argues that a social death occurs when prisoners, though still "physically alive," have lives that "no longer bear a social meaning." In this sense, solitary confinement can be understood as a "living death sentence" that violently assaults "the living intentionality of the human animal" (197). OCDC prisoners in isolation were "cut off from the world" (Sasha) physically and symbolically, left to feel that their lives did not matter, that "nobody gave a fuck" (Pierre).

\section{Conclusion}

As illuminated through prisoners' descriptions of their physical living conditions, OCDC resembles a human warehouse, wherein human beings are 'stored' in mass numbers as they await transfer or release. This warehousing character resembles descriptions of the 'supermax' prison in the United States (Pizarro and Stenius 2004; Ross 2007, 2013; Guenther 2013); however, unlike in the American context, the warehouse jail has not completely emerged as the result of conscious efforts by policy-makers; in fact, this model 
contradicts the rehabilitative orientation of the current provincial corrections ministry (Naqvi 2016).

The pains related to everyday conditions were salient components of prisoners' narratives of incarceration. Crowding, lack of privacy, unsanitary living conditions, the inability to maintain personal hygiene, frigid temperatures and poor food were experienced not only as embodied aspects of punishment, but also as 'symbolic pains' (Sexton 2015) that conveyed to prisoners their depreciated human worth. Lack of mental and physical stimulation, combined with reduced social contact with the outside world, further estranged prisoners from their identity as human beings. In solitary confinement, descriptions of cold temperatures, removal of bedding during the day, lack of human contact, and the absence of mental or physical stimulation bear resemblance to descriptions of torture.

In essence, OCDC prisoners described being reduced to a bare state of living where only their most basic physiological needs, such as access to food and shelter, were (barely) met. Denied were more complex human needs, including those related to safety, belonging, and esteem (Maslow 1943). It is unsurprising that both men and women repeatedly described feeling like they had lost their humanity.

"It's not right how they treat us like dogs. I wouldn't even treat my dog like that or an animal like that, how I was treated." (Bethany).

"You don't feel human there, they treat you like a piece of dirt" (Kristin).

“You're just helpless, you're nothing, you're just like not even a person anymore, you're an object" (Lucy).

"The way they treated me in there, it's like I was some kind of animal." (Pierre).

While the warehouse-like existence of prisoners was a defining feature of their experiences, other factors held salience in their accounts. In the following sections, I will 
explore how seemingly neutral practices and dynamics became the site of punishment. These include the social relations between guards and prisoners as well as prisoners' medical and health-related experiences. In practice, these components of jail life constituted or facilitated unintended yet profound forms of physical and symbolic harm (Sexton 2015). 


\section{CHAPTER 6: GUARD TREATMENT}

The topic of guard treatment was another central theme in both men and women's narratives of incarceration, lending weight to previous research emphasizing the salience of staff-prisoner relations in subjective accounts of punishment (e.g. Kruttschnitt et al. 2013; Liebling 2011). On the topic of guard treatment, several sub-themes emerged. At a general level, prisoners discussed elements of staff culture, i.e. the "commonly shared beliefs, practices and characteristic patterns of behaviour" observable among staff members (Crawley and Crawley 2008: 137). From prisoners' point of view, guard culture was perceived as being antagonistic towards prisoners and punitive in nature. Prisoners understood an anti-prisoner culture to be deeply entrenched in the fabric of the institution, making it difficult for new staff members to transcend. This underlying culture was viewed as giving way to a set of concrete practices that made the experience of incarceration harsh and unpleasant. Such practices included the belittling and insulting of prisoners, acts of cruelty, failure to meet prisoners' daily needs, the display of double-standards, and the perpetuation of violence. As prisoners' narratives reveal, guard treatment became a central mechanism through which the 'inmate' status was inscribed on prisoners.

Interestingly, prisoners noted that staff treatment was a factor that set OCDC apart from institutions that were similar in terms of underlying problems (e.g. crowding) and/or facility characteristics. That guard treatment comes to take on important meaning in the carceral environment illustrates how institution-level factors - which may be somewhat autonomous from prevailing punishment philosophies and socio-legal paradigms - can interject to shape the lived experience of punishment in practice. Below, I explore the various dimensions of guard treatment that factored into prisoners' accounts. 
“Basically, you put on the orange, you're an animal. You're not even human anymore. They don't treat you like a human."

\section{Guard culture}

Previous authors have noted that there are different 'guarding styles' (Irwin 2005; Micucci and Monster 2004). For example, in their study of a provincial jail in Canada, Micucci and Monster (2004) distinguished between rehabilitation-oriented and controloriented guards. While the former viewed their role as providing support to prisoners, the latter viewed themselves as agents of security and punishment. For prisoners, controloriented guards increased the pains of imprisonment, as revealed by the language they used to describe how guards made them feel, including "dogs, shit, and dirt" (Micucci and Monster 2004: 525). In the study at hand, the accounts of OCDC prisoners suggest that, while a similar distinction exists among guards at the institution, guard culture is viewed generally as antagonistic toward prisoners.

Prisoners discussed guard culture as being rooted in the belief that prisoners were sub-human. Prisoners' sense of lacking humanity in the eyes of guards was conveyed through the use of inanimate referents to describe how they felt.

"You're a number and that is it. They go home at night and forget all about you" (Sasha).

"The guards treat us like dirt" (Annie).

"They treated me like crap" (Kristin).

"They're just there for the money and treat you like a fucking piece of shit. 'Cause that's how they see you. A lot of guards do. When you go in there, basically you put on the orange, you're an animal. You're not even human anymore. They don't treat you like a human" (Ethan).

“They don't care who you are. It doesn't matter to them who you are. To them, you're an inmate. You need to shut up" (Lucy). 
As Grayson noted, the fact that many prisoners were pre-trial, and hence, legally presumed innocent, did not alter guards' views of prisoners. "I mean just the generalized like, the degrading of the guys there, like not everyone there is guilty, right? But like, the guards assume that everyone's guilty there, you know what I mean? Like some guys are like innocent." In effect, guard treatment became a key mechanism through which prisoners felt stripped of their pre-institutional identities and converted into 'inmates.'

Some prisoners expressed a sociological view of prisoner-guard dynamics, viewing guard dispositions not as a reflection of individual personality traits, but rather, a byproduct of the broader social environment. Illustratively, prisoners with a long-term view of the jail noticed a pattern whereby the benevolent intentions of new guards tended to fade over time.

"You'll see the new officers come in and want to make a change, right? And I mean zealous to do that. But after a couple years of spending with these old guys [guards], they become just bitter and callous like them. And they forget everything that they said that they would do" (Stan).

Lucy also described this pattern of change.

"When they first start, they seem like, you know, nicer, they want to just give you little extras, and will speak to you like a human being and like you're an adult. And then after being there for, even six months, a year, they all get into that same-like you're annoying them. Like as if you're panhandling asking them for change or asking them to donate one of their vital organs if you ask them what time it is" (Lucy).

Lucy drew a comparison between the processes of institutionalization experienced by prisoners and by staff. In her evaluation, while prisoners became institutionalized into 'inmates,' guards became habituated into agents of control and punishment.

"Just like how the inmates become zombie-robots, so do the staff, but the inmates become like where they just follow the instructions and don't have an opinion and know they just have to sit there. And they [guards] become like controlling where they just, you know, every little aspect of your day they want, it's like they come to work to ruin your day. Like 
that's how it seems to me, like everybody just comes there to say, "hey Ijust feel like ruining people's day today so any way I can, any little thing I can do, let me do it"”, (Lucy).

The tendency for guards to become more punitive over time has been observed in Canadian studies (Plecas and Maxim 1987, Larivière and Robinson 1996). For example, a study done by the Correctional Service of Canada (Larivière and Robinson 1996) found that punitive views were common among guards with more experience, while empathy and support for rehabilitation were more common among newer workers.

The notion that the guard mentality is developed 'on the job' resonates with Irwin's articulation of contemporary prisoner-guard dynamics. Irwin (2005: 65) suggests that the structural tension between prisoners and guards "is more a function of the particular institutional arrangements than the personal values and meanings that employees bring to the workplace." From his view, guards' antagonistic dispositions towards prisoners are influenced by informal guard culture, combined with direct experiences with prisoners, which lead to guards "distrusting, demeaning, and often hating prisoners."

\section{"They're not correcting shit."}

\section{Guard practices that increase the pains of imprisonment}

Several concrete practices emerged from a guard culture marked by the view that prisoners were sub-human. Such practices included the belittling and insulting of prisoners, acts of cruelty, failure to fulfill job duties, and the display of double-standards. For prisoners, these practices increased the pains of imprisonment and served as a source of deep frustration. Alongside such symbolic practices were those that involved direct forms of violence.

In their daily interactions with staff, many prisoners felt they were treated with disrespect. 
"They treat you like shit, the guards. They always have bad comments to say about somebody" (Loretta).

"I mean I'm 50 years old but you know, these kids today, I don't care if they have a good job and they're a guard or whatever, they have no respect. I hear the way they talk to people and it's just - there's no respect" (Floyd).

"They say "oh bye, we'll see you next week," you know, when people are getting released. It's like you're just, you're just telling them, "you're gonna fail, you're gonna be back," or they'll sometimes just come straight out and say, "you'll be back anyway," and they think it's funny" (Lucy).

Several prisoners recalled examples where they felt belittled or insulted by guards.

Lucy recalled different examples of harsh name-calling.

"I remember the guard was walking us down to video court, and he's like, "move it along crack whores." Like I've never done drugs in my life, so I was like, who is he talking to? Like I didn't understand why they would speak to everybody like that there...

We were in a program with Elizabeth Fry volunteers that had come and she [a prisoner] was banging on the door and the guard was like, "shut the fuck up, you fat bitch," she's like, "I stripped searched you, I saw your fat ass, you're a fat pig"”' (Lucy).

Like Lucy, Floyd felt he was belittled by guards. For example, he recalled being labelled a 'drug addict' by guards, despite having overcome addiction. "I've been in treatment for four years I haven't used a drug in, you know, four or five years, but I got some Joe Schmo telling me that I'm a drug addict." Some prisoners also described being taunted by guards. For example, Annie recalled being made fun of because of her appearance: "The guards pick on me 'cause they know I'm weak and cry. I had guards make faces behind my back cause I have no teeth."

Prisoners also recalled examples where staff engaged in small yet significant practices that were seen as motivated by a desire make prisoners' daily lives unpleasant. For example, Grayson recalled guards taking the deserts from prisoners' meals. "It's like, why are you guys doing this? You guys get paid like 30 dollars an hour, you guys get to 
leave, you guys get to eat whatever you want." He also recalled guards intentionally disrupting prisoners' sleep.

"When the guards go and do their walk at night, they always bang on the door as they're going by, and like, you know, they're just ass holes. They do once every hour, sometimes every half hour, it depends on, if there's enough guards or whatever. And you'll hear them, they deliberately smash the door" (Grayson).

Ethan recalled the seemingly intentional damage caused by guards to his property during a cell search.

"I had one guy, one guard destroy three of my brand new like Ivory soaps I bought no more than two days before. They're like ten bucks a bottle... And I say, this is for what reason? Because I have a clean cell? I made a complaint about it and I guess the warden or supervisor said, "too fucking bad, you're in jail, get used to it", (Ethan).

From Grayson's perspective, guards intentionally antagonized prisoners.

"It's almost like they want, they're trying and they want to like get the inmates to fight or like cause riots or like, you know what I mean, cause then they can justify their actions" (Grayson).

Many prisoners also felt that guards did not adequately fulfill their job responsibilities, which resulted in prisoners' daily needs going unmet. The sentiment that "a lot of them are just there for their pay cheques and they don't really care what's going on" (Dale) was common.

"Everything is a hassle, to get a phone call, to get a meal, to get yard time, anything, to wash your clothes, you know, a new cup, anything is just a complaint and a burden to the guards" (Britney).

"They don't care what you ask for. They ignore ya. You're just ignored" (Floyd).

Leo lamented the lack of accountability at the institution.

"I don't know what they do, but they don't, definitely don't do their job, that's for sure. And a lot of it's because of the union. Once you start in there, and get into a union, it's hard for them to get fired, so they can just do whatever they want and that, you know, and in jobs like that, it shouldn't be unionized, they should be all be held accountable for their - what they do to the inmates." 
From prisoners' point of view, certain problems at the institution could be attributed to idleness on the part of staff, rather than issues with understaffing.

"They're lazy, they don't wanna do nothing. Sit there, text all day or on the computer" (Loretta).

"A lot of staff there's lazy. They don't want to do anything... It's like they all act like they don't want to be there and they're honestly doing you a favour by even coming to work" (Lucy).

Several prisoners believed that guards impeded program delivery by arbitrarily cancelling program sessions.

"They [the guards] decide if they [the program volunteers] come in or not, eh? The guards. And if they're in a bad mood, a pissed off mood, and nothing worked good at home or whatever, they come in and take it out on ya. And then they refuse, they refuse the EFry. It's the way they are." (Loretta).

"The guards, when the NA or AA people come sometimes, they shoe them away at the front door and they wouldn't get in... It's all about favouritism and who's working the front door. You could have a bad guard that says "nope, I don't feel like sitting there booking them in" (Karen).

Prisoners noted that they suffered the consequences when staff did not adequately fulfill their job duties.

"When you walk around, like you see all these groups of guards just sitting down, and hanging out, feet up on the desk, talking on their phones, on their cells phones. Like, it's like, what do you mean, like, you know, my lawyer even tried to come visit once and he couldn't even get a professional visit because, "well, we don't have a guard for that" (Grayson).

Guards' blatant display of double-standards, as well as breaking of institutional rules, was another source of frustration among prisoners. As Kevin explained, rulebreaking was endemic among guards.

"I think it's part of, I think it's part of the job description, when you become a copper [guard], and you work, you know, behind the wall, I think it's almost engrained in the system itself that you are gonna, you know, you are going to bend the rules" (Kevin). 
Illustratively, women noted that guards smoked in the outside perimeter despite a general smoking ban.

"They [the guards] smoke outside in the yard where we were, but we can't smoke? And I thought if you smoke on government property, that's a big fine. So why are they doing it?... The smoking is not fair... That's not right" (Annie).

"You're not supposed to smoke, and the guards are smoking in the yard in the corner of the yard. They're not supposed to smoke there. And when the doors open you can smell the smoke. You can't do anything" (Cora).

Annie perceived the highly differential consequences for rule-breaking to be unfair.

"You go to the hole for a cigarette, which is horrible, 'cause they smoke right there" (Annie).

The mistreatment of prisoners was also seen as a display of double-standards, given that prisoners themselves were punished for mistreating guards.

"The guards can go up to you and say, "ah fuck you, ya bitch." You know what I mean? They can do that. But let me try and say that to you. Where am I going? You know. It's not fair. Not fair" (Annie).

"They make you angry and then you can 't say nothing. Right? You can't mouth off to them" (Bethany).

Women also noted that staff sometimes used services intended for prisoners, such as medical care. The ability of staff members to readily access basic pain medication that was unavailable to prisoners served as an illustration of the vast power asymmetries that characterized relations in the jail.

"Those nurses and doctors work for us, right? I saw a guard in there getting his shot, his B12, from the nurse. He should be getting that somewhere else, not in jail. And another time I seen a guard saying they had a headache and went to a nurse when she was going by and got Tylenol off of her. But yet, if we got pain, we're not allowed to have Tylenol. We have to get it prescribed from the doctor" (Annie).

Whereas the perceived lack of professionalism among guards was viewed as a source of frustration by prisoners, the violence associated with guard culture was viewed 
as a source of injustice. As prisoners recalled, guards most often perpetrated violence without directly taking part in it. For instance, several prisoners felt that guards intentionally started fights by housing individuals together who were known to be incompatible.

"Sometimes if the guards know you're having a hard time with somebody, they'll stick you in the cell with them if they don't like you, you know, just so you could get tortured or beat up" (June).

"They stick you in with different people in order to start a fight. Like they intentionally start fights. I don't know if they place bets with each other, but they actually start fights" (Jolene).

"I've had the guards, like when they know I'm beefing with somebody, and the guards dislike ya, he'll put you in that same cell with the person, and they walk away until your beef's done. They do that a lot there. You know, and it's like, "fight it out boys, " you know... and you gotta fight it out because you got no choice" (Leo).

Others stated that they witnessed guard-prisoner collusion, whereby guards would encourage or otherwise allow prisoners to harm other prisoners.

"Let's say the guard knows you're going to his institution, and let's say he just doesn't like you, he doesn't like your beef, he's never met you before but he knows what you're in for, he knows you did it, and just - he's fingering you, then he'll put the word out. Right? Yeah, so everyone already knows before you get there" (Kevin).

"I've seen like, I don't know, this guy wants to punch out that guy, so he knows the guard and he gets along with him, so he says to the guard, "listen, can you just take off for ten minutes or so so I can have a little discussion with this guy?" And the guard would normally say, "yeah ok, just make sure it's nothing too brutal," you know?" (Dale).

Some stated that guards would direct prisoners to harm other prisoners in exchange

for some type of perk.

"You know the guards are - they're not stupid, eh?... There's always an inmate that that would do the bidding, so to speak... And, you know, in return, that particular inmate would get whatever, perks (Kevin). 
Several male prisoners also stated that they witnessed or experienced direct guardon-prisoner violence. According to prisoners, acts of violence typically took place out of sight of other prisoners and surveillance cameras.

"We'd know when they were gonna go beat someone up 'cause they'd drag them away. And like they'd drag the prisoner away into a little like offset room, but I mean, you wouldn't see that guy for two weeks and he'd come back and be all like bruised in his face and he'd be like "yo man, they kicked the shit out of me, they threw me - they threw me in a cell with no toilet, or like no flushable toilet"'"(Grayson).

"An inmate would be called for some bullshit meeting that didn't exist and the only thing that showed up would be, you know, three or four guards and you. What are you gonna do? And, you know, it's that, it's that, when and if that happened, you weren't brought back to the range, you were thrown in the hole so no one saw your damage. And there's not a lot you can do about it so you just, you just, you bit your teeth" (Kevin).

Leo, who was incarcerated many times at OCDC over the course of two decades, said he experienced violence at the hands of guards on several occasions.

"I mean I've had the guards beat me up several times there, you know? They would beat me up if I didn't wanna do what they're telling me to do... or if you mouth them off, you know, tell them to "fuck off" or you know... I can get pretty mouthy when I get mad, you know, and when I'm being treated unfairly, I get a pretty big mouth and, but I keep forgetting, they don't fight fair there" (Leo).

As Leo noted, guards can escape accountability because of holes in the surveillance system. "I mean they do have cameras in there, but still there's a lot of the jail that doesn't and so they just take you where there's no cameras - pop pop pop."

Rather than viewing guard violence as isolated, prisoners viewed it as endemic to guard culture. Their observations parallel findings by Marquart (1986: 348), who argues that 'unofficial' guard violence is a "socially structured tactic of prisoner control" that is "well entrenched" in institutional culture. Prisoners" assertations are also affirmed in a report produced by the Ontario Ombudsman (Marin 2013), which found guard-perpetrated violence in Ontario institutions to be engrained in institutional cultures. This report, which 
originated in response to a high number of 'use of force' complaints, described how a 'code of silence' breeds the perpetuation and concealment of guard violence in institutions like OCDC.

While women and men held similar perceptions of guards, the topic of guard violence revealed importance gender differences. Women did not describe experiencing or witnessing the same type of direct physical beatings that men described. They did, however, describe experiencing or witnessing other types of coercion. For example, one woman noted that male guards would reward women who exposed themselves by giving them food or other perks. "I seen guards give them cologne to show their, the girls to show their tits. I've seen that.... He'd give them cologne and he'd tell her to put her hair in pony tails and show off her tits" (Loretta).

The gendered nature of violence may perhaps be related to the institutional masculinities associated with guard work, which Ricciardelli (2017) has identified in her research with male guards working in provincial facilities across Canada. More specifically, in response to various physical, emotional, and cognitive vulnerabilities in the institutional environment, she found that male officers engage in gendered strategies to mitigate risk. At OCDC, enacting masculinity is perhaps similarly a means through which guards may assert control over carceral space, whether through the displays of physical strength or other coercive practices. However, the extent to which guard-perpetrated sexual coercion occurs at OCDC was not revealed in the study at hand. More generally, the gendered nature of guard-perpetrated violence in Canadian prisons and jails is a topic in need of greater exploration. 


\section{"I couldn't even believe the difference in guards." Comparing staff across institutions}

The structural divide between prisoners and guards is not unique to OCDC; indeed, the prisoner-guard division was thoroughly discussed in early prison research (e.g. Sykes 1958, Clemmer 1958; Sykes and Messinger 1960), and, as Irwin (2005) notes, antagonistic relations between guards and prisoners remain fundamental to carceral culture. However, accounts of former OCDC prisoners suggest that staff culture varies across context. Many prisoners had experiences at other institutions, allowing them to draw comparisons between OCDC guards and staff elsewhere. As Sexton (2015) notes, perceptions of punishment are partially shaped by expectations of punishment, which are in turn influenced by, among other factors, experiential knowledge. Repeatedly, in comparisons to other institutions, OCDC stood out as the worst in terms of staff culture.

Quinte Detention Centre was a point of comparison for some prisoners. The jail, located approximately 2.5 hours away from Ottawa, in Napanee, Ontario, serves primarily as a remand centre. Like OCDC, the institution faces similar issues related to crowding, having held up to triple the number of people it was originally designed to hold. Like at OCDC, prisoners have been triple-bunked, forcing some to sleep on the floor next to the toilet (Ashley 2008). However, when it comes to the topic of staff treatment, prisoners stressed a fundamental difference. In comparison to OCDC, Sasha stated, "I couldn't even believe the difference in guards." Kevin similarly stated, "I found the rapport between copper [guard] and inmate at Napanee was 100 percent better."

Comparisons were also made with the Central East Correctional Centre (CECC), a provincial jail in Lindsay, Ontario. It is known in the province as a 'super jail,' holding approximately twice as many prisoners as OCDC. Far from being immune from problems, 
the institution faces issues such as unsanitary living conditions, inadequate medical care, and at times, crowding (Edwards 2017; Gervais 2013). Ethan was shipped from OCDC to CECC after he was sentenced. While he noted that, "it's not nicer, it's just a bigger jail, more people," he noted that one significant difference was at of guard treatment. "The guards at Lindsay were a hell of a lot nicer than the ones over at Innes." Loretta also stated she preferred the Lindsay institution for various reasons, including the fact that the guards "don't even bother you."

Comparisons were also made between OCDC and jails in Quebec. Lucy recalled her experience at Maison Tanguay, a former women's jail in Montreal. “At Tangauy, they call you Madam, whatever your last name is, you know, they speak to you like you're an adult. It's completely different there." Leo also described better relations between staff and prisoners in Prison de Bordeaux, a provincial jail located in Montreal.

"That was an old jail but it was great... the guards there, they way they are, you respected them, they respected ya back... I think Quebec, they understand, you treat the inmates good, you won't have as much problems. Not like around here" (Leo).

Another prisoner, Floyd, recalled in detail his experience at the Hull detention centre, located approximately 20 kilometres away from OCDC, in the province of Quebec.

"Oh they treat you like, with such respect over there, and it runs like clockwork... The guards, if you ask them a question, they'll actually go find out. If you say to a guard in Innes Road, "yeah excuse me um, I never got my methadone," they just say, "fuck off"", (Floyd).

Floyd's shock at the differences between the detention centres even prompted him to compliment a staff member at the Quebec jail.

"I told him, I said, you know, "I got so much respect for you guys over here, your prison system, the way you're running it, it works." And I mean, you were not treated like dogs. He knew I was from Ontario, and he knows about Innes Road." 
Guard treatment at OCDC was also juxtaposed with normative assumptions about how guards should treat prisoners.

"I thought a guard was there to take care of you, make sure you're not hurt, you know, that you get your meals, you bath, whatever, you know? There might be two out of 30 who are" (Annie).

Stan and Grayson questioned the 'correctional' function of guards.

"When you become a guard, you take an oath, to swear to help. Because that's one of the oaths... I don't know what the oath is, but "I swear I will do everything in my duty to help" cause that's what they ask. That's why they want to become correctional officers, to correct. They're not correcting shit when you piss on us all"'(Stan).

"They're just there because, well they have to be and, they don't want to be there, you know what I mean, there's no corrections in it, it's just more like, you know, demanding, and like pushing around" (Grayson).

Previous authors have suggested that the dehumanization of prisoners may help guards carry out morally-ambiguous practices. For example, Irwin (1974: 142) suggests that prison staff, in an effort to resolve potential feelings of sympathy, injustice or pity, "tend to embrace the view that the prisoners are moral inferiors who deserve their state of reduced circumstances." With Irwin's insights in mind, it is tempting to speculate that the inhumane nature of conditions at OCDC breeds an institutional staff culture marked by the view that prisoners are sub-human. This orientation perhaps allows guards to minimize feelings of guilt or cognitive dissonance. Comparative accounts, however, complicate this speculative assumption, as prisoners recalled guard culture at OCDC as unique from institutions that face similar problems. The precise reasons why, exactly, variations in guard culture exist is an empirical question in need of further investigation. 
"We're all in the same boat. They're on one side of the fence, we're on the other side of the fence, but it really doesn't matter."

\section{Nuanced perceptions of guards}

Despite the structural divide between guards and prisoners at OCDC, many prisoners drew similarities between the two groups. Some commented that guards were 'doing time' in their own way.

"You may go in and out, in and out, but you're going to be coming in for the next fifty years. Fucking right. And I'm only here for six months. Bye. You keep coming back in and you're going to spend all your life in here as the keeper of man" (Ethan).

"I understand their plight too, right? I understand their struggle, right? We're all in the same boat. They're on one side of the fence, we're on the other side of the fence, but it really doesn't matter... So you gotta turn the key, but you're gonna spend the next 20 years turning that key, so you're on a life installment plan. You're doing time with us too. You don't like the fact that you have to come here, day after day, hour after hour. Some of the guys are not too easy, either. Some of the guys give them attitude and what not" (Stan).

Prisoners also noted that some guards contravened the dominant guard culture by being helpful and supportive. However, prisoners who discussed supportive staff members stated that they constituted a minority.

"Some of them are good. Some of them are, some of them are just a pain in the ass. Some of them are there to help. Some of them will, you know, go out of their way to, if you need an extra blanket or whatever, or an extra piece of clothing, some of them will... Probably about 30 percent" (Kale).

"Some of them are ok, I'm not going to say all of them are bad. But I would have to say maybe 20 percent were decent. Two out every ten coppers [guards]" (Kevin).

"I've met maybe five guards, not even, maybe three that I can say actually cared or went above and beyond" (Sasha).

Some prisoners stated they were able to develop a rapport with guards.

"When you get to know some of the guards in OCDC, like I know them, some of them are actually alright. They are. Some of them actually empathetic, you know what I mean? But I go in there like - I'm a people person so I make them laugh, right? And that's one of the weapons, it's an actual weapon" (Stan). 
Interactions that involved staff treating prisoners like human beings had positive meaning in prisoners' accounts. Chloe, who was 23 and incarcerated for the first time, recalled having meaningful discussions with guards.

"Some of them, they'd pull me aside, and we'd have some good talks and stuff. Cause they just didn't see me in there, like you know? "You're so young, like why are you here?" And just try to give me advice and whatever, 'cause they didn't want to see me back there."

Much like prisoners rejected the stereotypes placed upon them, so too did they avoid painting all guards in a single colour. While the cultural environment of the jail was seen as influencing guards' views of and interactions with prisoners, the ability of guards to enact agency and transcend the 'guard role' brought complexity to prisoner-guard dynamics. However, an anti-prisoner sentiment was perceived to be rooted in guard culture, meaning that change may not come easy. In Sasha's view, "for OCDC to be okay, it needs to be all new staff, because of the culture" (Sasha).

\section{Conclusion}

The relationship between guards and prisoners factored heavily into men and women's retrospective accounts of jail incarceration. In various ways, guard culture at OCDC manifested in practices that increased the symbolic and embodied pains of imprisonment. At a general level, prisoners viewed guard culture as being fundamentally shaped by the view that prisoners were sub-human. This mentality was viewed as mediating the way in which guards treated those under their 'care.' Through the belittling and insulting of prisoners, acts of cruelty and failure to meet prisoners' daily needs, guards increased the symbolic pains of imprisonment by inscribing the 'inmate' status onto prisoners. At the physical level, the interpersonal harms perpetuated by guards illustrate 
how violence - while no longer written into official penal narratives (Foucault 1977) - has not been removed from the practice of punishment.

Interestingly, the fundamental divide between prisoners and guards was often not characteristic of prisoners' experiences at other institutions; indeed, guard culture at OCDC was viewed as uniquely harsh. Given the centrality of guards in shaping prisoners' experiences of incarceration, the topic of guard culture, including its internal dynamics, variations, and potential for change, is worthy of greater empirical investigation. 


\section{CHAPTER 7: HEALTH AS A SITE OF PUNISHMENT}

The extent to which incarceration impacts the health of prisoners is a telling example of how the body remains implicated in the experience of punishment (Shantz and Frigon 2010). In the study at hand, the narratives of OCDC prisoners, and those of women in particular, were often framed around the negative impact of incarceration on health. Former prisoners recounted a set of practices and conditions they perceived as detrimental to their health, including denied medical support upon admission, inadequate healthcare and medical neglect, lack of psychiatric care, denied medical agency, and the mistreatment of pregnant prisoners. For those with pre-existing medical concerns, the institutional environment proved unable to adequately accommodate or treat them, hence illustrating how disabilities and health conditions can become entangled with punishment. At the same time, the institutional environment, marked by unsanitary and unhealthy living conditions, precipitated new health problems by exposing prisoners to significant health threats.

The greater focus among female participants on the topic of health might be somewhat explained by incarcerated women's higher rates of health problems in comparison to their male counterparts (Binswanger et al. 2010; Bernier and MacLellan 2011; Martin et al. 2012; Alves, Maia and Teixeira 2015). Furthermore, incarcerated women who are pregnant tend to be a high risk obstetric group (van den Bergh, Plugge and Aguirre 2014), yet face difficulty accessing adequate prenatal care and receiving proper accommodation (Bernier and MacLellan 2011; Hatton, Kleffel and Fisher 2006; Ferszt and Clarke 2012). In general, the lack of gender-specific forms of healthcare may reflect the care model that exists within penal settings, which is "based on a military model, which assumes a healthy male" (Irwin and Owen 2005: 97). 
Reflecting the incarcerated population more generally, the women in this study had complex health needs; ten discussed having substance abuse issues, four had previously been homeless, five were pregnant during one of their stays, and many had serious health conditions, including HIV, hepatitis C, diabetes, arthritis and cancer. Similarly, of the 17 male participants, seven openly discussed struggling with substance abuse issues, while six discussed having mental health issues. Physical and mental health problems described by men included hepatitis C, asthma, pneumonia, schizophrenia, post-traumatic stress disorder and fetal alcohol syndrome.

\section{"Half the time you get released before you get your medication."}

\section{Concerns upon admission: Denied medications and medical support}

The issue of healthcare continuity was a major concern for prisoners upon admission. At OCDC, prisoners are not allowed to bring their medications into jail with them; only medication prescribed by the jail doctor and administered by medical staff is permitted. However, due to crowding and limited healthcare staff, prisoners often experienced considerable delays before seeing the jail doctor. As a result, they were sometimes forced to abruptly stop medications or treatments they had been receiving on the outside. Harriet, for example, was initially denied their HIV medications upon admission.

"Sometimes you get released before you get to see a doctor. I'm HIV positive. I'm Hep C positive. Half the time, you get released before you get your medication. You get real sick. When you miss a few days of your medication of HIV, it's like starting all over again. So then it takes about two or three months before the effects start in" (Harriet).

Like Harriet, Cora also indicated that she was denied her HIV medication, as well as her Seroquel, upon admission. In such cases, "it is not the application of medical care but the omission of care that inflicts pain" (Vaughn and Smith 1999: 200). 
Prisoners' accounts also suggest there is a lack of adequate healthcare to assist substance-users who are suffering the effects of withdrawal when they arrive at the jail. While a methadone treatment program is available, prisoners reported that they often experienced delays in treatment upon admission, as well as delayed and skipped doses throughout their stays. Noah and Floyd recalled the painful effects of missing their methadone treatments.

"When I went in there, I was on 135 milligrams of methadone, I went three days with no methadone. I was so sick, violently. That's dangerous. Because you can have heartattacks... you don't get that, it's worse than heroin. So when you get sick off methadone, it's brutal. It's dangerous because, yeah, your heart rate goes up, you know, your body's in shock' (Floyd).

"I was on methadone the last few times I went in. So yeah, you end up waiting like two or three days for your first dose. Oh, you're very sick. I know sometimes, like if you don't get your dose for three days in a row, you have to, by law, they have to start you at lower dose, start you all over again. So if you're at 120 or something, they'll throw you back to 40 or something... You get body aches and all your muscles ache, your bones ache" (Noah).

Problems with the methadone program have been documented by the jail's Community Advisory Board, who have found that treatment times vary day to day, causing "heightened anxiety and craving" due to extended time between doses (Porter et al. 2016). Indeed, missed methadone treatments appear to be a systemic problem at the institution. In March of 2017, local media reported that a representative from a community drug clinic had made unsuccessful attempts to meet with managerial staff at the jail to assist them in preventing missed methadone treatments. This problem was described as a "frequent and common concern" (Seymour 2017c). As Floyd noted, the denial or delay of methadone is experienced as "cruel and unusual punishment," forcing prisoners to experience the physical and psychological effects of withdrawal, while exposing them to serious health risks. 
Other prisoners facing addiction similarly described receiving little to no medical support to ease the pains of withdrawal upon admission. Cora recalled, "When I first came in, I was sicker than a dog. I had been on [morphine] since 20, 25 years... The pain, the withdrawal... I'm hearing voices and like I wanna kill somebody." To her dismay, Cora noted that she received no medical support for her withdrawals. "They didn't treat me when I told them right away that I was coming off of morphine." June also described receiving no medical assistance while coming off drugs. She recalled, "it's torture. It's hard. Your stomach hurts, your [having] diarrhea, your body just aches." Pierre, who had fetal alcohol syndrome, stated that substance withdrawal caused to him to experience a seizure, which led to a head injury. For prisoners, the lack of care to assist those with addiction forces them to them into depths of withdrawal, causing excessive mental and physical forms of suffering.

“It's scary, 'cause, you know, you could die in there." Inadequate healthcare and medical neglect

Throughout their stays, prisoners recalled receiving minimal healthcare. As Jessica explained, "for you to even be able to see a doctor, it takes weeks. They put you on a list. Most of the time, they forget about you and they say it's not serious." Lucy described the lack of healthcare available at the institution as a disaster waiting to happen, "it's scary, 'cause, you know, you could die in there. And it's, it's a reality, it's not like, "oh it happens sometimes." No, it happens a lot, like way too many times than it should."

Even when prisoners were able to see the jail doctor, they described visits as rushed. As Grayson recalled, "the doctor, you have to fill out a request form, and when I finally saw him, he maybe saw me for like five seconds cause there's like 30 other inmates that he had to see, right?" Prisoners sensed that medical staff did not care about the health and 
well-being of prisoners. Some prisoners felt that medical staff, like guards, were "just in there for the money" (Ethan).

"I tried to see the doctor. They have a doctor, they got a doctor parade every like I guess - he comes once a week or something... So you go to see the doctor and the doctor doesn't care. He could care less. You go there and he says "no" and then you go back" (Noah).

Prisoners felt that they were viewed with suspicion by medical staff and that their concerns were not taken seriously. Some felt that medication was denied, regardless of medical need, because all prisoners were viewed as drug abusers in the eyes of medical staff.

"I had a problem with drugs back then, you know, and I'm in this kind of pain, and you try to tell them, and they say, "oh you just want the pills to get high." It wasn't about that" (Tammy).

"I was on my meds for 15 years and they just changed everything... I understand like if it was for like addiction or something, but I don't have an addiction issue, I've never. So I don't understand it"' (Kristin).

"I mean I've asked for sleeping medication and they look at me and be like, "oh you're just a drug addict, just try and close your eyes, you know, put a towel over your eyes." Well, yeah, you know what I mean, there's always a light on in your cell in there" (Grayson).

Some felt that medical staff perceived prisoners as seeking medical attention to improve their living situation. For example, Grayson, who suffered from pneumonia, stated that he was denied admission to the medical unit because he was suspected of simply trying to get out of his triple-bunked cell: "they really didn't want me to go to the medical wing. Obviously I've got a good enough excuse... he's [the doctor] like "I don't see any just cause for you going to medical, I think you're just trying to get out of the sleep with three guys in a cell."' Even in the medical section, however, prisoners faced crowding and unsanitary living conditions. Noah recalled, "I was in med. seg. once and there was three people in the cell. There was two guys on the floor, one on the bed, and two on the floor." 
Similarly, Cody stated, "I was in there with two other guys. And the two other guys, one guy was real elderly and the other guy had crutches."

Those living with medical conditions and disabilities described the institution as non-accommodating to their needs. For example, Kristin was denied her mobility aid device and forced to sleep on a top bunk. "I have hip dysplasia, and I was having issues, and I had a cane to walk, and they wouldn't let me have it." Grayson, who suffered from asthma, had difficulty obtaining a puffer. He noted that when he finally received a puffer, it was kept in the guard station, where he could not readily access it if needed.

For those experiencing serious medical issues, the 'prisoner' status took precedence over the patient role, as illustrated by Tammy's story. While detained at OCDC, Tammy noticed a lump on her breast. During a brief visit with the jail doctor, she was told it was likely a harmless cyst. As time passed and the lump grew, Tammy made daily requests to be taken to the hospital for a proper examination. After repeated requests were denied, she filed a complaint with the Ontario Ombudsman. Following her complaint, she was finally taken to the hospital, where she was informed she had cancer and required a mastectomy. She recalled, "when I found it [the lump], it was the size of a pea. By the time they finally took me to a hospital, it was the size of a golf ball." While the experience of having cancer would have been difficult regardless of her circumstances, Tammy recalled how the greatest source of pain was the way in which her medical condition became implicated in the experience of punishment.

Tammy discussed several key moments when her prisoner status took precedence over her patient role, leading her medical experience to be infused with punitive meaning. For example, during her surgery, Tammy was cuffed at one arm and one leg to the bed, 
illustrating how the prisoner status - requiring security and punishment - became incorporated into the patient role. Recalling a particularly traumatic event, she described being taunted by an accompanying guard when she awoke from her surgery.

"When I had come out of surgery and I was like coming to, the first words that one of the guards, the female guard who was in the room with me, said, "oh, I saw your boob in a bowl," and I just started bawling. Like what a thing to say to someone. That was her first thing she said to me. Not how are ya, how ya feelin? "I saw your boob in a bowl." And laughed at me... I was just a mess, you know. Bawled my eyes out. Like how mean is that" (Tammy).

The recovery process also became implicated in punishment. Soon after her surgery, Tammy was transferred back to OCDC. She recalled, "the doctor didn't want me to go back to the jail so fast. They wanted to keep me there. They refused. They wanted me back in the institution." Security concerns led to her being placed in isolation for two months. Tammy noted, "they didn't want me out and about with the other girls in case if a fight broke out." In effect, isolation served as a form of punishment; she recalled "I was going nuts being by myself." In addition to being held in isolation, Tammy did not receive proper aftercare. She was denied adequate pain medication and had to "fight for" regular Tylenol. Her bandages were changed only weekly instead of daily, which left her fearful she would develop an infection. After attempting to make a complaint about her treatment, her communication with the outside world was restricted. She remarked, "it was like I was being punished for having cancer."

Tammy's story illuminates the tensions that emerge when the competing logics of incarceration and healthcare meet. The principles of security and punishment, which prevail in the jail setting, took precedence over compassion and care, making the treatment she endured possible. As noted by Parker (2004: 264), for incarcerated women, "the provision of care sometimes occurs within the context of penal harm." Indeed, in the jail 
setting, healthcare becomes tied to the prerogative of punishment. This is particularly true in settings where healthcare is provided by the very agency in charge of punishment, as in the case of Ontario institutions (Kouyoumdjian et al. 2016).

\section{"If you want to talk to a psychiatrist, you have to put in a request and that could take six months."}

\section{Lack of psychiatric care}

As noted by the Public Services Foundation of Canada (2015), provincial jails have come to serve as ad hoc warehouses for persons with mental illness due to the lack of services in the community. Despite the high numbers of provincially-incarcerated prisoners suffering from mental illness, very limited psychiatric services are available at remand centres. At OCDC, as Floyd explained, there is no special unit for individuals with mental health issues, forcing them to live in general population where they may enact or be subject to violence.

"They're throwing people in, you know, that have mental issues. There's no certain department for them to be housed, they're just housing them in, and you know, these people are bugged right out. They're not on their right proper medications. So what happens? They get punched out because whatever actions they're doing amongst the other prisoners... So they have to do something definitely for psychiatric patients. They have to do something. Because these people are basically being overwhelmed" (Floyd).

Men and women suffering from mental health issues stated that their attempts to access mental health services were met with long delays and inadequate care.

"If you want to talk to a psychiatrist, you have to put in a request and that could take six months. And their reasoning for that is, "oh this is a remand centre, it's not a jail" (Grayson).

"I was always seeing my psychiatrist on the outside, like I still see her once a week. So when I was there, I couldn't talk to anyone. Like I tried to see a psychologist, and the psychologist never saw me" (Jolene).

"There's girls there with mental health issues, like myself that we don't get the proper care, the doctor doesn't see you, we go in on certain medications and they change your 
medication. And there's fights and there's problems because you're not used to being on this medication" (Kristin).

Ethan, who was diagnosed with schizophrenia, recalled having to engage in selfharm in order to access care.

"I seen a psychiatrist probably once every two months. And I needed to see them more than that. And it didn't help out. So I pretty much went on suicide watch a few times, just to get what I wanted. Sad you have to fucking try to kill yourself with a fucking piece of plastic. Start cutting your skin just so it starts drawing blood and then, "oh fuck he's got it sharp enough to kill himself"" (Ethan).

However, the quality of psychiatric care, when accessed, was described as being poor.

"I managed to get in to see the psychologist there, and I told her my situation of what happened, and I'm trying to break out of the cycle... Garbage. You know? She didn't know. [She gave] breathing advice, that's about it" (Kale).

The mistreatment of prisoners with mental health problems at OCDC has been noted by the jail's Community Advisory Board. In their 2014 and 2015 annual reports, the board noted that the institution was not equipped to house prisoners with mental illness. "An issue of great concern facing inmates at the institution is the number suffering from mental illness and the lack of services to recognize and address their particular needs" (Porter et al. 2015). The board has noted that living conditions exacerbate mental health issues. "The limited access to psychiatric or psychological care available in the institution does not meet the significant needs that these individuals bring; resulting in lack of opportunity for rehabilitation and often an increase in symptom severity" (Porter et al. 2016). 


\section{"They have a hard time when people are actually aware of like whatever issues they have."}

\section{Denied medical agency}

In addition to facing structural obstacles to accessing adequate healthcare, prisoners were denied agency over their bodies through a set of medical practices and responses. The inability of prisoners to take responsible for their health runs counter to the theoretical logic of the penal system, whereby individual prisoners are expected to take responsibility for their decisions and adopt 'pro-social' values (Moore and Hannah-Moffat 2005). Kilty (2012) has noted this paradox in relation to the mental health experiences of incarcerated women: ““'[d]espite the neoliberal emphasis on empowerment as a way to responsibilize incarcerated women, criminalized women are not truly expected to be responsible, selfgoverning agents of their own mental health destinies." Similarly, in relation to their physical health, prisoners in this study felt deprived of the ability to make basic healthcare choices, while several practices signified to them their loss of agency and adult status.

For instance, some prisoners stated that they were altogether denied medications that they had been receiving on the outside. As Annie recalled, "I got [fibromyalgia] and arthritis, and they weren't giving me enough Tylenol. They took me off my Percocets. They say they don't give them in jail, which I'm not an abuser of pills. So I don't get nothing." Some women also described having their medications altered without having the reasons for changes explained to them. For example, Kristin recalled that her medication was changed without her informed consent. This change caused her to experience anxiety, fatigue and other adverse physical side-effects. Jolene also recalled that the jail doctor switched her anti-anxiety medications without explaining why or coordinating with her outside doctor. 
Both men and women stated that they were unable to access basic pain medication for problems such as toothaches or headaches. During one visit, Annie recalled that she was denied basic pain medication for a bad toothache because she was pregnant. "I had two here that were in pain and I kept rubbing salt, rubbing them 'cause they wouldn't give me nothing for the pain. I was pregnant. Anyway, they wouldn't give me like regular Tylenol." Similarly, Loretta stated she was denied Tylenol for a toothache that lasted the four months she was incarcerated, forcing her to live in constant pain. Ethan recalled that the doctor would only give him children's Tylenol for a toothache: "He gives me fucking children's Tylenol for my tooth, and it was just throbbing like there was no tomorrow, it had a huge hole in it." Prisoners also lacked access to cold and cough medications. As Dale recalled, "if you have a cold or flu or whatever, which is very common to be going around in them places, that you're not gonna get no cough syrup. You can't buy it off canteen. And it's like rough."

Such practices, including the denial of medications and treatments, the switching of medications without explanation, and the unavailability of basic pain and cold medication, signify prisoners' lack of agency over the body. Related to these practices were the perceptions held by staff, from the point of view of prisoners, that prisoners lacked knowledge about their health and were unable to make informed healthcare choices. Some women described drawn-out disputes with medical and institutional staff in their quest to regain control over their health.

For example, Chloe, who lived with diabetes, spent the duration of her stay attempting to regulate her insulin levels in an environment where she was deprived of the agency to control her food and insulin intake. Chloe had lived with diabetes since her 
childhood and felt confident in both her knowledge of her condition and her ability to manage it. She soon found, however, that uncompromising institutional structures made accommodation difficult for those with special dietary and medical needs. Changes to her diet and medication schedule led her to become seriously ill.

“They'd try to send me to bed with my blood sugar's being 20. Your whole body hurts, you're throwing up, you're really dry, like, you're thirsty, it makes you pee, you feel nauseous, you have a headache, you just, you feel really sick. And it's not healthy for you either... you can go into diabetic coma, you can get ketoacidosis, which you get really sick with" (Chloe).

Chloe felt belittled by the staff who assumed prisoners could not be well-informed or knowledgeable about their own health conditions.

"They have a hard time when people are actually aware of like whatever issues they have, or conditions, and know more than them. To them it was almost like they were upset about that, you know, I'm right and they were wrong, and they'd rather make me sick than argue. It was just ridiculous."

Chloe's experience at OCDC was fundamentally shaped by her health struggles, illustrating how pre-existing health conditions can become intertwined with punishment. While in the outside world, Chloe was able to make health choices that enabled her to manage her condition, inside the jail, she was forced to experience her illness as a salient aspect of her punishment. Her case also highlights the 'fallacy of self-governance' noted by Kilty (2012), whereby prisoners lose control over their bodies at the same time as they are expected to become responsibilized agents.

\section{"I was sleeping on the floor, and you know, like being in the second trimester of my pregnancy, they didn't care." Lack of healthcare and accommodation for pregnant women}

Given that provincial jails are ill-equipped to offer even basic healthcare services, their inability to provide gender-specific forms of care is unsurprising. As noted by Siefert and Pimlott (2001), "[p]regnancy imposes physical demands that are exacerbated by the 
physical conditions of incarceration, and studies of pregnancy outcome among women prisoners have demonstrated high perinatal mortality and morbidity." Five of the women in this study were pregnant at least once while incarcerated at OCDC. All reported receiving virtually no prenatal care or even basic accommodations to enhance their health or comfort. As in the case of prisoners with pre-existing health conditions, the experience of pregnant prisoners illustrates how the body becomes the unintended site of punishment.

Like many jails, OCDC does not have any special units for pregnant woman or standard accommodating practices. Unless pregnant women are put into medical segregation, they must live in the harsh conditions of general population and are treated no differently than other prisoners. As one woman noted, "I was sleeping on the floor, and you know, like being in the second trimester of my pregnancy, they didn't care" (Lucy). In addition to living in crowded, unsanitary and chaotic environments, women had limited opportunities for fresh air and exercise and were fed the standard jail diet, consisting of three small, pre-made meals per day. Attempting to negotiate modifications to their diet was viewed as pointless, given that most food is produced at an off-site location. Furthermore, pregnant women did not receive regular monitoring by medical staff, leaving them uncertain as to the health of their unborn babies.

One woman's tragic story illustrates the heightened layer of pain that pregnant women experience when their unborn child becomes implicated in punishment. Kristin was in her early twenties when she was pregnant and incarcerated at OCDC. She alerted staff that she feared for her safety due to tension she was experiencing with two other prisoners. No measures were taken and, at five months pregnant, Kristin was assaulted by the two women. The attack caused her to go into labour. Rather than taking Kristin to the hospital 
immediately, staff members placed her in solitary confinement, informing her that she would be taken to the hospital when her labour was "full-blown." After 14 hours, Kristin was finally taken to the hospital, where she delivered her son, who died three days later.

While the death of Kristin's son was unlikely the outcome of malicious intentions on the part of staff, the circumstances of her labour were enabled by a rigid institutional environment unable to accommodate the basic needs of pregnant women. The lack of options for women who do not feel safe in the general population, for example, reflects such uncompromising institutional structures. Even during labour, institutional objectives took precedence over concern for Kristin's well-being. As Kristin noted, instead of being brought to the hospital when she went into labour, she was put into solitary confinement for 14 hours. While this may have reflected a disregard for her well-being, it was likely also related to institutional pressures faced by staff. Given that the institution is regularly under-staffed, outside trips - which require staff accompaniment - are likely minimized as much as possible. Consequently, maintaining basic institutional operations takes precedence over competing concerns.

Even when women are brought to the hospital to give birth, the security and punishment logics of the jail follow them. Incarcerated pregnant women are still presumed to be threatening subjects in need of security measures; hence, not only are they accompanied by jail staff, they also may be restrained through the use of handcuffs and shackles. Karen, for example, recalled the experience of being shackled while in the hospital: "my foot was shackled to the bed, right up to labour. Shackled to the bed, as if I'm going to run away while I'm in labour... Don't ask me why I'm shackled." This practice is not only dehumanizing and painful, but is unsafe for the mother and child, and is 
condemned by international human rights law and medical organizations (Doetzer 2007; Sussman 2008; Ocen 2012).

The women who gave birth while incarcerated were released from the hospital and sent back to OCDC. Their newborns were taken by either family members or the Children's Aid Society, thus women were unable to have further direct contact with their babies until they were released. This caused them to experience significant stress. Karen recounted, "they let me hold the baby twice. I was begging them to let me go back and see the baby. Within two to three days I think he was in a family. And then I see a baby ten months later that doesn't know me" (Karen). Sasha, who also gave birth at OCDC, arranged for a family member to take her baby, but was only able to receive visits with her son through glass.

As these stories reveal, the institutional prerogative of security, combined with a punitive staff culture, shape the treatment of pregnant women. During pregnancy, women are forced to live in the harsh conditions of general population with little to no accommodation, elevating their obstetric health risks. Labour also becomes a punitive experience, as evidenced most clearly by the use of restraints. After birth, women are unable to have physical contact with their newborns until they are released from custody. While increasing the risks associated with pregnancy is not an overt intention of policymakers or jail staff, it is nonetheless enabled by the security and punishment logics of the institution.

\section{“[T]he diseases I've had, I caught it in jail both times." Damaged health}

Thus far I have considered how pre-existing health conditions and medical needs become implicated in the experience of punishment. Another fundamental concern among prisoners, however, was the way in which the jail environment precipitated health 
problems. More specifically, prisoners discussed how the nature of institutional living marked by unsanitary and crowded living conditions, poor diet and lack of physical activity - contributed to the contraction of diseases, damaged health, and negative mental health effects.

Women in particular expressed concern over being housed in a population that faces a high level of communicable diseases. As one woman noted, “you don't have a choice of who you are in a cell with. You can end up with someone that has AIDS, hepatitis C, MRSA. They really just don't care." As another woman noted, prisoners are forced to share personal hygiene items: "they give you one set of nail clippers for everybody to share. And you know, a lot of inmates have Hep C and AIDS so that's not sanitary. And tweezers too" (Lucy). One woman noted she filed a complaint regarding the lack of measures in place to combat the spread of diseases. She lamented, "they refused, told us we're in jail, to live with it... I don't have anything and I don't want anything. Yes, I went to jail but that doesn't mean I should leave with a disease" (Kristin).

For some women, the fear of contracting an infection became a reality. Three of the women interviewed had contracted Methicillin-resistant Staphylococcus aureus (MRSA), a highly contagious bacterial infection that tends to occur in spaces of group living. At the same time as institutional conditions breed the spread of disease, the lack of medical staff and resources prevent quick and effective treatment. For example, Jessica waited several weeks before she was able to see a doctor in regard to sores on her face. At her visit, the doctor brushed off her ailment, stating it was probably self-inflicted. “They don't care. They don't listen. They don't give a damn. And they send you back to your cell. And they kept telling me, it'll stop, it'll stop, just go back to your cell... They figured it was me picking 
at myself or something." The infection spread and she and her cellmate were finally diagnosed with MRSA.

Another woman, Annie, contracted MRSA and scabies during two separate visits. "I've never had a disease. And two times, the diseases I've had, I caught it in jail both times. That is so disgusting." Her experience of contracting diseases while in jail illustrates both the physical and symbolic dimensions of health damage and medical neglect. While she experienced harm to the body, the conditions that enabled this harm to occur signified her loss of human status. This sense of inhumanity was compounded by the treatment Annie received at the hands of guards when she had MRSA.

"I didn't know what it is. Neither did the guards. They put me in the hospital part in there, and the guards were scared of me, because I had big bubbles it looked like. And I couldn't put nothing on it. It was so much in pain. The third day it busted open all over the place. It was so disgusting. It was unreal. And they were throwing my food at me! They were scared to come in to give me my food. They had a little hole in the door and they were throwing at me."

The contraction of diseases is an extreme example of how institutional conditions may cause harm to the body, and in effect, implicate health in the experience of punishment. There are, of course, more subtle ways in which the institutional environment negatively impacts health. For prisoners who spent an extended period of time at the jail, the institutional lifestyle - marked by dirty and unhealthy physical conditions, poor diet, chronic inactivity, sensory deprivation and high levels of stress - took its toll. Lucy recalled seeing herself in a mirror for the first time after several months of incarceration at OCDC and experiencing significant weight loss.

"It was my first time seeing a mirror in like eight months. I had lost 50 pounds. I didn't even noticed I lost it until I got there. And cause you're wearing a jogging suit, it's not like you're wearing your own clothes, and when I saw myself in the mirror, I couldn't believe how disgusting I looked... And it's not liked I needed to lose 50 pounds so it didn't look nice" (Lucy). 
However, prisoners most often stressed the less visible mental health effects they endured. As the following quotes reveal, the psychological pains of imprisonment extended beyond the jail setting, illustrating the 'breadth' of punishment (Crewe 2015).

"I've been through a lot in my life, but I think that was one of the hardest thing that I've ever gone through, and how cruel people were to me, like you know? It still hurts, you know?" (Tammy).

"I've been to jail twice and both times ended up not good, first my son, and then I witnessed [a] girl get sexually assaulted, it wasn't good. Yeah, I have PTSD now. I'm on medication because of it. More the first than the second [experience]. But now I'm on medication, my anxiety, I don't like crowds, even here [at a halfway house], they have rooms with doublebunking, and I can't be in a double bunk because my anxiety gets so bad" (Kristin).

"I'm not a suicidal person, I was like, if I have to stay here, I wanna kill myself. And I consider myself a pretty strong person, you know, I had a really rough childhood and I grew up in the system, I've been through a lot, I had kids young. And being there, I was like, I can't do this... when you go home, you don't even know what to do with yourself... You forget that you're in your thirties, you feel like you're five, and not just like a regular five-year old, you feel like you're a mentally challenged five-year old that should be hospitalized, because that's how they're treating you. Like you're stupid, you don't know anything.... It was very traumatizing for me" (Lucy)

"I mean it doesn't go away. I still have it all in my head. I still think about it" (Jessica).

"I still get nightmares over it, you know, still get nightmares and think about it all the time, you know what I mean? You know, you're still, you're still thinking about it" (Kale).

"I think I had like post-traumatic stress a little bit. A friend of mine was, like we were having a conversation on the bus, and he said, "I wouldn't be able to do this a few months ago, I wouldn't be able to have a conversation on a bus, you know? " And then I realized, yeah, I was the same way. I guess from the crowding and the, I don't know. Being in a crowded bus, I have to get off" (Noah).

"I did six months segregation that time. I've been diagnosed with PTSD, post-traumatic stress disorder, because of that. And it affected me for the rest of my life. I know, I've been told... Like one minute I'll be sitting here all happy, but the next minute, I'll be right, I'll start fucking bawling. And I don't think that it's right. I didn't do anything to deserve this. And from what they tell me, it's gonna haunt me for the rest of my life" (Pierre).

Prisoners' accounts of their health experiences illustrate how violence is engrained in institutional conditions and healthcare practices. The incompatibility between 
punishment and healthcare mandates has led some jurisdictions to transfer responsibility for healthcare to ministries of health (Martin et al. 2012; John Howard Society of Ontario 2016). According to the John Howard Society of Ontario (2016) such transfers have had positive results, including improved healthcare continuity, superior healthcare services and better healthcare outcomes. In Ontario, the corrections ministry is currently exploring the possibility of transferring healthcare services to the Ministry of Health and Long-Term Care (Ministry of Community Safety and Correctional Services 2017e). However, the transfer of healthcare to a separate ministry does not negate the fact that healthcare will continue to occur within an inherently punitive and unhealthy setting; while this fundamental tension may be softened, it will remain at play.

\section{Conclusion}

Prisoners' accounts illustrate that, while harm to the body may not be an intended or planned act on the part of institutional staff, it is nonetheless enabled by a combination of forces. In an unhealthy environment where healthcare resources are minimal, and a culture of suspicion pervades staff-prisoner relations, harmful medical outcomes ensue. At OCDC, prisoners experienced the denial of medication, medical treatment and healthcare, the loss of medical agency, as well as the contraction of disease and damaged health, illustrating the continued structural violence of incarceration. The particular salience of healthcare struggles in the accounts of women may reflect the greater healthcare needs of incarcerated women, as well as the fact that institutional environments are not designed with their needs in mind. Insofar as the punitive and security logics of penal institutions take precedence over competing concerns, and the 'prisoner' status mediates medical treatment, the health of prisoners is fundamentally at risk. 


\section{Defining the pains of imprisonment: Summary and conclusion}

Prisoners' narratives of incarceration shed light on the lived realities of punishment and challenge the structural silencing enforced through their captivity (O'Connor 2003). In defining the pains of imprisonment, OCDC prisoners recalled a set of physical and symbolic harms that shaped their experience. In the key areas discussed - including physical living conditions, guard treatment and healthcare - prisoners emphasized both the physical harm caused to the body, as well the symbolic assaults enacted against their dignity and humanity. The stories of OCDC prisoners call into question claims that the mind has replaced the body as the site of punishment, while also revealing the fundamental sense of inhumanity that characterizes the jail. Their accounts also reveal how the most salient aspects of punishment may not be those that are intended or recognized in law, hence pointing to the need to examine punishment as it is experienced at the level of practice (Sexton 2015).

In describing their warehouse-like living conditions, men and women stressed the pains of crowding, lack of privacy, unsanitary living conditions, the inability to maintain personal hygiene, frigid temperatures, poor food, lack of mental and physical stimulation, social alienation and individual isolation. These pains were experienced not only at an embodied level, but also at a symbolic level, communicating to prisoners their reduced status as human beings. Through guard treatment, prisoners experienced further erosion to their humanity, as guard-prisoner interactions became a central mechanism through which the 'inmate' status was inscribed on prisoners. From the point of view of prisoners, guards served to increase prisoners' pains of imprisonment with an apparent degree of intentionality. Perhaps most notably, guard practices that enacted physical harm by way of 
direct violence and/or practices that enabled it illustrate how violence remains implicated in the practice of punishment. Finally, material conditions and social relations combined to create an atmosphere of medical neglect and health damage. Women's accounts in particular illustrate how the lack of healthcare services available to prisoners, combined with exposure to health and safety threats, rendered prisoners' bodies the site of harm.

As prison scholars have long argued, however, prisoners are not merely passive recipients of punishment; rather they interact with the carceral environment in a variety of ways that demonstrate agency. In the following section, I will consider how prisoners responded to the pains of imprisonment, exploring both the collective and individual techniques employed. As I will explain, prisoners' discussions of prisoner culture complicate functionalist understandings of the prison social world as serving an adaptive purpose (Sykes 1958), while accounts of individual forms of adaption illustrate how the institutional environment impairs the ability of prisoners to meaningfully incorporate agency and creativity into the process of 'doing time.' 


\section{CHAPTER 8: PRISONER ADAPTATION AND RESISTANCE}

Individuals living in penal institutions face a unique set of social conditions. They exist in 'batch living' (Goffman 1961), that is, "in groups with a complete breakdown of the separate spheres of life" (Godderis 2006a: 62). They are stripped of their preinstitutional identities and deprived of agency in all areas of life (Goffman 1961). As revealed in the preceding section, in warehouse-style institutions, prisoners are reduced to a ‘zoo-like' existence where even primary needs may go unmet (Robertson 1997).

As noted, however, prison sociologists do not tend to view prisoners as passive recipients of penal power; rather, key to the sociological study of imprisonment is understanding how prisoners respond to their circumstances through various forms of adaptive and/or resistant behaviours (Sykes 1958; Clemmer 1958; Goffman 1961; Seymour 1977). Mirroring trends in penal scholarship more generally, most existing research on adaptation has focused on the experiences of sentenced prisoners within prisons, with minimal attention paid to prisoners in jails (for an exception, see: Walker 2014). As will be explained below, the jail constitutes a unique institutional backdrop, where structural conditions mediate both the social relations among prisoners, as well as the nature of individual adaptation and resistance.

In this section, I will consider how OCDC prisoners responded to the institutional environment in both collective and individual ways. At the collective level, a jail culture, particularly pronounced among male prisoners, had some commonalities with the tenets of prisoner culture identified in both classic and contemporary studies of the prison. Such similarities included a hierarchy that divided prisoners according to status, a "code of 
silence' that deterred prisoners from speaking out against other prisoners, and the pervasive use of violence.

However, paralleling the findings of Ricciardelli (2014a) in relation to federal prisoner culture, the in-group solidarity of prisoners was undermined by an individualistic orientation that prioritized self-preservation in a tumultuous social terrain. On the one hand, an individualistic disposition enabled prisoners to maintain some level of autonomy and privacy in the context of crowded and dehumanizing conditions. On the other hand, in the absence of social cohesion, prisoners described living in a state of chronic insecurity due to the unpredictable nature of prisoner relations. To prisoners, the violence embedded in prisoner culture was an expressive reaction to the nature of institutional conditions, rather than a functionalist mechanism intended to reaffirm social norms, as Sykes observed in his classic study. In general, prisoners' accounts suggest that institutional conditions may mediate prisoner social relations in a way that compounds the pains of imprisonment. Their experiences hence complicate the functionalist view of prisoner culture as serving an adaptive purpose.

At the individual level, the coping strategies employed by prisoners reflected the austere nature of the institutional environment. Seemingly mundane practices, such as reading, attending programming, working, sleeping and cognitive techniques, became prisoners' only 'escape' from the harsh realities of their existence. As Baer (2005) notes, however, simple practices can take on great meaning in the context of penal institutions insofar as they enable prisoners to enact a small degree of agency over their body and/or environment. At OCDC, such activities enabled prisoners to challenge the sense of inhumanity enacted upon them and imbue their own meanings to carceral space. 
Importantly, prisoners also responded to their environment by way of resistance. However, as I will explain, structural obstacles, including ineffective grievance mechanisms and an environment hostile to dissent, impeded prisoners' efforts to challenge conditions via institutionally-available options. Perhaps as a consequence, OCDC prisoners have also pursued wide engagement with external mechanisms of resistance. Complementing prisoners' narratives with reports and news media articles, I will conclude by considering forms of resistance that have taken place outside of the jail walls. Such efforts, I suggest, illustrate many prisoners' perceptions of the provincial penal system as lacking legitimacy and in fundamental need of change.

\section{The social qualities of the jail environment}

As a point of departure, it is worth describing the institutional characteristics that render the jail environment unique from that of the prison. This comparison is not meant to romanticize prison conditions, but emphasize how certain features that may shape prisoner adaptation in prisons are not present in the jail setting. To begin, but for a few unpaid work opportunities, there are few incentives or mechanisms that encourage prisoners to adopt the Foucauldian style of 'self-governance' noted elsewhere (e.g. Crewe 2007). Jails like OCDC lack meaningful reward structures that are capable of orienting individual behaviour and prisoner culture. For example, because most prisoners are pretrial or serving short sentences, they often lack the opportunity to apply for a decrease in security rating and/or transfer. Pre-trial prisoners at OCDC are also unable to work toward or apply for day parole or early release, since they have yet to be found guilty and/or sentenced. While in theory, provincial prisoners may apply for temporary absences (Ministry of Correctional Services Act 1990), in practice, outside passes are rarely 
accorded to OCDC prisoners. Hence, the drive to achieve institutional rewards does not appear to meaningfully impact individual behaviour or prisoner culture as Crewe (2007), for example, observed in his U.K. study.

In addition to having few incentives for conformity, prisoners face unknown risks in the jail environment due to the transient and diverse nature of the population. Frequent admissions, transfers and discharges mean OCDC is marked by a continually shifting population. This leaves prisoners unable to gain a sense of familiarity with their social surroundings. As Ethan explained, “even if you keep going in and out, in and out, it's still nerve-wracking 'cause you never know what's gonna happen. New day, new group of people." OCDC prisoners also vary greatly in terms of the charges that brought them there. As Dale explained, however, "they don't stick a common thief with a common thief, a fraud guy with a fraud guy, a shoplifter with a shoplifter. They'll mix a shoplifter with a murderer. They don't really care about that. They don't look at that. They just mix them all in, stick them all in there and let them sort it out." The unpredictability embedded in the social environment of the institution means prisoners may live in a perpetual state of uncertainty.

Remand prisoners also bear the additional burden of unresolved court cases. Because they have yet to be tried and/or sentenced, such prisoners face uncertain futures, not knowing if or when they will be released from custody. As Cody explained, "it's very stressful and hard on anyone, like they're going to be stressed out wondering when they are going to get out and what's going to happen to them when they're there." Cora noted, “it is a very stressful environment, especially when you haven't been to trial and you're sitting, just sitting there, you know?" In the context of waiting, time is experienced as idle 
and slow-moving. "You're just waiting. You're just waiting your time, you know what I mean? Everything moves slow." (Kale).

In sum, "[t]he conditions, the uncertainty and the high turnover create a climate of hostility and tension in detention centres" (John Howard Society of Ontario 2005: 2). Consequently, the collective and individual forms of adaptation that emerge in the jail environment reflect the unique challenges prisoners are confronted with. Below, I explore how the nature of the institutional environment mediates social relations at OCDC. Following an exploration of prisoner culture, I will then consider the individual forms of adaptation and resistance undertaken by prisoners to improve or challenge their circumstances. Like prisoner culture, individual responses are impaired by institutional structures, leading prisoners to turn to external mechanisms of resistance.

\section{The jail social hierarchy}

Likely due to the more transient nature of the prisoner population, as well as other factors shaping the social environment of the jail, prisoner culture at OCDC lacked the complex set of roles and figures identified in earlier studies of prisoner culture (Sykes 1958; Clemmer 1958; Irwin and Cressey 1962). To be sure, the hierarchical nature of male social relations identified in early studies was characteristic of male prisoner culture at OCDC. Men's social status was constructed around broad lines such as level of intimidation, charge type, racial identity, as well as personal characteristics. In comparison to men, women lacked a clear informal hierarchy. Illustratively, women did not discuss female equivalents of power-heavy figures, nor did they discuss race as an organizing feature of social life. The lack of established social structures may be due to the fact that the female population is comprised of around 50 women who are divided between two 
dorms and cell ranges. It may be that the small and transient nature of the female population contributes to a more varying set of social roles and relations.

Among men, the top of the social hierarchy was occupied by prisoners who held 'solid' (i.e. respectable) charges and evoked intimidation. In dorms, the prisoners 'in charge' were referred to as 'dorm heavies.' Noah explained, "the dorm heavy is the guy that's kind of charge by violence." Male prisoners recalled being confronted by the prisoner(s) in charge upon entry into the dorms.

"There's usually one to five people in charge depending on where you are. [They] will ask you, you know, have you been in before, you know? They will ask you if you have anything - I'm not going to get into that. Then they'll tell you to take a shower" (Blake).

"They wanna test you. They want to know if you're gonna be a, you know, if you're gonna be their bitch, or you're just gonna be one of them, so to speak" (Kevin).

One way in which power was expressed by dorm heavies was through control over food distribution. Joseph explained, "the meal comes in and when they push in the meal on the cart, it's the inmates that give the meal out, not the guards that work there. The two biggest guys. The two inmates." While some prisoners did not experience or witness problems with food distribution, others stated that dorm-heavies took other prisoners' food, particularly when meals contained valued items, such as fruit or cookies. As Joseph recalled, 'later at seven o'clock at night, we're hungry, like I'm starved because their taking some of my meal and putting it aside. So seven at night the two guys that are handing food out have all types of food. And you got basically nothing."

In men's maximum-security ranges, where prisoners are confined to cells, range cleaners held the most status and power. As Kevin and Ethan explained, cleaners were granted greater mobility and freedom in a highly-controlled environment. "It's a rinky-dink job, like you don't do it for that, you do it because of the things you are able to get as a 
result, you know? It gave you a little bit of status, right? And you were respected by the guys as well, right? It was a good thing" (Kevin). One of the ways in which cleaners exercised power was through control over the television. "Pretty much the cleaners are in charge of the TV... and if you have a problem with that, good luck, cause they're the biggest guys on the range" (Ethan). Stan noted that if a prisoner was not liked by a range cleaner, he could face trouble. "If you're not liked by one or two of them, you could be asked to fight, you could be asked to leave, you could be jumped, you know what I mean? If you have something that they want and you don't want to give it up, it can be taken from you."

While dorm heavies and range cleaners carried relative status and power, some male prisoners had a depreciated social status by virtue of their charges and/or other social characteristics. As previous researchers have noted, prisoners who have acted against children and women, and especially those who have perpetrated sexual harms, are often ostracized within prisoner populations (Åkerström 1986; Schwaebe 2005; Ricciardelli and Moir 2013; Ricciardelli and Spencer 2014). None of the prisoners interviewed explicitly discussed having committed such harms; however, some did describe the social marginalization of those who had. Dale explained that men tried to cover up stigmatized charges. "They somewhat try to hide sexual offences, or say if the guy's in for a domestic, beating up his girlfriend... and like sexual assaults and stuff like that, those individuals, they don't want no one to know about that, because they're gonna end up getting beat up." However, Dale felt that Black prisoners facing stigmatized charges were less vulnerable due to greater solidarity among racialized prisoners. "They stick together. If this guy's in on a sexual offence, the other guy knows about it, he isn't gonna say anything to anyone else because that's a taboo thing and they pretty much back each other up." 
Indeed, from the point of view of some men, racial identity was another factor that mediated prisoners' social experiences. Kevin, who had a longitudinal view of the institution, felt that racial identities had taken on increased social importance at OCDC. "More so now, is they started having and gangs and stuff in there, Somalians and what not, and I'm not racist but, you have the Blacks in the majority of ranges now." Some white men felt that institutional politics were fused with racial tensions.

"There are some ranges in there now that they actually have groups, like cliques, like gangs, Somalis, Blacks, people who want to take over the range. And you better do what they tell you to do, or else you're gonna get it" (Joseph).

"Every single day, people were getting jumped and basically, between the Blacks and the whites. C pod was mostly Black and there was maybe 30, there was 30 Blacks and maybe ten whites" (Floyd).

Some men at OCDC described feeling like their white identity, rather than serving as a source of privilege, became a liability. "The white guys have a hard time there cause there's Somalian gangs and stuff like that" (Noah). "If you were a white guy going on to the range, you were scrapping" (Kevin). Pierre, who was Indigenous, noted that, "because it's so full of Black people in there now, all the white people go PC." Their statements suggest that some men came to experience 'race' in new ways, illustrating how racial identities can take on unique meanings within penal settings (Kruttschnitt and Hussemann 2008).

Some prisoners suggested that social status was also mediated by personal characteristics, and in particular, those that affected a prisoner's ability to fit in. Those who lacked previous experience of incarceration, for example, felt that their 'new fish' status rendered them vulnerable within the jail social world. Kale, for example, who had no previous experience of incarceration, relocated to protective custody (PC) because he was 
unable to withstand the social conditions of general population. Ethan and Joseph also recalled the intimidation they experienced as newcomers.

"The first time I went in, I was pushed around 'cause I was new. I was scared. I didn't know anybody at first" (Ethan).

"When I went in, I was terrified out of my mind... when you go in there, you're very intimidated, and there's no really, I don't want to say protection, but if you're not big and not tough, you're going to be in for a rough ride" (Joseph).

As noted, women's experiences were less shaped by clearly-defined status divisions. While women did describe expressions of power and violence as commonplace, they did not discuss power figures comparable to the 'dorm heavies' and range cleaners that dominated male prisoner culture. Unlike men, a few women emphasized the positive role of friendships in mediating the jail experience. In describing her first experience at OCDC, for example, Jessica recalled the importance of social familiarity. "I was terrified. But as soon as I walked into the cells... I just walked in, and it was everybody I knew, all my friends. And I was like, "oh ok, I can do this."' Cora and Kristin similarly recalled the benefits of social connections. "I was one of the lucky ones that new most of the girls in there from this halfway house, so not many people bothered me" (Kristin). "It [having friends] makes a difference. A lot of people knew me from streets. They knew that I was coming" (Cora). The importance of social connections in mediating the pains of imprisonment among women has also been noted by Kruttschnitt et al. (2013: 33), who found that "[w]omen prisoners who report having good friends in prison are $41 \%$ more likely to feel control over their daily lives."

Despite the role of social connections in mediating the jail experience, however, female prisoners did not describe the patterns of kinship and pseudo-family ties that were identified in earlier studies of female prisoner culture. This may be partially due to the 
more transient nature of the population, but also the complexity of interpersonal relations within the jail, a topic that will be explored below. Similar findings have been reported by Greer (2000: 259), who found female prisoners employed "an individualistic approach to doing time rather than a kinship structure that developed in other facilities." She attributes changes in women's prisoner culture to a variety of social factors both in and out of carceral institutions, including, for example, changes to the nature of imprisonment as well as evolving gender norms.

In contrast to men, race was rarely discussed by women in relation to prisoner culture. As noted by Greer (2000: 463-463), "racial conflicts and gang activity have affected women's prisons less than correctional institutions for men." Of course, racial identity remains a sociological factor that mediates the carceral experience, as noted by Kruttschnitt and Hussemann (2008). In addition to taking on new meaning, race politics can be 'imported' from the outside world (Richmond and Johnson 2009; Walker 2016). The importation of racism was evident in the experience of Cora, for example, who recalled being isolated by other prisoners. "When I was in the dorms, there was old ladies think they were running the show, and there was a bit of racism there, 'cause I was the only Native in there, and I had my own little corner, just to myself." However, on a structural level, race relations did not appear to shape prisoner culture for women in the same way as they did for men. On the one hand, this may suggest that gender mediates race relations at OCDC. On the other hand, it may also reflect the relatively small size of the female population at the institution, which does not lend itself to the formation of ethno-cultural sub-groups. 
For both men and women, certain biographical traits were viewed as beneficial in the jail social world. For example, Kevin felt his social skills enabled him to avoid problems.

"I think I was rounded enough that I was able to interact with the muscle in the joint, and also able to interact with the geeks in the joint, you know what I mean? I was never told get lost. I was always welcome and I was always respectful of everybody. And it didn't mean I didn't have trouble. Of course I had problems. I think I was able to maneuver in a way that I didn't, I wasn't always in conflict with somebody" (Kevin).

Like Kevin, Chloe felt her personality enabled her to get along with both prisoners and staff.

"I'm a pretty easy-going person, understanding and stuff like that, and I didn't have any problems and I got along with all of them pretty well... I never caused problems there either, you know, never got in fights, I never got misconducts, I got along with everybody" (Chloe).

Interestingly, Ethan, who had schizophrenia, felt that his mental health status kept him relatively safe insofar as it kept others away: "It helps when you walk into jail as a paranoid schiz. People leave you alone somewhat."

Mastering the 'carceral habitus' also helped both male and female prisoners navigate the social world of the jail. As noted, the carceral habitus consists of the mentality and set of dispositions that enable prisoners to respond to situations in socially-appropriate ways so as to minimize the risk of violence (Caputo-Levine 2012). Caputo-Levine found such habits to include non-verbal forms of communication (e.g. intimidating body language and blank facial expressions), hypersensitivity to one's surroundings, and swift responses to perceived forms of disrespect. OCDC prisoners described a more general disposition that involved 'toughening up.'

"[The] second time I went in, I just didn't give a fuck if I know you or not, I gotta stand my ground, 'cause if not, I'm gonna be walked on all the time - not happening"' (Ethan). 
"I had to learn to be tough because I was always in, in and out of jail, so they were gonna beat up on me if I didn't fight back" (Karen).

Annie learned to use verbal intimidation to avoid physical confrontation.

"I might be a big girl but I'm not a fighter. I try to use my mouth by being loud and stuff so nobody does hurt me" (Annie).

In summary, social relations were influenced by different factors at OCDC. Among men, power differentials and social status were shaped by factors such as one's level of intimidation, charge type and racial identity. Hierarchical divisions were less characteristic of women's social relations, although the social formations described in early prison writings were absent in their accounts. Among both men and women, biographical characteristics, including personality traits and previous carceral experiences, were also viewed as influencing one's social experience.

In the subsequent sections, I will explore how relations among both men and women were influenced by, and reproduced, key cultural characteristics of the jail social world. Such characteristics included an individualistic orientation, a prisoner 'code of silence,' and the widespread presence of violence and intimidation. As I will suggest, while these features of jail culture were shaped by the qualities of institutional life, they did not always serve an 'adaptive' function in the Sykesian sense of reducing the pains of imprisonment.

\section{"Stick to yourself and do your time and don't bug anybody." Individualism}

As previously noted, the accounts of both men and women suggest that prisoner culture at OCDC lacks the solidaristic tones described in early prison research (Sykes 1958; Sykes and Messinger 1960) and the familial-like tendencies identified in research on women's prison culture (Giallombardo 1966; Ward and Kassebaum 1964; Foster 1975; 
Propper 1982; Severance 2005). Instead, a strong ethic of individualism marked prisoners' orientation towards 'doing time.'

“The rules are pretty simple: keep to yourself, don't look at other people's stuff, don't take stuff from other people, you know, mind your business... I'm here to do my stuff and go home" (Blake).

"Stick to yourself and do your time and don't bug anybody" (Kale).

"Mind your own business, that's just common sense" (Ethan).

"It's like either you shut up and say nothing and just mind your own business or else you're gonna get it" (Joseph).

To a certain extent, 'keeping to oneself' served as an adaptive strategy that not only enabled some degree of autonomy in the context of crowding, but helped prisoners avoid trouble. Some prisoners described disassociating with others so as not to become involved in institutional politics.

"I kept to myself. I didn't try to cause any shit. I'm just gonna do my time and that's it. I'm not gonna get involved in nobody's shit, in the politics, or rules of can and can't do. I just kept to myself' (Cora).

"A lot of the time, I stayed up in my bunk and read, 'cause I don't want to get caught up with it" (Kristin).

"I kept to myself. If you don't say anything to anybody it's a lot easier... I was mainly trying to stay in my place there because there was a lot of rough people... For me it's like, I didn't want to associate with anybody" (Casey).

Irwin (1980) has noted that 'withdrawal' from the prisoner social world can help prisoners reduce the likelihood of victimization, and hence, may be understood a strategy of survival. Similarly, Ricciardelli (2014a, 2014b) notes that a more individualistic disposition may be a response to the high levels of risk prisoners are presented with, which may inhibit the formation of solidaristic bonds. 
Of course, upholding individual privacy and autonomy can only be actualized through the enactment of shared social customs and practices; hence, an individualistic orientation required patterns of mutual respect and constant mindfulness of others. The structural underpinnings of an individualistic social orientation were most evident in the presence of ground rules that enabled greater predictability in an otherwise chaotic environment. Blake recalled some of the basic rules that assisted with everyday living.

"No noise before 11 in the morning or after 11 at night. Just basic, you know, you're living with other people rules. You know, clean up after yourself. Your mom doesn't live here type stuff. Always wear your shoes. Don't walk around naked. Just participate in the cleaning" (Blake).

Rules around personal space also enabled prisoners to maintain some degree of personal autonomy in a small and crowded space. "You don't touch anybody in there" (Kale). Keeping your word and paying your debts were other key rules that enhanced social predictability. "Pay your debts, don't make promises you can't keep" (Blake). “Any deals you make, you never break a deal", (Kale).

Perhaps as an adaptive response to the crowded, unsanitary, transient and dehumanizing nature of the environment, strict rules regarding hygiene and cleanliness were also in place. Upon entry into a range, prisoners were required by other prisoners to shower.

"They'll tell you to take a shower. They don't care if you've taken a shower ten seconds ago, they want you to take another shower when you get to the range. There's diseases and bugs that you don't want" (Blake).

"As soon as you come in, you gotta follow the rules, you have to take a shower, you have to take a shower when you get in there right away so you don't bring any germs in from the outside" (Kale).

Maintaining hygiene throughout one's stay was another important rule. 
"Shower everyday or at least every second day - that's usually really, really, highly enforced" (Blake).

"The guys get on each other if they think anyone is being uncleanly, so, so yeah, it's good that way" (Cody).

As Sandy noted, prisoners were also expected to take part in daily cleaning activities.

"They were really fussy about the bathrooms there, you know, like, some of the girls would get really - start fighting with the other girls if they didn't keep the bathroom clean, which is important, I find."

While perhaps a seemingly trivial component of prisoner culture, rules around hygiene and cleanliness may constitute a form of adaptation that contests the qualities of jail life. Sloan (2012) suggests that practices of cleanliness allow prisoners to exercise control in a context where they have few opportunities to enact agency. At a collective level, rules around cleanliness may also represent symbolic and practical efforts to resist the dehumanizing and degrading nature of the environment. Cleaning rituals hence illustrate how prisoners can modify their bodies and environments in a way that counters the dominant meanings entrenched in the material space they inhabit (Ricciardelli and Memarpour 2016).

\section{"If you see something, you didn't see it."}

\section{The code of silence}

On the one hand, the principle of 'doing your own time' allowed prisoners to maintain some level of personal privacy and autonomy in the context of crowding, thereby serving an adaptive function in relation to the pains of imprisonment. On the other hand, the principle drove a 'code of silence' that prevented prisoners from speaking out against other prisoners. Ethan explained the code of silence: 
"Keep your mouth shut, mind your own business, if you see something, you didn't see it. Just mind your business... The instant you open up your mouth and say, "yeah, I seen it all," pack your shit. Pack it and leave right now. Why? Cause you're about to get hurt. I learnt that fast" (Ethan).

Rather than reflecting a sense of in-group solidarity, as Sykes (1958) observed, the code of silence was implicated in unequal power relations among prisoners. As Joseph explained, the code of silence deterred prisoners from reporting incidents of violence.

"A friend of mine, they took his head, they smashed it against the sink. And the next day he said, "oh I fell." Because if you tell someone, you are a rat or goof, and everybody in the system will come for you" (Joseph).

Women described the code of silence as making it difficult to escape victimization.

"If you didn't like something, you couldn't go to a guard and say, "excuse me." You can't do that because then you're called a rat. And that's worse on you, so you get picked on more" (Bethany).

After being assaulted by another prisoner, Annie recalled, "I've never did nothing about it. You know why? Because you're called a rat."

However, the 'no ratting' rule, while apparently well-known, did not always determine prisoners' actions. The potential for disconnect between the norms and practices of carceral life was observed early on in prison sociology by Sykes (1958), who noted that the prisoner code was an 'ideal type,' rather than a description of all prisoner behaviour. Illustratively, Kristin, recalled an experience where she and other prisoners intervened on the part of prisoner who was being sexually victimized by alerting staff. Dale also recalled an incident where "the honour amongst thieves didn't really stand tall." After a violent attack that led to a prisoner's death, he recalled, "the investigation went through and a few of the people said who it was, said what happened." In these cases, prisoners used their own moral judgments, rather than the rules of the prisoner code, to dictate their action. 


\section{"You're always at risk, so you're always on edge." Violence and intimidation}

For both men and women, the violence embedded in prisoner culture often shaped discussions of the jail social world. In Sykes' (1958) account, the violence associated with prisoner culture served to uphold social norms and, in a functionalist sense, maintain social solidarity. From his perspective, the level of violence required to maintain the social order was less than what would otherwise unfold without the 'prisoner code.' At OCDC, while violence was similarly used to enforce rules, it was not viewed by prisoners as reflecting efforts to sustain a cohesive identity, but rather, as an expressive reaction to institutional circumstances. Their understandings of violence resonate with Walker's (2014: 132) argument that "extremes in behaviour are best understood as reactions to the extremes of penal living."

More specifically, several prisoners felt that violence was largely the by-product of institutional conditions marked by crowding, boredom and other problems.

"You get 30 guys in a room together. You're locked up together for more time then you would spend with your closest - your family, your wife, your children, your husband, whatever-you're locked in a room with these 30 people for X amount of time. You got, you know, 30 different personalities. And it's just difficult. It's very tense. It's - there's a lot of aggression" (Blake).

'When you're in an institution with hundreds of men, somebody's always having a bad day, right? And that person having a bad day just happened to look up and you happened to be standing there" (Kevin).

Stan believed that the violence that characterized daily living stemmed from divisive social conditions.

"Because of overcrowding, right, tensions rise all the time. There's always fights, and, you know what I mean, guys are getting shoved from one range to the next for whatever the problem may be. It's unfortunate, right? You know what I mean, because we are supposed to coexist as a body of people and it's not happening, right? And it's stands true, the saying 
stands true, a kingdom divided against itself cannot stand. And that's exactly what is happening there. We've become divided against ourselves" (Stan).

It was common for prisoners to recall incidents of violence that they had witnessed or experienced first-hand. Pierre, for example, recalled witnessing a violent assault against a man who had contravened the rules of hygiene by refusing to shower.

"They had this poor little guy, 'cause he wouldn't shower, we were in the dorms, he wouldn't shower, they kept asking him to shower... They had this guy, his neck was almost coming off his body. They stomped him almost to death" (Pierre).

Dale, who had done multiple stints at OCDC over a period of decades, recalled a tragic incident that resulted in one man's death.

"There was an incident where the guy was, he was down in minimum-security working in the kitchen and he - I don't know what he did, but he ended up going up to maximumsecurity... A few of the guys wanted to beat the guy up, and they were all valiumed up and they got carried away... and they killed him" (Dale).

Women also recalled traumatic experiences of violence. Annie, for example, described an invasive 'search' she underwent at the hands of another prisoner.

"There was a girl that came in with drugs. She lost them, I'm the pregnant one, so I'm not using, right? So she figured that I'm the one hiding them inside, that I found them, and I'm gonna hide them until whatever... She got a glove from the guard, and took me in the back room and put her hand up inside me" (Annie).

Kristin recalled witnessing traumatic episodes of violence.

"I seen girls get their face hit with the phones and, one girl got choked with the chord on the phone so now they made them shorter. It's pretty horrifying... I seen one girl, she got sexually assaulted, and the guards didn't take her seriously... She was helpless...we heard her scream cause we watching TV and we look over and we see it happen in the glass" (Kristin).

She also recalled experiencing an assault that took place while she was pregnant.

"I said I have a problem with these two girls, I don't want to be with them, and they ended up jumping me... They said it [the baby's death] was due to me going into labour early. I was only five and a half months" (Kristin). 
Previous authors have argued that the violence embedded in prisoner culture fundamentally shapes the subjectivities of prisoners (Neuber 2011; Caputo-Levine 2012). As Caputo-Levine (2012: 171) notes, "prisoners often structure their daily routines around avoiding or controlling violence." In the study at hand, male prisoners in particular described feeling like they were constantly 'on edge.'

"You wake up, and you don't know what's gonna happen because a new guy will come in and he'll try to run everything, or you gotta beef with somebody, then you got to watch your back constantly" (Brock).

"If you're having problems with somebody, like there's tension in the dorm or something, or you got a beef with somebody, you never know when he's gonna come over. The guy might try to hit you with something, you know? You always gotta watch him, you know?" (Noah).

"You're always at risk, so you're always on edge. You're always watching your back, you know what I mean?" (Stan).

In summary, the characteristics of prisoner culture at OCDC reflect the unique challenges of mass cohabitation in the warehouse-style jail. The principle of 'doing your own time' enabled prisoners, at an individual level, to avoid problems and, at a collective level, promote prisoner autonomy and privacy in the context of chronic crowding. While such an individual orientation appears to contradict the solidaristic spirit of prisoner culture noted in earlier writings, the realization of individual autonomy and privacy required prisoners to work together to develop the conditions that enabled it. However, an individualistic orientation also precipitated a code of silence that deterred prisoners from speaking out against victimization. Rather than reflecting and reproducing an 'in-group' identity and protecting collective interests, however, the code of silence was embedded in unequal power relations and enabled the continuation of prisoner-on-prisoner violence. 
Such violence was viewed by prisoners not in functionalist terms, but instead, as an expressive reaction to the nature of institutional conditions.

\section{Individual strategies to reduce the pains of imprisonment}

In addition to examining collective responses to institutional conditions, researchers have also considered the individual coping techniques and practices employed by prisoners in response to the pains of imprisonment. Individual strategies can include those that seek to adapt to conditions, often by way of positive activities, as well as those that resist them. Scholars have expressed divergent views regarding the distinction, if any, between forms of adaptation and resistance. To some (e.g. Ricciardelli and Memarpour 2016; Ugelvik 2011; Godderis 2006b), actions that seek to reduce the pains of imprisonment, and that are non-punitive in nature, are resistant insofar as they counter the dominant logics of incarceration. To others, however, the term resistance is only appropriately designated to politically-motivated actions that consciously seek to disrupt penal power (Rubin 2015). Below, I first consider actions that seek to grant positive meaning to 'doing time' and therefore, disrupt the logic of punishment. I will then consider forms of actions that challenge the legitimacy of conditions, and hence, fall more clearly within the parameters of resistance. Like collective responses, individual strategies were fundamentally constrained by the nature of institutional conditions.

As emphasized throughout this analysis, the jail experience is tantamount to human warehousing. Prisoners' experiences are characterized by forced idleness, with few opportunities or resources to 'do time' in ways that run counter to the institutional logic of containment. In this context, the coping mechanisms available to prisoners are constrained by their material and symbolic impoverishment. Hence, while the strategies described by 
prisoners may seem trivial, it is important to remember that "it is under the extreme conditions of the penal environment (e.g. the loss of liberty and freedom), that these seemingly mundane actions can hold a great deal of significance for prisoners" (Ricciardelli and Memarpour 2016: 185). Indeed, researchers have noted that everyday activities and behaviours can take on new meaning within penal institutions (Ricciardelli and Memarpour 2016; Sloan 2012; Labotka 2014). For OCDC prisoners, such activities included playing cards, reading, writing, sleeping, walking and watching television.

Reading was the most common practice described by prisoners to give positive meaning to time. As previous authors have noted, books can take on profound meaning within penal institutions (Terry 2003; Billington 2011). At OCDC, reading became an opportunity for some prisoners to escape the realities of the immediate setting, or to "be in [their] own space" (Dale). Elliott recalled the symbolic importance of reading during his 30-day stint at OCDC. In that time, his access to a single book structured his experience. "I took to reading King Lear, Shakespeare, and that's how I passed my time on the mattress on the floor... I kept going over the words in my mind, the story and that, rolling it over and over sort of" (Elliot).

He recalled a strategy of deep reading.

"I'd read excerpts and, first maybe I'd read over the story, and then get a little deeper into it, explore the character, read the footnotes, try to understand what's going on" (Elliot).

While many used reading to pass the time, however, access to books was limited. As Grayson recalled, "I did a lot of reading, but I mean even that, you don't have a library there, like you know what I mean? There's lots of library books there but they don't let you go and - "cause there's not a guard to supervise you pick the book"' (Grayson). Similarly, Sandy recalled, "they had a room that had books in it, and sometimes they had a cart, but I think they should have had more, you know? They should have offered it more." Kale 
recalled, "there is a library but the library - the books aren't refreshed for two weeks." Kale also noted that books primarily consisted of novels, rather than educational or selfhelp books. "Most of them are just novels, you know, there's nothing, there's nothing really to help yourself with, you know, or to enhance yourself, you know what I mean? If you wanted to study something, you couldn't do that, you know?"

Participation in the limited number of cultural and recreational programs was another means by which prisoners described passing the time.

“I got out [to programs] as much as I could to try and get out... 'cause I can't handle being locked in" (Jolene).

"I always went to programs when they were there, just cause, you know what I mean, it gives you a chance to get out of the dorm and to go do something" (Chloe).

Ethan attempted to improve his education while at OCDC, although he found that the institutional environment was not set up to facilitate schooling.

"I tried to get in some school, I tried to do some school there at Innes, but it takes way too long and it's pathetic, like nobody will help you with it. Like if you get stuck, it's like, well what I'm supposed to do, there's no teacher, no nothing, they just hand you the book and then pass it to the teacher afterwards when you're done" (Ethan).

Some prisoners were also able to pass the time by taking one of the limited number of laundry, kitchen or cleaning jobs. As Tammy noted, working helped prisoners stay busy. "I'm always a cleaner. They always give me a job when I'm there because I have to stay busy or else I find myself getting into trouble." Prisoners also valued the additional time spent out of cells or dorms. However, prisoners noted that they were not paid for work. "They pay you with a sticky bun. What the hell is that?" (Jessica). "I don't want to work for free. They don't pay you to work when you're in there in the kitchen. It's just, it just helps the day go by faster" (Blake). 
Beyond these limited activities, prisoners had few means to pass the time. Some described adjusting their mental state in order to cope with incarceration. Jessica, for example, recalled modifying her thought processes and orientation towards time in order to cope with her immediate circumstances.

"It's a state of mind. I remember crying. I was talking to my ex-husband at the time crying, saying, "how am I gonna do it?" He says, "just close your mind. This is where you live. There's no future. There's no past. Just day by day." That's the only way to get through it. And that's what I did. And eventually, my day came to leave. And I said, "wow, there's a world again"”, (Jessica).

Tammy recalled using humour as a way to avoid experiencing sadness.

"When I'm there, I always try to make the best of it, you know? I don't know how many times I got in trouble for laughing too much, like "you're way too happy to be here." No, you know what? I'm trying to make the best of it, where I am, and if I wanna laugh, I'll laugh. It's better than crying all the time, which I'd really like to do, but I won ' $t$ "' (Tammy).

For Ethan, thinking of his loved ones became an important coping mechanism.

"I just had to hold on to my thoughts of my friends and family, always have them writing to me, that's what kept me sane. Just knowing my mom's writing to me everyday and people, friends out there writing to me."

Some women described shutting their minds off completely by sleeping as much as possible. "To do time, you wanna sleep as much as you can" (Loretta). "I just slept through, like day and night like. Like to avoid everything, you know? Time goes faster" (Casey).

In summary, prisoners described a limited set of activities that helped them cope with the pains of imprisonment. The lack of opportunities to find positive meaning illustrates how warehouse institutions force prisoners to experience incarceration as 'hard time.' As Toch (1992: 29) explains, "[d]oing "hard time" in prison parlance means that the inmate is conscious of a seemingly endless confinement which stretches drearily over interminable days and long nights." For remand prisoners, time is experienced as "a waiting 
game, a seemingly limitless sentence to unsentenced time" (Neustatter 2002: 52). In this context, simple activities are the only means through which prisoners can enact choice, designate positive meaning to their experience, or simply make time pass more quickly.

Of course, many prisoners did not merely accept the realities of their existence; resistant actions, i.e. those that rejected the existing state of affairs, were another key response to conditions. At the institutional level, mechanisms of resistance available to OCDC prisoners include internal grievances, ombudsman complaints, and more recently, complaints to the Community Advisory Board (CAB). From the point of view of prisoners, however, structural obstacles, including ineffective complaint processes and an environment hostile towards dissent, inhibited prisoners' efforts to improve their circumstances. Perhaps as a consequence, external mechanisms of resistance have also been employed by OCDC prisoners to advocate for change. Below, I consider forms of resistant action pursued by prisoners to publicize and challenge inhumane conditions and treatment. In addition to analyzing prisoners' narratives, I will draw on reports and news media articles so as to provide a more detailed depiction of the nature and effects of resistant strategies employed by OCDC prisoners.

\section{Strategies of resistance}

The internal grievance system at OCDC consists of written complaints or requests directed at 'white shirts' (managerial staff). This system was viewed as problematic and ineffective due to the fact that guards were in charge in providing, receiving and submitting complaint forms. Some, like Floyd and Kevin, had little faith in this process.

"I find too with the paperwork now, they just, especially with the overcrowding, paperwork, it's like chhhchhh [ripping sound]. They don't care" (Floyd). 
"A lot of times, your request would be handed to the copper and then the copper would take it, they'd walk down the range, and tear it up" (Kevin).

Kevin explained that prisoners would strategically select guards when submitting complaints or requests.

"We used to pick and choose which copper we'd give it to, 'cause we knew that therewe'd know which copper would actually take the request and actually leave the range with $i t$, the whole range with it, and bring it to put it in the appropriate box" (Kevin).

Systemic problems with the internal request/complaint system were discussed in the 2016 OCDC government task force report. In this report, a new process was recommended. "MCSCS [Ministry of Community Safety and Correctional Services] should review and revise the inmate request and internal complaint process to ensure the systems in place are tracked, clear and transparent, with clearly defined service standards for complainants. This should include annual public disclosure of the nature of inmate complaints made to the ministry, remedial action taken and number of days to resolution" (Welch et al. 2016).

In their first progress report, the Ministry noted that the complaint process had been updated to include a Complaint Tracking Sheet and other protocol to improve effectiveness (Ministry of Community Safety and Correctional Services 2016a). In a second progress report, released in early 2017, the Ministry declared that the new system was effective and that 122 of 127 complaints filed between September 30 and January 12 had been resolved (Ministry of Community Safety and Correctional Services 2017b). However, whether or not the new complaint process has led to substantive improvements for prisoners requires further examination of their experiences.

In addition to internal grievances, prisoner complaints can be made to the Office of the Ontario Ombudsman, the provincial oversight body for government services. 
According to the Office, complaints from OCDC prisoners are common; in fact, OCDC is the third most complained about penal institution in the province, despite its relatively small size (Welch et al. 2016). In the 2014 to 2015 fiscal year, the Office received just under 400 complaints regarding OCDC, with most complaints focusing on matters related to healthcare (Welch et al. 2016). The Office has also conducted investigations on issues of a systemic nature across Ontario, including the problematic use of solitary confinement (Dubé 2017) and guard violence (Marin 2013).

However, some prisoners were disillusioned with the ombudsman complaint process. Lucy, for example, noted problems with confidentiality.

"Just recently when I was there, when I asked for an ombudsman form, they made me write a request for it. And I had to sign it, saying I received one. So it's not like it's anonymous like it used to be. It's like they want to know who got a form, who's making complaints" (Lucy).

Others described problems in relation to accessibility and responsiveness. "As far as the ombudsman, forget it. You can't even get through on the phone, so that's a waste of time" (Floyd). "I've called the ombudsman when I was there, it didn't do any good... Nobody does anything when you're in jail, you have no rights and that's, you know, the honest to God truth" (Jessica). However, the ombudsman complaint process was not always futile; as noted earlier, for Tammy, it proved pivotal in accessing adequate medical care.

The institution also has an independent Community Advisory Board, established in 2014 to foster public transparency and accountability (Bell 2013; Porter et al. 2015). As noted, the reports of the $\mathrm{CAB}$ have been pivotal in documenting structural problems at the institution (Porter et al. 2015, 2016). However, when asked, many prisoners stated that they were unaware of the board's existence. In response to this, an information brochure 
designed for prisoners was prepared by myself and a group of undergraduate students. The brochure was subsequently placed around the institution (albeit with changes made by management). Among other things, the brochure contained information regarding the roles and responsibilities of the $\mathrm{CAB}$. Ideally, through brochures and word of mouth, prisoners will become more aware of the advocacy potential of $\mathrm{CAB}$ members.

One shortcoming of current grievance mechanisms is the exclusion of prisoners in advocacy and advisory processes. In contrast to federal prisons and some provincial institutions, OCDC does not have a prisoner committee. As noted by George (2006: 5), prisoner committees are "bodies of prisoners elected by prisoners to provide a collective voice on systemic issues that arise in the running of a prison." Prisoner committees exist in diverse locations and take different forms, but are underpinned by a similar desire to foster some degree of democratic participation in the context of institutions that are otherwise void of accountability (George 2006).

In an opinion piece submitted to a local newspaper, an OCDC prisoner argued that the establishment of a prisoner committee at OCDC could enhance the accountability of staff by affording prisoners a collective voice. He argued that such committees can help balance out the power asymmetries that shape institutional relations. As he explained, "[c]ommittee members act diplomatically for various inmate grievances. They represent a voice for the inmate population to request changes, or to simply request necessities" (Chartrand 2016). Such a mechanism could enable prisoners themselves to identify areas of need and work collaboratively to forge solutions, potentially enhancing institutional social relations in the process. 
To be sure, there are certainly challenges to implementing a prisoner-based advocacy committee at OCDC. The transient nature of the population, as well as the ongoing nature of many prisoners' court cases, mean that committees may face high turnover in membership. There is also the danger that the recommendations of such a body would become coopted and transformed by authorities to enhance penal power (Mathiesen 1990). In other words, the efforts of a prisoner committee could come to be used in the service of disciplinary and security objectives, rather than to promote the well-being of prisoners. The question of how such a body could maintain autonomy in the context of totalizing power structures calls for responses that take into account the tendency for penal power to absorb resistance (Mathiesen 1990) (e.g. legal orders to ensure prisoner consultation).

Another obstacle to the effectiveness of current grievance mechanisms relates to institutional hostility towards dissent. Prisoners in this study described experiencing or fearing consequences for speaking out against their treatment. For example, Lucy noted that she was threatened with extra time after she made a complaint to an external agency regarding food and healthcare problems at the jail. She speculated that her general mistreatment by staff may have been a consequence of her advocacy efforts.

"It's not just about the complaints I made about my own situation. I'm always telling other people, complain about this, complain about that. They don't like that 'cause they want us to believe that we don't have rights. They want us to believe that "oh you did something, so you deserve to be treated like this. You don't deserve any better than this"' (Lucy).

Sasha also felt she was mistreated for being outspoken. "I have a big mouth, outspoken, and I didn't agree with the way they treated people there. That's why, for three and a half months, they kept me in lockdown." Grayson recalled how a protest over poor food was met with a punitive response. "We put up a protest and they didn't really get us 
anywhere, even more lockdowns. We received some heat and they just said "alright" and then continued on." Some prisoners stated that they did not complain out of fear of punishment. "There's a lot of situations where I want to speak, but then you know better 'cause you get - if you stand up for yourself against the guards or something, you'll probably go to the hole, and that's not a place I want to go" (Brock).

Perhaps as a consequence of the perceived ineffectiveness of current grievance mechanisms, prisoners have also pursued external forms of resistance. One key tactic has been the use of legal mechanisms, including lawsuits, human rights complaints and Charter challenges, to dispute the legality of conditions. Current and recent lawsuits include those launched by a woman who gave birth in an OCDC cell after being ignored for several hours (Gillis 2016), a prisoner with mental health problems who was beat and put in solitary confinement (Seymour 2016c), five men who were subject to abuse by guards (Seymour 2014), as well as a class-action suit over degrading treatment (Fedio 2016). In the study at hand, two participants stated they were involved in lawsuits, both relating to medical neglect.

Other prisoners have appealed to the Ontario Human Rights Tribunal to challenge conditions of confinement. As noted, Christina Jahn, a woman with mental health problems who was also suffering from terminal cancer while at OCDC, filed a successful human rights complaint after being held in solitary confinement for over 100 days between 2011 and 2012. In addition to financial compensation, her settlement included a list of remedies to improve the treatment of women with mental health problems in provincial custody (Seymour 2015). The Canadian Charter of Rights and Freedoms has also been used to dispute conditions in at least two cases; in 2004, Wahab Dadshani, who was confined in 
solitary confinement and subject to poor conditions, argued his treatment at OCDC violated the Charter (McCooey 2006), and, in 2016, Mutiur Rehman launched a Charter challenge after spending months in solitary confinement, although his case was later dismissed (Lofaro 2016b).

In addition to legal action, prisoners and their families have contributed to public awareness of conditions at OCDC through media engagement. Outspoken prisoners include Julie Bilotta, who gave birth at OCDC (Gillis 2016), a war veteran who was denied his proper psychiatric medications (Gillis 2014), a man who lost his eye after being denied adequate medical attention (Seymour 2014), a woman who was subject to inhumane treatment during a miscarriage (Seymour 2017d), a man who was housed in a 'shower cell' (Dimmock 2016), and an immigrant detainee who was traumatized after spending five days at OCDC while awaiting his work permit (Pfeffer 2016). Former and current prisoners have also written about their experiences at OCDC in opinion pieces and other forms of writing (Seguin 2016; Tossounian 2014, 2017).

The contributions of former OCDC prisoners have also been key to the efforts of the Criminalization and Punishment Education Project's campaign to bring attention to conditions at OCDC. Events and activities featuring prisoners' voices have included three public forums discussing problems at the institution, guest presentations in university classrooms and other contexts, as well as media materials, including a mini-documentary series, entitled "Life Inside Ottawa's Jail” (McKendy 2016). Former prisoners and their loved ones have also contributed to the development of the information brochure for OCDC prisoners, which is now posted throughout the institution. The centrality of prisoners' voices in these efforts reflects a desire to challenge the structural social silencing they 
endure and to incorporate their experiential knowledge in the service of social change. The impassioned efforts of many current and former prisoners point to the sense of illegitimacy that characterizes prisoners' perceptions of the institution, as well as the sentiment that change is both necessary and possible.

\section{Conclusion}

As Toch (1985: 59) argues, “[m]en and women by nature are not commodities that can be stored, shelved, and retrieved." While the warehouse jail fundamentally deprives individuals of their humanity, prisoners respond to their environment in both collective and individual ways. However, as the above discussion of jail culture reveals, institutional conditions influence the nature of social relations. At OCDC, prisoner culture is shaped by the problems associated with an environment marked by chronic crowding, unpredictability and insecurity. These qualities do not lend themselves to a culture of solidarity that enables prisoners to reduce the pains of imprisonment through a shared social system. Instead, prisoner culture is fundamentally shaped by prisoners' quest to seek autonomy and privacy in the context of forced mass cohabitation. The qualities of jail life, including crowding, forced idleness and high levels of stress, also breed a culture of violence and intimidation. As a result, for many, prisoner culture serves to compound rather than ameliorate the pains of imprisonment.

Prisoners were also constrained in their ability to cope with incarceration through individual forms of adaptation and resistance. As noted, the warehouse jail impairs the ability of prisoners to 'do time' in ways that incorporate prisoner agency and creativity. In this sense, prisoners were forced to "do time without a way to give time meaning" (Toch 1985: 63). While prisoners could engage in a limited number of positive activities to escape 
the monotony and unpleasantness of their circumstances, their ability to challenge conditions via institutionally-available mechanisms was impaired by structural obstacles to dissent. However, prisoners' engagement with external mechanisms of resistance, including legal and media efforts, as well as other types of activism, suggest that many prisoners do not passively accept their treatment, but recognize, and seek to challenge, the forms of injustice imposed by the provincial penal system. 


\section{CHAPTER 9: CONCLUSION}

While claims that prison scholarship has disappeared may be overstated, scholars continue to neglect the experiences of those detained inside jails (Irwin 1985; Welch 1999; Klofas 1990; Griffin 2006; Walker 2014). Likewise, theoretical accounts of punishment, which focus largely on trends in sentenced punishment, fail to capture the particularities of the jail experience. Importantly, the study of jail experiences can add nuance to penal theory and prison sociology. This is because, as articulated by Irwin (1985) and Welch (1999), jails are distinct from prisons in terms of the populations they hold, their underlying social purposes and the nature of their institutional conditions (Irwin 1985; Welch 1999).

In Canada, jails are increasingly being used to hold remanded prisoners, many of whom are facing relatively minor criminal code violations (Reitano 2017; Deshman and Myers 2014). As remand rates have increased relative to sentenced punishment, a temporal reconfiguration of punishment has taken place; in other words, individuals are increasingly serving time prior to a finding of guilt. While time spent on remand is not 'punishment' in the legal sense, it retroactively becomes credited towards one's sentence. Moreover, at the experiential level, remand 'looks and feels' like punishment (Walker 2014). As numerous reports on Canadian jails have articulated, problems such as crowding, unsanitary living conditions, violence, poor food, inadequate health and psychiatric care and lack of programming are widespread (Deshman and Myers 2014; Tilley 2012; John Howard Society of Ontario Standing Committee on Prison Conditions in Ontario 2007; Marin 2013; Public Services Foundation of Canada 2015; Jesseman et al. 2017). In fact, some argue that the jail delivers the harshest 'punishment' within the entire penal system (Irwin 1985; Walker 2014). 
As previous authors have noted, bail and remand processes are not socially neutral, but rather, are implicated in and reproduce inequalities relating to structures of colonialism, racism, patriarchy, capitalism and ableism. As Irwin would predict, Canadian jails are used widely to warehouse groups who are socially 'offensive' and 'disreputed,' but relatively non-dangerous, including those facing poverty, homelessness, substance addiction and mental illness (Deshman and Myers 2014; Novac, Hermer, Paradis and Kellen 2006; Kellough and Wortley 2002; Statistics Canada 2015; Perreault 2014; Public Services Foundation of Canada 2015; Tilley 2012; John Howard Society of Ontario 2015). While the context surrounding the use of Canadian jails has been well-documented in studies and reports (Deshman and Myers 2014; Webster, Doob and Myers 2009; Statistics Canada 2017), little research has examined jail punishment as a subjective experience.

Responding to this research gap, this project explored the experiences of men and women who were previously housed as a remanded and/or sentenced prisoner at the Ottawa-Carleton Detention Centre. As noted, this institution has been plagued by issues such as crowding, unsanitary conditions, violence and lack of programming since its inception. Notwithstanding political shifts in punishment rhetoric, and in particular, the displacement of the Progressive Conservatives 'no frills' efficiency model (Moore and Hannah-Moffat 2002; McElligot 2007) with the current Liberal government's focus, at least rhetorically, on more benevolent social goals (Naqvi 2016), fundamental human rights issues persist.

Employing a 'subjective' understanding of punishment (Sexton 2015), I considered how OCDC prisoners defined, perceived and responded to their jail experiences. A narrative-style interviewing approach allowed prisoners themselves to determine which 
aspects of their experience were worthy of discussion, thereby shedding light on the themes that held importance in their interpretations. Interestingly, the pains that held salience were seldom ones that could be easily traced to formal policy texts, but rather, related to seemingly unintentional forms of harm precipitated by institutional conditions and social relations. Hence prisoners' accounts illustrate the need to study punishment as a lived experience, rather than as simply articulated in law (Sexton 2015).

The topic of everyday living conditions was prominent in the accounts of both men and women. Prisoners' depictions of daily living paralleled accounts of the 'warehouse prison,' most typically discussed in relation to the American supermax model (Pizarro and Stenius 2004; Ross 2007, 2013; Guenther 2013). Unlike in the American context, where the supermax prison emerged as a calculated response to deal with 'problem' populations (Pizarro and Stenius 2004; Ross 2007, 2013), the warehousing logic at OCDC appears to be related to long-standing problems at the institution, combined with current trends in the broader bail and remand system in Ontario (Deshman and Myers 2014).

On the topic of warehouse-like conditions, men and women described environmental features that undermined their humanity and imposed a zoo-like existence (Robertson 1997). Crowding, lack of privacy, unsanitary and uncomfortable living spaces, poor food and coerced idleness were described as embodied pains that also carried a strong symbolic element, communicating to prisoners their depreciated level of humanity. Prisoners' estrangement from their humanity was compounded by the sense of social alienation that characterized jail living. In solitary confinement, prisoners' sense of inhumanity was intensified; social isolation, sensory deprivation, frigid temperatures, the 
removal of bedding during the day and unsanitary living conditions magnified the animalistic quality of prisoners' existence.

The social relations between prisoners and guards constituted a second key theme in prisoners' narratives of incarceration, lending weight to previous research emphasizing the importance of guard treatment in subjective accounts of punishment (e.g. Kruttschnitt et al. 2013; Liebling 2011) and illustrating how institutional-level factors can interject to shape the experience of punishment. At a general level, prisoners described a punitive staff culture perceived to be rooted in the belief that prisoners were sub-human. Prisoners viewed this culture as reinforcing a set of practices that increased both the symbolic and physical pains of imprisonment. At the symbolic level, guard practices became a key mechanism through which the 'inmate' identity became inscribed on prisoners, with everyday interactions serving as the site of these inscriptions. At the physical level, the harm enacted or otherwise enabled by staff illustrates how violence continues to be carried out in the practice of punishment, albeit in ways that are not recognized officially in law and are concealed through a 'code of silence' (Marin 2013). The gendered nature of this violence may speak to the conflation of masculinity and power in the context of guarding work (Ricciardelli 2017).

A third theme that was salient in prisoners' accounts, particularly for women, related to medical experiences and the adverse health consequences of jail incarceration. The greater focus on health and medical experiences among women may partially reflect the fact that incarcerated women have higher rates of infectious diseases, chronic illnesses and mental health issues, and are impacted differently by the institutional environment in comparison to men (Alves, Maia and Teixeira 2015; Bernier and MacLellan 2011; Shantz 
and Frigon 2010 Martin et al. 2012). Furthermore, carceral spaces like OCDC are not designed with women's bodies and medical needs in mind, as vividly illustrated by the experiences of pregnant women.

On the topic of health and medical experiences, prisoners recounted how the institutional environment was ill-equipped to provide care and accommodation to those who required it. Through practices such as denied medication and medical support, inadequate healthcare and medical neglect, lack of psychiatric care, denied medical agency and non-accommodation, prisoners' bodies became the site of physical harm. At the same time as existing healthcare needs were not met, some prisoners also experienced damage to their physical and/or mental health as a result of unhealthy institutional living conditions. The topic of medical mistreatment and health damage illustrate how the body remains implicated in the experience of punishment, albeit in ways that are less obvious and direct than the forms of state-sanctioned violence that characterized corporal modes of punishment throughout history (Foucault 1977).

In addition to exploring the array of pains experienced by prisoners, I also considered how prisoners responded to their environment in both collective and individual ways. As noted, the social environment at OCDC is marked by qualities that may shape and constrain the nature of prisoner culture. Such qualities include population transiency (and, consequently, unknown social 'risks'), the absence of a meaningful reward structure, as well as high levels of stress due to unresolved court cases. These environmental features do not lend themselves to the formation of trust, loyalty, and an in-group mentality, but rather, precipitate an atmosphere of tension and mistrust. 
To be sure, there were some parallels with the classic tenets of male prison culture as articulated in the works of Sykes (1958) and others, including a status hierarchy, a 'code of silence' that deterred prisoners from speaking out against other prisoners and the widespread presence of violence. This culture, however, did not clearly serve an adaptive function as Sykes (1958) observed in his classic prison study, and was more individualistic than solidaristic in its orientation. Self-preservation, rather than collective social interests, took precedence among men. Similarly, women did not appear to enact the gendered social roles observed in traditional studies of women's imprisonment (Giallombardo 1966; Ward and Kassebaum 1965) and were more self-oriented in their approach toward 'doing time.' These findings parallel those of Ricciardelli (2014a) in relation to male federal prisoners in Canada.

On the one hand, an individualistic culture fostered social practices that promoted privacy and dignity (e.g. spatial boundaries and hygiene/cleaning rituals) and hence contested the dehumanizing qualities of the institutional environment. In this sense, prisoners confronted the qualities of their social environment by way of individualized social behaviours that promoted collective interests. On the other hand, in the absence of social solidarity, prisoners lived in an unpredictable social terrain, resulting in feelings of chronic insecurity. In this context, the perpetual threat of violence became a fundamental pain of imprisonment. Prisoners' accounts suggest that prisoner social relations may compound rather than ameliorate the pains of imprisonment, challenging the functionalist view of prisoner culture as fundamentally serving an adaptive purpose (Sykes 1958).

I also explored how individual adaptive strategies, like collective responses, were constrained by the qualities of the institutional environment. More specifically, I found that 
material and symbolic impoverishment made it difficult for prisoners to incorporate agency and creativity into the carceral experience so as to ameliorate the pains of imprisonment. A limited set of activities, such as reading books, became prisoners' only means to designate positive meaning to time, or to simply make the days pass more quickly. By and large, prisoners were forced to do 'hard time' (Toch 1992), structurally denied the ability to exercise agency and imbue their own meanings to carceral space.

Finally, I considered how prisoners responded to the environment through strategies of resistance. On this topic, prisoners tended to emphasize the ineffectiveness of institutionally-available options for dissent, such as internal grievances and ombudsman complaints. Perhaps as a consequence of the perceived shortcomings of institutionallyavailable options, OCDC prisoners in general have also pursued resistance via external avenues, including legal action, media participation and forms of direct action. The ongoing efforts of current and former OCDC prisoners have been pivotal in calling attention to the problems at the institution, as well as the personal and collateral consequences of jail incarceration.

\section{Areas for future research}

The use of narrative methodology to undertake this research project reflected a desire to gain a sense of the themes associated with incarceration that were important to prisoners themselves. The considerably wide range of topics that emerged from narratives can direct future researchers seeking to understand specific themes in more depth and/or in relation to different types of prisoners. In general, further research is needed to explore how the pains of jail imprisonment are experienced by different groups of people, and in particular, those whose identities and bodies deviate from patriarchal, ableist, 
heteronormative and ethnocentric normative structures. Future researchers might ask: How are the embodied and symbolic pains of jail imprisonment experienced by transgendered persons, elderly prisoners, racialized and Indigenous prisoners, and those living with physical disabilities?

In relation to staff-prisoner dynamics, subsequent research is needed to explore the factors that influence guard culture in distinct settings. As prisoners' accounts reveal, staffprisoner relations factor heavily into experiences of jail incarceration. A key question that remains, however, is why guard culture may vary across institutions that are quite similar in terms of institutional features and/or underlying problems. Underpinning this question is a more general need to consider how institution-level factors influence the experience of punishment in ways that stray from the normative and legal discourses that sustain the penal system. Furthermore, given the apparently gendered nature of guard treatment, future research may also consider the gender nuances of prisoner-guard dynamics, particularly as they pertain to practices of coercion.

In relation to prisoner adaptation, future research might explore how prisoner culture interacts with the pains of imprisonment in distinct penal settings. More specifically, researchers may consider how the prisoner social world responds to institutional conditions in ways that reduce the pains of imprisonment (i.e. render institutional living more manageable) as Sykes (1958) observed, but also in ways that compound them. Future research may also further explore how experiences of the prisoner social world are mediated by demographic factors, such as race, ethnicity, sexuality, health status and disability, as well as institutional factors, such as institution type and security level. 
Finally, subsequent researchers may explore the collective and individual forms of resistance pursued by prisoners in jails and other penal settings. Research seeking to understand prisoners' experiences with institutionally-available grievance options, as well as their use of external mechanisms of dissent, may assist in broader advocacy efforts to promote greater transparency and accountability in the realm of punishment.

\section{Final thoughts}

As previously noted, the Ontario government has recently announced its decision to close OCDC (Ontario of Community Safety and Correctional Services 2017e). It is tempting to view the forthcoming closure of OCDC as a step forward in the advancement of prisoners' rights. Such an optimistic interpretation would be warranted if this closure corresponded with a shift from carceral solutions to community-based alternatives. Unfortunately, however, the government's solution has been identified as the construction of a larger facility that will effectively accommodate rather than address the root causes of jail crowding (Piché 2017). Importantly, many of the fundamental problems described by prisoners would simply not be addressed by a newer and bigger facility.

Indeed, history is replete with examples of how 'new and improved' facilities have been unable to deliver on their promises of better conditions and improved human rights (Piché 2017). Ironically, when it first opened, OCDC was itself considered to be a modern state of the art facility. The Ottawa Sun (Laucius 2017) recently recalled that a journalist in 1972 described OCDC as a 'country club.' "The jail was equipped with lounges with televisions, colour-co-ordinated dormitories, a library with 3,000 books and a verdant setting that apparently reminded the Journal reporter of a country club." As the Sun 
remarked, “[j]ails, as it turns out, don't take long to go from latest-and-greatest to powder keg." 


\section{References}

Åkerström, M. (1986). Outcasts in prison: The cases of informers and sex offenders. Deviant Behavior, 7(1), 1-12.

Alves, J., Maia, Â. and Teixeira, F. (2015). Health conditions prior to imprisonment and the impact of prison on health views of detained women. Qualitative Health Research, (26)6, 782-792.

Arbour, L. (1995). Commission of inquiry into certain events at the Prison for Women in Kingston. Ottawa, ON: Canada Communication Group.

Arrigo, B. A. and Bullock, J. L. (2008). The psychological effects of solitary confinement on prisoners in supermax units: Reviewing what we know and recommending what should change. International Journal of Offender Therapy and Comparative Criminology, 52(6), 622-640.

Ashkar, P. J. and Kenny, D. T. (2008). Views from the inside: Young offenders' subjective experiences of incarceration. International Journal of Offender Therapy and Comparative Criminology, 52(5), 584-597.

Ashley, J. (2008, Dec. 11). Napanee jail at triple capacity, union says. The Kingston WhigStandard. Available online: <http://www.thewhig.com/2008/12/11/napanee-jailat-triple-capacity-union-says $>$.

Baer, L. D. (2005). Visual imprints on the prison landscape: A study on the decorations in prison cells. Tijdschrift Voor Economische en Sociale Geografie, 96(2), 209-217.

Barthes, R. (2013). Toward a psychosociology of contemporary food consumption. In C. Counihan and P. Van Esterik (eds). Food and culture: A reader, third edition. New York, NY: Routledge.

Bell, D. (2013, Aug. 28). Ottawa-Carleton Detention Centre seeking volunteers to keep tabs on inmates. The Ottawa Sun. Available online: $<$ http://ottawasun.com/2013/08/28/ottawa-carleton-detention-centre-seekingvolunteers-to-keep-tabs-on-inmates/wcm/958f9b2f-8888-4539-a33f$5 \mathrm{~b} 12205 \mathrm{c} 35 \mathrm{ec}>$.

Bell, E. (2014). There is an alternative: Challenging the logic of neoliberal penality. Theoretical Criminology, 18(4), 489-505.

Bell, P. (1996, March 05). Jail sends home weekend inmates because of strike, shortage of guards allows drunk drivers to escape punishment. The Ottawa Citizen, A1.

Bell, S. E. (1988). Becoming a political woman: The reconstruction and interpretation of experience through stories. In A. D. Todd and S. Fisher (eds). Gender and discourse: The power of talk. Norwood, NJ: Ablex. 
Bender, K. A. (2015). Exploring incarcerated women's memorable messages and the effects of prison relationships on doing time. PhD Thesis, Michigan State University.

Bernier, J. R. and MacLellan, K. (2011). Health status and health services use of female and male prisoners in provincial jail. Halifax, NS: Atlantic Centre of Excellence for Women's Health.

Berry, P. E. and Eigenberg, H. M. (2003). Role strain and incarcerated mothers: Understanding the process of mothering. Women \& Criminal Justice, 15(1), 101119.

Berry, P. E. and Smith-Mahdi, J. (2006). Doing mothering behind bars: A qualitative study of incarcerated mothers. Journal of Crime and Justice, 29(1), 101-121.

Billington, J. (2011). 'Reading for life:' Prison reading groups in practice and theory. Critical Survey, 23(3), 67-85.

Bilotta v. Her Majesty to the Queen in Right of Ontario Ottawa, Cochrane, Covell, Dorazio, Fraser, Garnett, Godin, Gyasi, Gyasi, Horner, Kamei, Last, Pilon, Robinson, Smiley, Thompson, Walsh, Wilkes, John Doe and Jane Doe. (2014). Ontario Superior Court of Justice 14-62057 (Statement of Claim). Available online: $<$ https://www.documentcloud.org/documents/1305128-julie-bilotta-statement-ofclaim.html>.

Binswanger, I. A., Merrill, J. O., Krueger, P. M., White, M. C., Booth, R. E. and Elmore, J. G. (2010). Gender differences in chronic medical, psychiatric, and substancedependence disorders among jail inmates. American Journal of Public Health, $100(3), 476-482$.

Blanchfield, M. (1989, July 05). Detention centre inmates continue to refuse to eat. The Ottawa Citizen, B7.

Blanchfield, M. and Doran, C. (1989, Feb. 10). Regional jail overcrowded, unsafe, union says. The Ottawa Citizen, C2.

Bold, C. (2012). Using narrative in research. London, UK: Sage Publications.

Bosworth, M., Campbell, D., Demby, B., Ferranti, S. M. and Santos, M. (2005). Doing prison research: Views from inside. Qualitative inquiry, 11(2), 249-264.

Bottoms, A. (1995). The Philosophy and politics of punishment and sentencing. In C. Clarkson and R. Morgan (eds). The politics of sentencing reform. Oxford, UK: Clarendon Press.

Bradley, R. G. and Davino, K. M. (2002). Women's perceptions of the prison environment: When prison is "the safest place I've ever been." Psychology of Women Quarterly, 26(4), 351-359. 
Brinkley-Rubinstein, L. (2013). Incarceration as a catalyst for worsening health. Health \& Justice, 1(3), 1-17.

Brisman, A. (2008). Fair fare: Food as contested terrain in US prisons and jails. Georgetown Journal on Poverty Law \& Policy, 15(1), 49-93.

Brown, D. (2013). Looking behind the increase in custodial remand populations. International Journal for Crime, Justice and Social Democracy, 2(2), 80-99.

Brownlee, I. (1998). New Labour - new penology? Punitive rhetoric and the limits of managerialism in criminal justice policy. Journal of Law and Society, 25(3), 313335 .

Campbell, R. and Adams, A. E. (2009). Why do rape survivors volunteer for face-to-face interviews? A meta-study of victims' reasons for and concerns about research participation. Journal of Interpersonal Violence, 24(3), 395-405.

Campbell, R., Adams, A. E., Wasco, S. M., Ahrens, C. E. and Sefl, T. (2010). "What has it been like for you to talk with me today?" The impact of participating in interview research on rape survivors. Violence Against Women, 16(1), 60-83.

Canadian Press NewsWire. (2002, March 18). Police called to Ottawa jail after 44 inmates cause disturbance. Canadian Press NewsWire.

Caputo-Levine, D. D. (2012). The yard face: The contributions of inmate interpersonal violence to the carceral habitus. Ethnography, 14(2), 165-185.

Carrier, N. (2010). Anglo-Saxon sociologies of the punitive turn. Critical timidity, reductive perspectives, and the problem of totalization. Champ Pénal/Penal Field, 7.

CBC News. (2012, Oct. 11). Inmates upset by cries of woman in labour, Elizabeth Fry Society says inmates 'traumatized' by hearing woman's cries. CBC News. Available online: $<$ http://www.cbc.ca/news/canada/ottawa/inmates-upset-by-criesof-woman-in-labour-1.1227469>.

CBC News. (2014, Sept. 24). Julie Bilotta launches \$1.3M lawsuit after jailhouse birth, statement of claim names province, Ottawa-Carleton Detention Centre, guards and staff. CBC News. Available online: $<$ http://www.cbc.ca/news/canada/ottawa/juliebilotta-launches-1-3m-lawsuit-after-jailhouse-birth-1.2776563>.

Champ and Associates. (2016). OCDC class action. Available online: $<$ http://champlaw.ca/class-action>.

Chartrand, C. (2016, April 19). Inmate committees a missing key to jail accountability. The Ottawa Sun. Available online: <http://www.ottawasun.com/2016/04/19/inmatecommittees-a-missing-key-to-jail-accountability $>$. 
Chartrand, V. (2015). Landscapes of violence. Women and Canadian prisons. Champ Pénal/Penal Field, 12.

Cheliotis, L. K. (2006). How iron is the iron cage of new penology? The role of human agency in the implementation of criminal justice policy. Punishment \& Society, 8(3), 313-340.

Clandinin, D. J. and Connelly, F. M. (2000). Narrative inquiry: Experience and story in qualitative research. San Francisco, CA: Jossey-Bass.

Clandinin, D. J., Pushor, D. and Orr, A. M. (2007). Navigating sites for narrative inquiry. Journal of Teacher Education, 58(1), 21-35.

Clark, J. (1995). The impact of the prison environment on mothers. The Prison Journal, 75(3), 306-329.

Clemmer, D. (1958). The prison community. New York, NY: Holt, Rinehart and Winston.

Cockburn, N. (2009, Nov. 20). Poor jail conditions, court delays affect us all. The Ottawa Citizen, $\mathrm{C} 3$.

College of Family Physicians of Canada. (2016). Position statement on solitary confinement. Mississauga, ON: College of Family Physicians of Canada.

Comack, E. Fabre, C. and Burgher, S. (2015). The impact of the Harper Government's "Tough on Crime" strategy: Hearing from frontline workers. Winnipeg, MB: Canadian Centre for Policy Alternatives Manitoba Office.

Comack, E., and Silver, J. (2008). A Canadian exception to the punitive turn? Community responses to policing practices in Winnipeg's inner city. Canadian Journal of Sociology, 33(4), 815-844.

Connelly, F. M. and Clandinin, D. J. (2006). Narrative inquiry. In J. L. Green, G. Camilli, and P. Elmore (eds.). Handbook of complementary methods in education research, third edition. Mahwah, NJ: Lawrence Erlbaum.

Copes, H., Hochstetler, A. and Brown, A. (2013). Inmates' perceptions of the benefits and harm of prison interviews. Field Methods, 25(2), 182-196.

Crawley, E. and Crawley, P. (2008). Understanding prison officers: Culture, cohesion and conflict. In J. Bennett, B. Crewe and A. Wahidin (eds). Understanding prison staff. New York, NY: Willan Publishing

Crawley, E. and Sparks, R. (2005). Older men in prison: Survival, coping and identity. In A. Liebling and S. Maruna (eds). The effects of imprisonment. Portland, OR: Willan Publishing.

Crewe, B. (2005). Codes and conventions: The terms and conditions of contemporary inmate values. In A. Liebling and S. Maruna (eds). The effects of imprisonment. Portland, OR: Willan Publishing. 
Crewe, B. (2007). Power, adaptation and resistance in a late-modern men's prison. British Journal of Criminology, 47(2), 256-275.

Crewe, B. (2009). The prisoner society: Power, adaption, and social life in an English prison. Oxford, UK: Oxford University Press.

Crewe, B. (2011). Depth, weight, tightness: Revisiting the pains of imprisonment. Punishment \& Society, 13(5), 509-529.

Crewe, B. (2015). Inside the belly of the penal beast: Understanding the experience of imprisonment. International Journal for Crime, Justice and Social Democracy, $4(1), 50-65$.

Crewe, B. (2016). The sociology of imprisonment. In Y. Jewkes, B. Crewe and J. Bennett (eds). Handbook on prisons, second edition. New York, NY: Routledge.

Crewe, B., Hulley, S. and Wright, S. (2017). Swimming with the tide: Adapting to longterm imprisonment. Justice Quarterly, 34(3), 517-541.

Dadshani v. Ministry of Community Safety and Correctional Services and Defence Counsel Association of Ottawa. (2006). Superior Court of Justice, 12256.

Datesman, S. K. and Cales, G. L. (1983). I'm still the same mommy:” Maintaining the mother/child relationship in prison. The Prison Journal, 63(2), 142-154.

Davis, J. E. (2012). Narrative and social movements: The power of stories. In J. E. Davis (ed.). Stories of change: Narrative and social movements. Albany, NY: State University of New York Press.

de Graaf, K. and Kilty, J. M. (2016). You are what you eat: Exploring the relationship between women, food, and incarceration. Punishment \& Society, 18(1), 27-46.

De Viggiani, N. (2007). Unhealthy prisons: Exploring structural determinants of prison health. Sociology of Health \& Illness, 29(1), 115-135.

De Viggiani, N. (2012). Trying to be something you are not: Masculine performances within a prison setting. Men and Masculinities, 15(3), 271-291.

Demers, J. (2014). Warehousing prisoners in Saskatchewan: A public health approach. Regina, SA: Canadian Centre for Policy Alternatives.

Dempsey, A. (2015, Jan. 28). Ontario broke solitary confinement promise lawyers say. The Star. Available online: <https://www.thestar.com/news/gta/2015/01/28/ontariobroke-solitary-confinement-promise-lawyers-say.html>.

Deshman, A. and Myers. N. (2014). Set up to fail: Bail and the revolving door of pre-trial detention. Canadian Civil Liberties Association and Education Trust.

DeVeaux, M. I. (2013). The trauma of the incarceration experience. Harvard Civil RightsCivil Liberties Law Review, 48(1), 257-277. 
Dimmock, G. (1999, March 17). Union predicts violence at jail: Some inmates making weapons in case guards strike tonight. The Ottawa Citizen, C1/Front.

Dimmock, G. (2016, March 24). Inside the Ottawa jail's shower cells: 'Nothing short of disgusting.' The Ottawa Citizen. Available online: $<$ http://ottawacitizen.com/news/local-news/0325-jail>.

Doetzer, G. (2007). Hard labor: The legal implications of shackling female inmates during pregnancy and childbirth. William and Mary Journal of Women and the Law, 14(2), 363-392.

Doob, A. and Webster, C. M. (2006). Countering punitiveness: Understanding stability in Canada's imprisonment rate. Law and Society Review, 40(2), 325-368.

Doyle, A. and Walby, K. (unpublished). The forgotten worst third of the system: The neglect of jails and its implications for theorizing punishment.

Doyle, A., McKendy, L., and Mathias, I. (2016, April 2). Firing superintendent won't cure what ails the Ottawa-Carleton Detention Centre. The Ottawa Sun. Available online: $<$ http://ottawasun.com/2016/04/02/firing-superintendent-wont-cure-what-ails-theottawa-carleton-detention-centre/wcm/29563831-6087-4768-9ac2d8a37ed4873c $>$.

Drake D. H. and Harvey, J. (2014) Performing the role of ethnographer: Processing and managing the emotional dimensions of prison research. International Journal of Social Research Methodology, 17(5), 489-501.

Dubé, P. (2017). Out of oversight, out of mind. Toronto, ON: Ombudsman of Ontario.

Dyregrov, K., Dieserud, G., Straiton, M., Rasmussen, M. L., Hjelmeland, H., Knizek, B. L. and Leenaars, A. A. (2011). Motivation for research participation among people bereaved by suicide. OMEGA-Journal of Death and Dying, 62(2), 149-168.

Edwards, P. (2017, March 6). Protest over Lindsay jail conditions enters second week, guards agree with prisoners that conditions are unsanitary but don't agree with hunger strike by one inmate. The Star. Available online $<$ https://www.thestar.com/news/canada/2017/03/06/protest-over-lindsay-jailconditions-enters-second-week.html $>$.

Enos, S. (1998). Managing motherhood in prison: The impact of race and ethnicity on child placements. Women \& Therapy, 20(4), 57-73.

Euvrard, E. and Leclerc, C. (2016). Pre-trial detention and guilty pleas: Inducement or coercion? Punishment \& Society, 1462474516670153.

Evans, T. and Wallace, P. (2007). A prison within a prison? The masculinity narratives of male prisoners. Men and Masculinities, 10(4), 484-507. 
Evenson, B. (1987, May 15). Criticism of courthouse security rejected by staff. The Ottawa Citizen, B2.

Ewick, P. and Silbey, S. S. (1995). Subversive stories and hegemonic tales: Toward a sociology of narrative. Law and Society Review, 29(2), 197-226.

Fedio, C. (2016, May 26). Former OCDC inmates launching lawsuit over 'degrading treatment,' lawyer says. $C B C$ News Ottawa. Available online: $<$ http://www.cbc.ca/news/canada/ottawa/ottawa-jail-conditions-lawsuit-paulchamp-1.3601276>.

Feeley, M. and Simon, J. (1992). The new penology: Notes on the emerging strategy of corrections and its implications. Criminology, 30(4), 449-474.

Feeley, M. and Simon, J. (1994). Actuarial justice: The emerging new criminal law. In D. Nelken (ed.). The futures of criminology. London, UK: Sage Publications.

Ferrell, J. (1998). Criminological verstehen: Inside the immediacy of crime. In J. Ferrell and M. Hamm (eds). Ethnography at the edge. Boston, MA: Northeastern University Press.

Ferszt, G. G. and Clarke, J. G. (2012). Health care of pregnant women in US state prisons. Journal of Health Care for the Poor and Underserved, 23(2), 557-569.

Fleury-Steiner, B. (2015). Effects of life imprisonment and the crisis of prisoner health. Criminology \& Public Policy, 14(2), 407-416.

Foster, T. W. (1975). Make-believe families: A response of women and girls to the deprivations of imprisonment. International Journal of Criminology \& Penology, $3(1), 71-78$.

Foucault, M. (1977). Discipline and punish: The birth of the prison. London, UK: Penguin Books.

Frank, A. W. (2002). Why study people's stories? The dialogical ethics of narrative analysis. International Journal of Qualitative Methods, 1(1), 109-117.

Franzosi, R. (1998). Narrative analysis - or why (and how) sociologists should be interested in narrative. Annual Review of Sociology, 24(1), 517-554.

Frase, R. S. (2005). Punishment purposes. Stanford Law Review, 58(1), 67-83.

Fraser, H. (2004). Doing narrative research: Analysing personal stories line by line. Qualitative Social Work, 3(2), 179-201.

Freeman, S. and Seymour, M. (2010). 'Just waiting:' The nature and effect of uncertainty on young people in remand custody in Ireland. Youth Justice, 10(2), 126-142.

Friedland, M. L. (2012). The Bail Reform Act revisited. Canadian Criminal Law Review, $16(3), 315-322$. 
Garfinkel, H. (1956). Conditions of successful degradation ceremonies. American Journal of Sociology, 61(5), 420-424.

Garland, D. (2000). The culture of high crime societies: Some preconditions of recent 'law and order' policies. British Journal of Criminology, 40(3), 347-375.

Garland, D. (2001). The culture of control: Crime and social order in contemporary society. Oxford, UK: Oxford University Press.

George, A. (2006). Prisoner committees in women's prisons: A report on women's prisoner committees in California Canada and South Africa. Victoria, Australia: Deakin University.

Gervais, L. (2013, Feb. 22). Triple bunking at Lindsay superjail. The Peterborough Examiner. Available online: <http://www.thepeterboroughexaminer.com /2013/02/22/triple-bunking-at-lindsay-superjail>.

Giallombardo, R. (1966). Social roles in a prison for women. Social Problems, 13(3), 268288.

Gilbert, J. (2017, May 6). Let's spend money on bail, not jail. The Ottawa Sun. Available online: <http://ottawasun.com/2017/05/06/gilbert-lets-spend-money-on-bail-not$\mathrm{jail} / \mathrm{wcm} / 3402$ fcea-25d4-4deb-b636-74e9adfc8375>.

Gillis, M. (2014, June 19). Vet suffers in jail without meds. The Ottawa Sun. Available online: <http://ottawasun.com/2014/06/18/vet-suffers-in-jail-without-meds/wcm/ 946e3fcf-9b11-495f-93b8-02aeb95c519f>.

Gillis, M. (2016, June 1). Prisoner who gave birth in jail challenges minister to deliver on promises. The Ottawa Citizen. Available online: <http://ottawacitizen.com/ news/local-news/prisoner-who-gave-birth-in-jail-challenges-minister-to-deliveron-promises>.

Godderis, R. (2006a). Food for thought: An analysis of power and identity in prison food narratives. Berkeley Journal of Sociology, 50, 61-75.

Godderis, R. (2006b). Dining in: The symbolic power of food in prison. The Howard Journal of Criminal Justice, 45(3), 255-267.

Goffman, E. (1961). Asylums: Essays on the social situation of mental patients and other inmates. New York, NY: Random House.

Goodman, P., Page, J. and Phelps, M. (2015). The long struggle: An agonistic perspective on penal development. Theoretical Criminology, 19(3), 315-335.

Gordon, A. (2010). Self-injury incidents in CSC institutions over a thirty-month period. Ottawa, ON: Correctional Service of Canada.

Grassian, S. (1983). Psychopathological effects of solitary confinement. American Journal of Psychiatry, 140(11), 1450-1454. 
Grassian, S. (2006). Psychiatric effects of solitary confinement. Washington University Journal of Law \& Policy, 22, 325-383.

Greer, K. R. (2000). The changing nature of interpersonal relationships in a women's prison. The Prison Journal, 80(4), 442-468.

Griffin, M. (2006). Penal harm and unusual conditions of confinement: Inmate perceptions of hard time in jail. American Journal of Criminal Justice, 30(2), 209-226.

Guenther, L. (2013). Solitary confinement: Social death and its afterlives. Minneapolis, MN: University of Minnesota Press.

Hall, C. (1989, Dec. 04). Ontario to add guards and space to relieve pressure in jail system. The Ottawa Citizen, A4.

Hallsworth, S. (2000). Rethinking the punitive turn: Economies of excess and the criminology of the other. Punishment \& Society, 2(2), 145-160.

Haney, C. (2003). Mental health issues in long-term solitary and "supermax" confinement. Crime \& Delinquency, 49(1), 124-156.

Haney, C. (2012). Prison effects of in the age of mass incarceration. The Prison Journal, OnlineFirst Version July 25, 2012.

Haraway, Donna. (1988). Situated knowledges: The science question in feminism and the privilege of partial perspective. Feminist Studies, 14(3), 575-599.

Harner, H. M. and Riley, S. (2013). The impact of incarceration on women's mental health: Responses from women in a maximum-security prison. Qualitative Health Research, 23(1), 26-42.

Harris, M. (2000, Nov. 19). Tough law to create 'no-frills' jails: Ontario challenges federal laws to produce a system 'no one will want to call home.' The Ottawa Citizen, A1/ Front.

Hatton, D. C., Kleffel, D. and Fisher, A. A. (2006). Prisoners' perspectives of health problems and healthcare in a US women's jail. Women \& Health, 44(1), 119-136.

Hebenstreit, C. L. and DePrince, A. P. (2012). Perceptions of participating in longitudinal trauma research among women exposed to intimate partner abuse. Journal of Empirical Research on Human Research Ethics, 7(2), 60-69.

Hesse-Biber, S. N. (2013). Feminist approaches to in-depth interviewing. In S. N. HesseBiber (ed.). Feminist research practice: A primer. Thousand Oaks, CA: Sage Publications.

Huggins, D. W., Capeheart, L. and Newman, E. (2006). Deviants or scapegoats: An examination of pseudofamily groups and dyads in two Texas prisons. The Prison Journal, 86(1), 114-139. 
Hurley, M. (2010, Nov. 27). Somali inmates say guards beat them, rules were followed in dealing with 'disruptive' men, authorities say. The Ottawa Citizen, D1.

Hutchinson, S. (2006). Countering catastrophic criminology: Reform, punishment and the modern liberal compromise. Punishment and Society, 8(4), 443-467.

Ibbitson, J. (1998, Sept. 25). Jail workers break off contract talks. The Spectator, C3.

Irwin, J. (1974). The trouble with rehabilitation. Correctional Psychologist, 1(2), 139-149.

Irwin, J. (1980). Prisons in turmoil. Boston, MA: Little, Brown.

Irwin, J. (1985). The jail: Managing the underclass in American society. Berkeley, CA: University of California Press.

Irwin, J. (2005). The warehouse prison: Disposal of the new dangerous class. Los Angeles, CA: Roxbury Publishing Company.

Irwin, J. and Cressey, D. R. (1962). Thieves, convicts and the inmate culture. Social Problems 10(2), 142-155.

Irwin, J. and Owen, B. (2005). Harm and the contemporary prison. In A. Liebling and S. Maruna (eds). The effects of imprisonment. Portland, OR: Willan Publishing.

Jacobs, J. B. (1974). Street gangs behind bars. Social problems, 21(3), 395-409.

Jesseman, R., Porter, M., Anderson, J., Dunbar, J., Boudreau, G., Challal, H. and Mohamed, H. (2017). Community Advisory Board annual report 2016. Ottawa, ON: Ontario Ministry of Safety and Correctional Services.

Jewkes, Y. (2005). Men behind bars: "Doing" masculinity as an adaptation to imprisonment. Men and Masculinities, 8(1), 44-63.

John Howard Society of Ontario Standing Committee on Prison Conditions in Ontario. (2007). Second report to the board: Remand in Ontario. Available online: $<\mathrm{http}$ //www.johnhoward.on.ca/pdfs/remand_in_ontario_2.pdf $>$.

John Howard Society of Ontario. (2005). Remand in Ontario: A backgrounder. Toronto, ON: John Howard Society of Ontario.

John Howard Society of Ontario. (2015). Unlocking change: Decriminalizing mental health issues in Ontario. Toronto, ON: John Howard Society of Ontario.

John Howard Society of Ontario. (2016). Fractured care: Public health opportunities in Ontario's Correctional Facilities. Toronto: ON: John Howard Society of Ontario.

Joly, D. and Beckford, J. (2006). "Race" relations and discrimination in prison: The case of Muslims in France and Britain. Journal of Immigrant \& Refugee Studies, 4(2), $1-30$. 
Jones, R. S. and Schmid, T. J. (2003). Parallels in the prison experiences of women and men. In B. H. Zaitzow and J. Thomas (eds). Women in prison: Gender and social control. Boulder, CO: Lynne Rienner Publishers.

Kellen, A., Freedman, J., Novac, S., Lapointe, L., Maaranen, R. and Wong, A. (2010). Homeless and jailed: Jailed and homeless. Toronto, ON: The John Howard Society of Toronto.

Kellough, G. and Wortley, S. (2002). Remand for plea: Bail decisions and plea bargaining as commensurate decisions. British Journal of Criminology, 42(1), 186-210.

Kilty, J. M. (2012). 'It's like they don't want you to get better:' Psy control of women in the carceral context. Feminism \& Psychology, 22(2), 162-182.

Klofas, J. M. (1990). The jail and the community. Justice Quarterly, 7(1), 69102.

Kong, R. and AuCoin, K. (2008). Female offenders in Canada. Ottawa, ON: Minister of Industry.

Kouyoumdjian, F., Schuler, A., Matheson, F. I. and Hwang, S. W. (2016). Health status of prisoners in Canada: Narrative review. Canadian Family Physician, 62(3), 215222.

Koza, P. and Doob, A. (1975). The relationship of pre-trial custody to the outcome of a trial. Criminal Law Quarterly 17(4), 391-400.

Kruttschnitt, C. and Hussemann, J. (2008). Micropolitics of race and ethnicity in women's prisons in two political contexts. The British Journal of Sociology, 59(4), 709-728.

Kruttschnitt, C., Slotboom, A. M., Dirkzwager, A. and Bijleveld, C. (2013). Bringing women's carceral experiences into the "new punitiveness" fray. Justice Quarterly, 30(1), 18-43.

Labotka, L. (2014). Healthy, beautiful hair: Cultivating the self in a women's prison. Ph.D. Thesis, University of Arizona.

Larivière, M. and Robinson, D. (1996). Attitudes of federal correctional officers towards offenders. Ottawa, ON: Correctional Service of Canada.

Larsson, S. and Sjöblom, Y. (2009). Perspectives on narrative methods in social work research. International Journal of Social Welfare, 19(3), 272-280.

Laucius, J. (2017, May 5). Hard time? If you're going to end up behind bars, you might want to do it at these prisons. The Ottawa Citizen. Available online: $<$ http://ottawacitizen.com/news/local-news/hard-time-if-youre-going-to-end-upbehind-bars-you-might-want-to-do-it-at-these-prisons $>$. 
Liebling, A. (2011). Moral performance, inhuman and degrading treatment and prison pain. Punishment \& Society, 13(5), 530-550.

Liem, M. and Kunst, M. (2013). Is there a recognizable post-incarceration syndrome among released "lifers?" International Journal of Law and Psychiatry, 36(3), 333337.

Lofaro, J. (2016a, April 25). 'It's a nightmare for them:' Mothers of inmates in Ottawa jail to host public forum. Ottawa Metro.

Lofaro, J. (2016b, Nov. 4). Judge tosses charter application for man who spent 18 months in solitary. The Ottawa Citizen. Available online: $<$ http://ottawacitizen.com/news/local-news/judge-tosses-charter-application-forman-who-spent-18-months-in-solitary>.

Lofaro, J. (2017, May 17). Lawyer to launch class-action lawsuit over 'inhumane' conditions at Ottawa jail. Metro News. Available online: $<$ http://www.metronews.ca/news/ottawa/2016/05/17/paul-champ-to-launch-classaction-against-ottawa-jail.html $>$.

Mallea, P. (2010). The fear factor: Stephan Harper's “tough on crime” agenda. Ottawa, ON: Canadian Centre for Policy Alternatives.

Manns, J. D. (2005). Liberty takings: A framework for compensating pretrial detainees. Cardozo Law Review, 26(5), 1947-2022.

Marcus, K. L. (2009). Jailhouse Islamophobia: Anti-Muslim discrimination in American prisons. Race and Social Problems, 1(1), 36-44.

Marin, A. (2013). The code: Investigation in the Ministry of Community Safety and Correctional Services' response to allegations of excessive use of force against inmates. Toronto, ON: Ombudsman of Ontario.

Marin, A. (2016, April 5). Marin: Ottawa-Carleton Detention Centre - Show you care, minister. The Ottawa Citizen. $<\mathrm{http}$ //ottawacitizen.com/opinion/columnists/marinottawa-carleton-detention-centre-show-you-care-minister $>$.

Marleau, B. (1989, April 28). Innes jail inmate slain. The Ottawa Citizen, A1/Front.

Marleau, B. and Ibbitson, J. (1989, April 29). Inquiry sought in killing of inmate. The Ottawa Citizen, A1/Front.

Marquart, J. W. (1986). Prison guards and the use of physical coercion as a mechanism of prisoner control. Criminology, 24(2), 347-366.

Martin, R. E., Buxton, J. A., Smith, M. and Hislop, T. G. (2012). The scope of the problem: The health of incarcerated women in BC. British Columbia Medical Journal, 54(10), 502-508.

Maslow, A. H. (1943). A theory of human motivation. Psychological Review, 50(4), 370. 
Massoglia, M. and Pridemore, W. A. (2015). Incarceration and health. Annual Review of Sociology, 41, 291-310.

Mathiesen, T. (1990). Prison on trial. London, UK: Sage.

Mathiesen, T. (2008). The abolitionist stance. Journal of Prisoners on Prisons, 17(2), 5863.

Matthews, R. (2005). The myth of punitiveness. Theoretical Criminology, 9(2), 175-201.

McCooey, P. (2006, April 25). Judge to decide if jail conditions violate accused killer's Charter rights. The Ottawa Citizen, B1/Front.

McElligott, G. (2007). Negotiating a coercive turn: Work discipline and prison reform in Ontario. Capital and Class, 31(1), 31-53.

McElligott, G. (2008). A Tory high modernism? Grand plans and visions of order in Neoconservative Ontario. Critical Criminology, 16, 123-144.

McKendy, J. (1999). Dialogue and the risk of responsibility. Humanity \& Society, 23(3), 238-253.

McKendy, J. P. (2006). 'I'm very careful about that:' Narrative and agency of men in prison. Discourse \& Society, 17(4), 473-502.

McKendy, L. (2016). Creative resistance: Using documentary-making as a tool to research and challenge penal harms. Render: The Carleton Graduate Journal of Art and Culture, 4.

Melde, C. (2008). Penal reform and the stability of prison adaptive modes. Journal of Crime and Justice, 31(1), 59-80.

Meyer, J., and O’Malley, P. (2009). Missing the punitive turn? Canadian criminal justice, 'balance' and penal modernism. Sydney Law School Legal Studies Research Paper No. 09/95.

Michalski, J. H. (2015). Status hierarchies and hegemonic masculinity: A general theory of prison violence. British Journal of Criminology, 57(1), 40-60.

Micucci, A. and Monster, M. (2004). It's about time to hear their stories: Impediments to rehabilitation at a Canadian provincial correctional facility for women. Journal of Criminal Justice, 32(6), 515-530.

Ministry of Correctional Services Act. (1990). R.R.O. Reg. 778.

Ministry of the Attorney General. (2017). Ontario making criminal justice system faster and fairer in Northwestern Ontario, province expanding bail programs and hiring more prosecutors. Ottawa, ON: Ministry of the Attorney General. Available online: $<$ https://news.ontario.ca/mag/en/2017/06/ontario-making-criminal-justice-systemfaster-and-fairer-in-northwestern-ontario.html $>$. 
Moen, T. (2006). Reflections on the narrative research approach. International Journal of Qualitative Methods, 5(4), 56-69.

Moore, D. and Hannah-Moffat, K. (2002). Correctional Renewal without the frills: The politics of "get tough" punishment in Ontario. In J. Hermer and J. Mosher J (eds). Disorderly people: Law and the politics of exclusion in Ontario. Halifax, NS: Fernwood.

Moore, D. and Hannah-Moffat, K. (2005). The liberal veil: Revisiting Canadian penalty. In J. Pratt, D. Brown, M. Brown, S. Hallsworth, and W. Morrison (eds). The new punitiveness: Trends, theories, perspectives. Portland, OR: Willan Publishing.

Murguia, S. (2015). The politics of food behind bars. In H. L. Davis, K. Pilgrim and M. Sinha (eds). The ecopolitics of consumption: The food trade. Lanham, MD: Rowman and Littlefield.

Naqvi, Y. (2016). Statement by Minister Yasir Naqvi on the Ottawa-Carleton Detention Centre Task Force report. Ottawa, ON: Ministry of Community Safety and Correctional Services. Available online: <https://news.ontario.ca/mcscs/en/ 2016/06/statement-by-minster-naqvi-on-the-ottawa-careleton-detention-centretask-force-report.html>.

Neuber, A. (2011). Understanding violence in the 'society of captives:' Sykes meets Bourdieu in prison. The Howard Journal, 50(1), 1-16.

Neustatter, A. (2002). Locked in. Locked out. The experience of young offenders out of society and in prison. London, UK: Calouste Gulbenkian Foundation.

Novac, S., Hermer, J., Paradis, E. and Kellen, A. (2006). Justice and injustice: Homelessness, crime, victimization, and the criminal justice system. Toronto, ON: Centre for Urban and Community Studies, University of Toronto.

O'Connor, P. (2003). Telling bits: Silencing and the narratives behind prison walls. In L. Thiesmeyer (ed.). Discourse and silencing: Representation and the language of displacement. Philadelphia, PA: John Benjamins Publishing Company.

O'Neill, J. (2004, Oct. 30). Corrections ministry, jail system go on trial. The Ottawa Citizen, E1/Front.

Ocen, P. A. (2012). Punishing pregnancy: Race, incarceration, and the shackling of pregnant prisoners. California Law Review, 100(5), 1239-1311.

Office of the Correctional Investigator. (2013). Risky business: An investigation of the treatment and management of chronic self-injury among federally sentenced women. Ottawa, ON: Her Majesty the Queen in Right of Canada.

Olson, B. (2006). Degradation, apathy, and acceptable casualties: Serving time in a women's federal correctional institute. Justice Policy Journal, 3(2), 1-27. 
Olson, B. F. and Kunselman, J. C. (2007). Acceptable casualties. Journal of Prisoners on Prisons, 16(2), 59-76.

Ontario Human Rights Commission. (2013). Schedule "A" in the matter of Christina Nadine Jahn v. Her Majesty the Queen in Right of Ontario, as represented by the Minister of Community Safety and Correctional Services before the Human Rights Tribunal of Ontario (Public Interest Remedies). Available online: $<$ http://www.ohrc.on.ca/sites/default/files/Jahn\%20Schedule\%20A_ accessible.pdf $>$.

Ontario Human Rights Commission. (2016a). Submission of the OHRC to the Ministry of Community Safety and Correctional Services Provincial Segregation Review. Toronto, ON: Queen's Printer for Ontario.

Ontario Human Rights Commission. (2016b). Supplementary submission of the Ontario Human Rights Commission to the Ministry of Community Safety and Correctional Services' Provincial Segregation Review. Toronto, ON: Queen's Printer for Ontario.

Ontario Ministry of Community Safety and Correctional Services. (2015). Inmate information guide for adult institutions. Available online: $<$ https://www.mcscs.jus.gov.on.ca/english/corr_serv/PoliciesandGuidelines/CS_In mate_guide.html\#P412_60903>.

Ontario Ministry of Community Safety and Correctional Services. (2016a). OttawaCarleton Detention Centre Task Force recommendations: Progress report \#1. Available online: <http://www.mcscs.jus.gov.on.ca/english/Corrections/Ottawa CarletonDetentionCentreTaskForce/OCDCTaskForceProgressReport1.html>.

Ontario Ministry of Community Safety and Correctional Services. (2016b). OttawaCarleton Detention Centre Task Force action plan. Available online: $<\mathrm{http}$ ://www.mcscs.jus.gov.on.ca/english/Corrections/OCDC_task_force.html $>$.

Ontario Ministry of Community Safety and Correctional Services (2016c). Policies and guidelines: Inmate telephone communication. Available online: $<$ http://www.mcscs.jus.gov.on.ca/english/Corrections/Policiesandguidelines/Corre ctionsInmateTelephoneCommunication.html $>$.

Ontario Ministry of Community Safety and Correctional Services. (2016d). Policies and guidelines: Visiting. Available online: $<$ https://www.mcscs.jus.gov.on.ca/english/corr_serv/PoliciesandGuidelines/CS_vi siting_policy.html>.

Ontario Ministry of Community Safety and Correctional Services. (2016e). Segregation in Ontario correctional institutions. Available online: $<$ https://news.ontario.ca/mcscs/en/2016/10/segregation-in-ontario-correctionalinstitutions.html>. 
Ontario Ministry of Community Safety and Correctional Services. (2017a). Ontario building stronger, safer communities: Province moving forward with largest policing transformation in a generation. Available online: $<$ https://news.ontario.ca/mcscs/en/2017/11/ontario-building-stronger-safercommunities.html>.

Ontario Ministry of Community Safety and Correctional Services. (2017b). OttawaCarleton Detention Centre Task Force recommendations: Progress report \#2. Available online: <https://www.mcscs.jus.gov.on.ca/english/Corrections/Ottawa CarletonDetentionCentreTaskForce/OCDCTaskForceProgressReport2.html>.

Ontario Ministry of Community Safety and Correctional Services. (2017c). OttawaCarleton Detention Centre Task Force recommendations: Progress report \#3. Available online: <https://www.mcscs.jus.gov.on.ca/english/Corrections/Ottawa CarletonDetentionCentreTaskForce/OCDCTaskForceProgressReport3.html>.

Ontario Ministry of Community Safety and Correctional Services. (2017d). Community advisory boards. Available online: <https://www.mcscs.jus.gov.on.ca/ english/corr_serv/CABs/CABs.html>.

Ontario of Community Safety and Correctional Services. (2017e): Ontario taking action to reform correctional system province investing in new jails in Thunder Bay and Ottawa, modernizing legislation. Available online: <https://news.ontario.ca/ mcscs/en/2017/5/ontario-taking-action-to-reform-correctional-system.html>.

Ontario Ministry of Community Safety and Correctional Services. (2017f). Correctional services: offender programs and services. Available online: $<$ https://www.mcscs.jus.gov.on.ca/english/corr_serv/OffenderProgramsServices/o ffender_programs.html $>$.

Parker, K. (2004). Pregnant women inmates: Evaluating their rights and identifying opportunities for improvements in their treatment. Journal of Law \& Health, 19(2), 259-295.

Pedwell, T. (2012, Oct. 17). Pregnant woman's treatment in Ottawa jail has mothers calling for inquiry. The Globe and Mail. Available online: $<\mathrm{https} / /$ beta.theglobeandmail.com/news/national/pregnant-womans-treatment-inottawa-jail-has-mothers-calling-for-inquiry/article4619179/?ref=http://www. theglobeandmail.com\&>.

Perreault, S. (2014). Admissions to adult correctional services in Canada, 2011/2012. Ottawa, ON: Minister of Industry.

Pfeffer, A. (2016, Aug. 16). 'Traumatized' by jail, immigration detainee encouraged by government review of system. $C B C$ News. Available online: $<\mathrm{http}: / /$ www.cbc.ca/news/canada/ottawa/immigration-detainee-encouragedannouncement-1.3722902>. 
Phelps, M. S. (2011). Rehabilitation in the punitive era: The gap between rhetoric and reality in US prison programs. Law and Society Review, 45(1), 33-68.

Piché, J. (2014). A contradictory and finishing state. Explaining recent prison capacity expansion in Canada's provinces and territories. Champ Pénal/Penal Field, 11.

Piché, J. (2016). Assessing the boundaries of public criminology: On what does (not) count. Social Justice, 42(2), 70.

Piché, J. (2017, May 7). The new Ottawa jail will just become another hellhole - don't build it. The Ottawa Citizen. Available online: <http://ottawacitizen.com/ opinion/columnists/piche-the-new-ottawa-jail-will-just-become-another-hellholedont-build-it>.

Piché, J. and Major, K. (2015). Prisoner writing in/on solitary confinement: Contributions from the Journal of Prisoners on Prisons, 1988-2013. Canadian Journal of Human Rights, 4(1), 1-31.

Piché, J., Gaucher, B. and Walby, K. (2014). Facilitating prisoner ethnography: An alternative approach to "doing prison research differently." Qualitative Inquiry, 20(4), 449-460.

Pilieci, V. (2017, Feb. 25). Lockdown at Ottawa jail for 'security reasons' leads to court delays. The Ottawa Citizen, A3.

Pizarro, J. and Stenius, V. M. (2004). Supermax prisons: Their rise, current practices, and effect on inmates. The Prison Journal, 84(2), 248-264.

Plecas, D. B. and Maxim, P. S. (1987). CSC correctional officer development study: Recruit survey. Ottawa, ON: Correctional Service of Canada.

Pogrebin, M. R. and Dodge, M. (2001). Women's accounts of their prison experiences: A retrospective view of their subjective realities. Journal of Criminal Justice, 29(6), 531-541.

Porter, L. and Calverly, D. (2011). Trends in the use of remand in Canada. Ottawa, ON: Minister of Industry.

Porter, M., Anderson, J., Dunbar, J. and Jesseman, R. (2015). Community Advisory Board annual report. Ottawa, ON: Ontario Ministry of Safety and Correctional Services.

Porter, M., Anderson, J., Dunbar, J., Jesseman, R. and Boudreau, G. (2016). Community Advisory Board annual report 2015. Ottawa, ON: Ontario Ministry of Safety and Correctional Services

Pratt, J. (2000). Emotive and ostentatious punishment. Punishment \& Society, 2(4), 417439.

Pratt, J. (2007). Penal populism. New York, NY: Routledge. 
Presser, L. (2009). The narratives of offenders. Theoretical Criminology, 13(2), 177-200.

Propper, A. (1982). Make-believe families and homosexuality among imprisoned girls. Criminology, 20(1), 127-138.

Provencher, N. and Mah, A. (2016, March 26). Naqvi bans jail 'shower cells,' announces task force on jail overcrowding. The Ottawa Citizen. Available online: $<$ http://ottawacitizen.com/news/local-news/naqvi-bans-jail-shower-cellsannounces-task-force-on-jail-overcrowding $>$.

Public Services Foundation of Canada. (2015). Crisis in correctional services: Overcrowding and inmates with mental health problems in provincial correctional facilities. Available online: <http://www.bcgeu.ca/sites/default/files/page/ attachments/Crisis\%20in\%20Correctional\%20Services\%20April\%202015\%5B2 \%5D.pdf/>.

Reevely, D. (2016, March 26). Yasir Naqvi's credibility on jail reform in pieces after shower-cell admission. The Ottawa Citizen. Available online: $<$ http://ottawacitizen.com/news/local-news/reevely-yasir-naqvis-credibility-onjail-reform-in-pieces-after-shower-cell-admission>.

Reitano, J. (2017). Adult correctional statistics in Canada, 2015/2016. Ottawa, ON: Minister of Industry.

Reiter, K. (2014). Making windows in walls: Strategies for prison research. Qualitative Inquiry, 20(4), 418-418.

Ricciardelli, R. (2014a). An examination of the inmate code in Canadian penitentiaries. Journal of Crime and Justice, 37(2), 234-255.

Ricciardelli, R. (2014b). Coping strategies: Investigating how male prisoners manage the threat of victimization in federal prisons. The Prison Journal, 94(4), 411-434.

Ricciardelli, R. (2015). Establishing and asserting masculinity in Canadian penitentiaries. Journal of Gender Studies, 24(2), 170-191.

Ricciardelli, R. (2017). Canadian provincial correctional officers: Gender strategies of achieving and affirming masculinities. The Journal of Men's Studies, 25(1), 3-24.

Ricciardelli, R. and Memarpour, P. (2016). 'I was trying to make my stay there more positive:' Rituals and routines in Canadian prisons. Criminal Justice Studies, 29(3), 179-198.

Ricciardelli, R. and Moir, M. (2013). Stigmatized among the stigmatized: Sex offenders in Canadian penitentiaries. Canadian Journal of Criminology and Criminal Justice, 55(3), 353-386. 
Ricciardelli, R. and Spencer, D. (2014). Exposing 'sex' offenders: Precarity, abjection and violence in the Canadian federal prison system. British Journal of Criminology, 54(3), 428-448.

Richards, M. A. (2014). Property of corrections: The experience of incarceration for female inmates in a New Zealand Prison. Master's Thesis, Victoria University of Wellington.

Richmond, L. P. and Johnson, C. W. (2009). "It's a race war:" Race and leisure experiences in California State Prison. Journal of Leisure Research, 41(4), 565-580.

Riessman, C. K. (2005). Narrative, memory and everyday life. Huddersfield, UK: University of Huddersfield.

Riessman, C. K. and Quinney, L. (2005). Narrative in social work: A critical review. Qualitative Social Work, 4(4), 391-412.

Risman, B. (2006). Feminist strategies for public sociology. In Blau, J. and Smith, K. E. I. (eds). Public sociologies reader. Lanham, MD: Rowman and Littlefield Publishing Group.

Roberts, L. and Indermaur, D. (2007). The ethics of research with prisoners. Current Issues in Criminal Justice, 19(3), 309-326.

Robertson, J. E. (1997). Houses of the dead: Warehouse prisons, paradigm change, and the Supreme Court. Houston Law Review, 34(4), 1003-1037.

Ross, J. I. (2007). Supermax prisons. Society, 44(3), 60-64.

Ross, J. I. (2010). Resisting the carceral state: Prisoner resistance from the bottom up. Social Justice, 36(3), 28-45.

Ross, J. I. (2013). The invention of the American supermax prison. In J. I. Ross (ed.). The globalization of supermax prisons. New Brunswick, NJ: Rutgers University Press.

Rowe, A. (2011). Narratives of self and identity in women's prisons: Stigma and the struggle for self-definition in penal regimes. Punishment \& Society, 13(5), 571-591.

Rubin, A. T. (2015). Resistance or friction: Understanding the significance of prisoners' secondary adjustments. Theoretical Criminology, 19(1), 23-42.

Ruggiero, V. (2012). How public is public criminology? Crime, Media, Culture, 8(5), 151160.

Rymhs, D. (2012). In this inverted garden: Masculinities in Canadian prison writing. Journal of Gender Studies, 21(1), 77-89.

Sandberg, S. (2010). What can "lies" tell us about life? Notes towards a framework of narrative criminology. Journal of Criminal Justice Education, 21(4), 447-465. 
Sapers, H. (2013). Annual report of the correctional investigator 2012-2013. Ottawa, ON: Her Majesty the Queen in Right of Canada.

Sapers, H. (2014). Annual report of the Office of the Correctional Investigator 2013-2014. Ottawa, ON: Her Majesty the Queen in Right of Canada.

Sapers, H. (2015). Annual report of the Office of the Correctional Investigator 2014-2015. Ottawa: Her Majesty the Queen in Right of Canada.

Sapers, H., Neault, N., McConaghy, E., Monteiro, A. and Deshman, A. (2017). Segregation in Ontario: Independent review of Ontario corrections. Ottawa, ON: Queen's Printer for Ontario.

Sarre, R. and Sarre, R. (2016). Challenging spiralling remand in custody rates: What legal and procedural changes can address the trend? Journal of Criminological Research, Policy and Practice, 2(3), 196-205.

Sawa, T. (2014, April 14). Prisoners given powerful drugs off-label, allegedly to 'control behaviour,' federal ombudsman probing 'outrageous' number of female inmates on mood-altering medications. $\quad C B C$ News. Available online: $<$ http://www.cbc.ca/news/prisoners-given-powerful-drugs-off-label-allegedly-tocontrol-behaviour-1.2609940>.

Schlosser, J. (2008). Issues in interviewing inmates: Navigating the methodological landmines of prison research. Qualitative Inquiry, 14(8), 1500-1525.

Schmid, T. J. and Jones, R. S. (1993). Ambivalent actions: Prison adaptation strategies of first-time, short-term inmates. Journal of Contemporary Ethnography, 21(4), 439463.

Schmid, T. J. and Jones, R. S. (1991). Suspended identity: Identity transformation in a maximum security prison. Symbolic Interaction, 14(4), 415-432.

Schnittker, J. (2014). The psychological dimensions and the social consequences of incarceration. The Annals of the American Academy of Political and Social Science, 651(1), 122-138.

Schwaebe, C. (2005). Learning to pass: Sex offenders' strategies for establishing a viable identity in the prison general population. International Journal of Offender Therapy and Comparative Criminology, 49(6), 614-625.

Seguin, L. (2016, Sept. 17). Despite rhetoric, little meaningful change at troubled OCDC. The Ottawa Sun. Available online: <http://ottawasun.com/2016/09/17/despiterhetoric-little-meaningful-change-at-troubled-ocdc/wcm/591adc02-df25-473692f9-b727b89ba202>.

Severance, T. A. (2005). "You know who you can go to:" Cooperation and exchange between incarcerated women. The Prison Journal, 85(3), 343-367. 
Sexton, L. (2015). Penal subjectivities: Developing a theoretical framework for penal consciousness. Punishment \& Society, 17(1), 114-136.

Seymour, A. (2014, June 19). Killer, arsonist, carjacker sue Ottawa jail for $\$ 3.5 \mathrm{M}$ over alleged abuse. The Ottawa Citizen. Available online: $<$ http://ottawacitizen.com/news/local-news/embargoed-killer-arsonist-carjackersue-ottawa-jail-for-3-5m-over-alleged-abuse $>$.

Seymour, A. (2015, March 27). Jail report recommendations on mentally ill 'positive and progressive,' lawyer says. The Ottawa Citizen. Available online: $<\mathrm{http}$ ://ottawacitizen.com/news/local-news/jail-report-recommendations-onmentally-ill-positive-and-progressive-lawyer-says $>$.

Seymour, A. (2016a, March 30). Ottawa jail again used shower cells, despite minister's orders. The Ottawa Citizen. Available online: $<$ http://ottawacitizen.com/news/local-news/ottawa-jail-again-used-shower-cellsdespite-ministers-orders $>$.

Seymour, A. (2016b, April 8). Building new jail would fail taxpayers, Naqvi says. The Ottawa Citizen. Available online: <http://ottawacitizen.com/news/localnews/building-new-jail-would-fail-taxpayers-naqvi-says>.

Seymour, A. (2016c, July 08). Ex-inmate sues Ottawa jail after excessive beatings from officers led to him being thrown 'in the hole.' Post Media News. Available online: $<$ http://news.nationalpost.com/news/canada/ex-inmate-sues-ottawa-jail-afterexcessive-beatings-from-officers-led-to-him-being-thrown-in-the-hole $>$.

Seymour, A. (2017a, Jan. 31). Health care, mental health units among improvements at Ottawa jail, province says. The Ottawa Citizen. Available online: $<$ http://ottawacitizen.com/news/local-news/health-care-mental-health-unitsamong-improvements-at-ottawa-jail-province-says $>$

Seymour, A. (2017b, Feb. 01). Progress shown in jail upgrades; 'good steps taken' says advocate. The Ottawa Citizen, A4. Available online: $<$ https://www.pressreader.com/canada/ottawacitizen/20170201/281603830194678>.

Seymour, A. (2017c, March 19). Why can't Ottawa methadone clinic get a meeting with the jail? The Ottawa Citizen. Available online: $<$ http://ottawacitizen.com/news/local-news/ottawa-methadone-clinic-trying-formonths-for-meeting-with-jail $>$.

Seymour, A. (2017d, Feb. 10). Inmate says she was strip-searched, handcuffed after jailcell miscarriage. The Ottawa Sun. Available online: $<$ http://ottawasun.com/2017/02/10/inmate-says-she-was-strip-searchedhandcuffed-after-jail-cell-miscarriage/wcm/6f2c6c7a-3027-421d-8783b25aee $5 \mathrm{c} 9 \mathrm{bab}>$. 
Seymour, J. (1977). Niches in prison. In H. Toch (ed.). Living in prison: The ecology of survival. New York, NY: Free Press.

Shalev, S. (2008). A sourcebook on solitary confinement. London, UK: Mannheim Centre for Criminology.

Shamai, M. and Kochal, R. B. (2008). "Motherhood starts in prison:" The experience of motherhood among women in prison. Family Process, 47(3), 323-340.

Shantz, L. and Frigon, S. (2010). Home free? The (after) effects of imprisonment on women's bodies, physical and mental health and identity. Aporia, 2(1), 6-17.

Sherman, L. W. (1993). Defiance, deterrence and irrelevance: A theory of the criminal sanction. Journal of Research in Crime and Delinquency, 30(4), 445-474.

Shore Davis Johnston. (2017). More beds, more bodies - induced demand and Ottawa's new jail. Available online: $<$ https://shoredavis.com/2017/05/09/news-beds-bodiesinduced-demand-ottawas-new-jail/>.

Siefert, K. and Pimlott, S. (2001). Improving pregnancy outcome during imprisonment: A model residential care program. Social Work, 46(2), 125-134.

Sim, J. (2009). Punishment and prisons: Power and the carceral state. London, UK: Sage Publications.

Simmel, G. (1997). The sociology of the meal. In D. Frisby and M. Featherstone (eds). Simmel on culture: Selected writings. London, UK: Sage.

Simon, J. (2000). The 'society of captives' in the era of hyper-incarceration. Theoretical Criminology, 4(3), 285-308.

Sloan, J. (2012). 'You can see your face in my floor:' Examining the function of cleanliness in an adult male prison. The Howard Journal of Criminal Justice, 51(4), 400-410.

Smoyer, A. B. (2015a). "It's the black girls that have the most:" Foodways narratives and the construction of race in a women's prison. Food and Foodways, 23(4), 273-285.

Smoyer, A. B. (2015b). Making fatty girl cakes: Food and resistance in a women's prison. The Prison Journal, 96(2), 191-209.

Smoyer, A. B. and Lopes, G. (2017). Hungry on the inside: Prison food as concrete and symbolic punishment in a women's prison. Punishment \& Society, 19(2), 240-255.

Smoyer, A. B., Kershaw, T. S. and Blankenship, K. M. (2015). Confining legitimacy: The impact of prison experiences on perceptions of criminal justice legitimacy. Journal of Forensic Social Work, 5(1-3), 258-270.

Souza, K. A. and Dhami, M. K. (2010). First-time and recurrent inmates' experiences of imprisonment. Criminal Justice and Behavior, 37(12), 1330-1342. 
Spalek, B. and Wilson, D. (2002). Racism and religious discrimination in prison: The marginalization of imams in their work with prisoners. In Basia Spalek (ed.). Islam, crime and criminal justice. New York, NY: Routledge.

Spector-Mersel, G. (2010). Narrative research: Time for a paradigm. Narrative Inquiry, 20(1), 204-224.

Statistics Canada (2015). Adult correctional statistics in Canada, 2013/2014. Ottawa, ON: Minister of Industry.

Statistics Canada. (2017). Trends in the use of remand in Canada, 2004/2005 to 2014/2015. Ottawa, ON: Minister of Industry.

Sussman, D. (2008). Bound by injustice: Challenging the use of shackles on incarcerated pregnant women. Cardozo Journal of Law \& Gender, 15(3), 477-502.

Sykes, G. and Messinger, S. (1960). The inmate social system. In R. A. Cloward, D. R. Cressey, G. H. Grosser, R.McCleery, L.E. Ohlin, G. Sykes and S. L. Messinger (eds). Theoretical studies in social organization of the prison. New York, NY: The Social Science Research Council.

Sykes, G. M. (1958). The society of captives: A study of a maximum security prison. Princeton, NJ: Princeton University Press.

Szczepanik, R. and Siebert, S. (2016). The triple bind of narration: Fritz Schütze's biographical interview in prison research and beyond. Sociology, 50(2), 285-300.

Taylor, J. M. (2009). Diogenes still can't find his honest man. Journal of Prisoners on Prisons, 18(1/2), 91-110.

Terry, C. (2003). From C-Block to academia: You can't get there from here. In J. I. Ross and S. C. Richards (eds). Convict criminology. Toronto, ON: Nelson Thomson Learning.

Terry, C. M. (1997). The function of humor for prison inmates. Journal of Contemporary Criminal Justice, 13(1), 23-40.

Terry, C. M. (2000). Beyond punishment: Perpetuating difference from the prison experience. Humanity \& Society, 24(2), 108-135.

Terry, C. M. (2004). Managing prisoners as problem populations and the evolving nature of imprisonment: A convict perspective. Critical Criminology, 12(1), 43-66.

The Globe and Mail. (1975, June 07). Ottawa police check hangouts for four escapers. The Globe and Mail, 10.

The Globe and Mail. (1976, Jan. 24). New electric security system, procedures are installed after latest Ottawa jailbreak. The Globe and Mail, 10. 
The Ottawa Citizen (1989, June 18). Angry Ontario guards endorse job action. The Ottawa Citizen, A5.

The Ottawa Citizen (2004, Nov. 02). Ottawa's jail is a disgrace. The Ottawa Citizen, C4.

The Ottawa Citizen. (1990, Sept. 24). Police/fire: Prisoners fasted for a week; inmates end hunger strike. The Ottawa Citizen, F2.

The Ottawa Citizen. (1997, March 15). Detention centre inmates protest over quality of food. The Ottawa Citizen, C2.

The Ottawa Citizen. (1998, March 07). Inmates begin detention centre hunger strike: Prisoners angry at 'inedible,' bug-ridden food. The Ottawa Citizen, E2.

Tilley, K. (2012). Justice denied: The causes of BC's criminal justice system crisis. Vancouver, BC: British Columbia Civil Liberties Association.

Toch, H. (1985). Warehouses for people? The Annals of the American Academy of Political and Social Science, 478(1), 58-72.

Toch, H. (1992). Living in prison: The ecology of survival. Washington, D.C.: American Psychological Association.

Toch, H. (1998). Hypermasculinity and prison violence. In L. Bowker, (ed.). Masculinities and violence. London, UK: Sage.

Tossounian, J. (2014). Songs from the slammer. Ottawa, ON: Anklebone Books.

Tossounian, J. (2017, May 27). There are real reasons why Ottawa needs a new jail. The Ottawa Sun. Available online: <http://ottawasun.com/2017/05/27/tossounianthere-are-real-reasons-why-ottawa-needs-a-new-jail/wcm/ee1 feff7-ca64-47cf8546-2af2a2dcac7e>.

Trotter, C. and Baidawi, S. (2015). Older prisoners: Challenges for inmates and prison management. Australian \& New Zealand Journal of Criminology, 48(2), 200-218.

Tubex, H. (2015). Reach and relevance of prison research. International Journal for Crime, Justice and Social Democracy, 4(1), 4-17.

Ugelvik, T. (2011). The hidden food: Mealtime resistance and identity work in a Norwegian prison. Punishment \& Society, 13(1), 47-63.

Ugelvik, T. (2014a). Paternal pains of imprisonment: Incarcerated fathers, ethnic minority masculinity and resistance narratives. Punishment \& Society, 16(2), 152-168.

Ugelvik, T. (2014b). Power and resistance in prison: Doing time, doing freedom. New York, NY: Pallgrave MacMillon. 
United Nations News Centre (2011, Oct. 18). Solitary confinement should be banned in most cases, UN expert says. United Nations. Available online: $<$ http://www.un.org/apps/news/story.asp?NewsID=40097\#.WgN1ImhSzIU>.

United Nations Office on Drugs and Crime (2015). United Nations standard minimum rules for the treatment of prisoners (the Nelson Mandela rules). Vienna, Austria: United Nations Office on Drugs and Crime.

van den Bergh, B. Plugge, E. and Aguirre, I. Y. (2014). Women's health and the prison setting. In S. Enggist, L. Møller, G. Galea and C. Udesen (eds). Prisons and health. Copenhagen, Denmark: World Health Organization.

Vaughn, M. S. and Smith, L. G. (1999). Practicing penal harm medicine in the United States: Prisoners' voices from jail. Justice Quarterly, 16(1), 175-231.

Vis, A. (1993, Dec. 23). Local detention-centre workers protest 'dangerous' staff shortage. The Ottawa Citizen, $\mathrm{C} 3$.

Von Hirsch, A. (1992). Proportionality in the philosophy of punishment. Crime and Justice, 16, 55-98.

Wacquant, L. (2002). The curious eclipse of prison ethnography in the age of mass incarceration. Ethnography, 3(4), 371-397.

Wacquant, L. (2005). The great penal leap backward: Incarceration in America from Nixon to Clinton. In J. Pratt, D. Brown, M. Brown, S. Hallsworth, and W. Morrison (eds). The new punitiveness: Trends, theories, perspectives. Portland, OR: Willan Publishing.

Waldram, J. B. (1993). Aboriginal spirituality: Symbolic healing in Canadian prisons. Culture, Medicine and Psychiatry, 17(3), 345-362.

Walker, M. L. (2014). Punishment and coping in "Golden County:" An ethnography of jail living. $\mathrm{PhD}$ Thesis, University of California, Riverside.

Walker, M. L. (2016). Race making in a penal institution. American Journal of Sociology, 121(4), 1051-1078.

Walmsley, R. (2014). World pre-trial/remand imprisonment list, second edition. London, UK: International Centre for Prison Studies.

Ward, B. and Hall, C. (1989, Oct. 24). Striking guards fail to disrupt prison routine. The Ottawa Citizen, A1/Front.

Ward, D. A. and Kassebaum, G. G. (1964). Homosexuality: A mode of adaptation in a prison for women. Social Problems, 12(2), 159-177.

Webster, C. M. and Doob, A. N. (2015). US punitiveness 'Canadian style?' Cultural values and Canadian punishment policy. Punishment \& Society, 17(3), 299-321. 
Webster, C. M., Doob, A. N. and Myers, N. M. (2009). The parable of Ms. Baker: Understanding pre-trial detention in Canada. Current Issues in Criminal Justice, 21(1), 79-102.

Weinrath, M. (2009). Inmate perspectives on the remand crisis in Canada. Canadian Journal of Criminology and Criminal Justice, 51(3), 355-379.

Welch, M. (1999). Jail overcrowding: Social sanitation and the warehousing of the urban underclass. In Punishment in America: Social control and the ironies of imprisonment. Thousand Oaks, CA: Sage.

Welch, M., Jones, P., Wood, M., Denis, R., Pitfield, D., Vieselmeyer, M., Collin, D., Hockey, T., Bair, V., Porter, M, Lamb, D., Mathias, I. and Baxter, B. (2016). Ottawa-Carleton Detention Centre Task Force action plan. Ottawa, ON: Ontario Ministry of Community Safety and Correctional Services.

West Coast Prison Justice Society. (2016). Solitary: A case for abolition. Vancouver, BC: The Law Foundation of British Columbia.

Weston-Henriques, Z. and Jones-Brown, D. D. (2000). Prisons as "safe havens" for African-American women. In M. W. Markowitz and D. D. Jones-Brown (eds). The system in black and white: Exploring the connections between race, crime, and justice. Westport, CT: Praeger.

Yuen, F. (2011). "I've never been so free in all my life:" Healing through Aboriginal ceremonies in prison. Leisure/Loisir, 35(2), 97-113.

Zedner, L. (2006). Neither safe nor sound? The perils and possibilities of risk. Canadian Journal of Criminology and Criminal Justice, 48(3), 423-434.

Zimonjic, P. (2002, March 19). Ottawa prison rocked by second riot in two days. Calgary Herald, A8. 